Final Report

FHWA/IN/JTRP-2002/5

\title{
EFFECTIVENESS OF THE BORMAN EXPRESSWAY ITS PROGRAM ON LOCAL AIR QUALITY
}

\author{
By \\ Timothy M. C. LaBreche \\ Research Engineer \\ School of Civil Engineering \\ Purdue University \\ Robert B. Jacko \\ Principal Investigator \\ Professor of Civil Engineering \\ Purdue University \\ Barry K. Partridge \\ Chief, Research Division \\ Indiana Department of Transportation \\ William Schneider \\ Graduate Research Assistant \\ School of Civil Engineering \\ Purdue University \\ Ahmed Soliman \\ Graduate Research Assistant \\ School of Civil Engineering \\ Purdue University \\ Joint Transportation Research Program \\ Project No. C-36-67ZZ \\ File No. 9-10-51 \\ SPR-2338 \\ Conducted in Cooperation with the \\ Indiana Department of Transportation \\ and the U.S. Department of Transportation \\ Federal Highway Administration
}

The contents of this report reflect the views of the authors who are responsible for the facts and accuracy of the data presented herein. The contents do not necessarily reflect the official views or policies of the Indiana Department of Transportation and Federal Highway Administration. This report does not constitute a standard, specification, or regulation.

Purdue University

West Lafayette, Indiana

September 2002 


\section{ACKNOWLEDGMENTS}

- Troy Boyd of the Indiana Department of Transportation for his frequent assistance in acquiring ITS system information

- Denton Moore of the Indiana Department of Environmental Management for assistance in ambient monitoring protocol and calibration of gases

- Steve Lengerich of the Indiana Department of Environmental Management for assistance in ambient monitoring protocol

- Dr. Michael Ungar of the Hammond Sanitary District. For graciously permitting us to use the Southeast Hessville Pumping station in the Hammond Sanitary District. 
TECHNICAL REPORT STANDARD TITLE PAGE

\begin{tabular}{|c|c|c|}
\hline $\begin{array}{l}\text { 1. Report No. } \\
\text { FHWA/IN/JTRP-2002/5 }\end{array}$ & 2. Government Accession No. & 3. Recipient's Catalog No. \\
\hline \multirow{2}{*}{\multicolumn{2}{|c|}{$\begin{array}{l}\text { 4. Title and Subtitle } \\
\text { Effectiveness of the Borman Expressway ITS Program on Local Air Quality }\end{array}$}} & $\begin{array}{l}\text { 5. } \quad \text { Report Date } \\
\text { September } 2002\end{array}$ \\
\hline & & 6. Performing Organization Code \\
\hline \multicolumn{2}{|c|}{$\begin{array}{l}\text { 7. Author(s) } \\
\text { Timothy M. C. LaBreche, Robert B. Jacko, Barry K. Partridge, William Schneider, and } \\
\text { Ahmed Soliman }\end{array}$} & $\begin{array}{l}\text { 8. Performing Organization Report No. } \\
\text { FHWA/IN/JTRP-2002/5 }\end{array}$ \\
\hline \multirow{2}{*}{\multicolumn{2}{|c|}{$\begin{array}{l}\text { 9. Performing Organization Name and Address } \\
\text { Joint Transportation Research Program } \\
1284 \text { Civil Engineering Building } \\
\text { Purdue University } \\
\text { West Lafayette, IN } 47907-1284\end{array}$}} & 10. Work Unit No. \\
\hline & & $\begin{array}{l}\text { 11. Contract or Grant No. } \\
\text { SPR-2338 }\end{array}$ \\
\hline \multirow{2}{*}{\multicolumn{2}{|c|}{$\begin{array}{l}\text { 12. Sponsoring Agency Name and Address } \\
\text { Indiana Department of Transportation } \\
\text { State Office Building } \\
100 \text { North Senate Avenue } \\
\text { Indianapolis, IN } 46204\end{array}$}} & $\begin{array}{c}\text { 13. Type of Report and Period Covered } \\
\text { Final Report }\end{array}$ \\
\hline & & 14. Sponsoring Agency Code \\
\hline
\end{tabular}

15. Supplementary Notes

Prepared in cooperation with the Indiana Department of Transportation and Federal Highway Administration.

\section{Abstract}

Particulate Matter less than $2.5 \mu \mathrm{m}$ in diameter $\left(\mathrm{PM}_{2.5}\right)$, carbon monoxide $(\mathrm{CO})$, and meteorological parameters were monitored at 10 second averaging intervals adjacent the Borman Expressway in Northwestern Indiana before and during the implementation of an Intelligent Transportation System. Traffic data was collected from sensors on the expressway. The high-resolution data permitted the expressway contribution to local air quality to be separated from background components of local air quality and significant correlations were made between pollutant flux and traffic flow and pollutant flux and highway occupancy. Traffic incidents (accidents / congestion) were shown to have a rapid impact on local air quality. In many examples, during-incident pollution flux increased 2 to 3 times pre-incident levels. Oversaturated traffic operating conditions deleteriously affected local air quality and if avoided by ITS or other methods would significantly improve local air quality.

\section{Key Words}

ITS, Intelligent, Transportation, Systems, Environmental, Air, Pollution, Database, $\mathrm{PM}_{2.5}$, CO, Fine, Particulate, Matter, Carbon, Monoxide, Borman, Expressway, Ambient Monitoring

18. Distribution Statement

No restrictions. This document is available to the public through the National Technical Information Service, Springfield, VA 22161

\section{Security Classif. (of this report) \\ Unclassified}

20. Security Classif. (of this page)
Unclassified

Unclassified

21. No. of Pages
91

22. Price 


\section{TECHNICAL Summary}

INDOT Research

Technology Transfer and Project Implementation Information

TRB Subject Code:17-4 Air Quality Studies

Publication No.: FHWA/IN/JTRP-2002/5, SPR-2338

September 2002

Final Report

\section{Effectiveness of the Borman Expressway ITS Program on Local Air Quality}

\section{Introduction}

The Borman Expressway in Northwestern Indiana is one of the most heavily traveled freeways in the United States especially among heavy duty diesel vehicles such as semi tractor trailers. Heavy duty diesel vehicles are a major source of fine particulate matter, or $\mathrm{PM}_{2.5}$, and with the recent revisions in the National Ambient Air Quality Standards focusing on $\mathrm{PM}_{2.5}$, vehicles with diesel engines as well as other mobile sources will be targets for significant $\mathrm{PM}_{2.5}$ emissions reductions. Intelligent Transportation Systems (ITS) present one method of reducing emissions from all vehicles including those that are diesel powered. By smoothing out traffic flow, reducing traffic congestion, and minimizing accident response and clearance times ITS could reduce vehicle acceleration and deceleration cycles which are associated with increased pollutant emissions.

An environmental monitoring station
adjacent to the Borman Expressway in
Northwestern Indiana has been collecting data on $\mathrm{PM}_{2.5}$, Carbon Monoxide (CO), and meteorological parameters since September of 1999. Monitoring began prior to the installation of ITS technology and is continuing, as of this draft, while the last components of the ITS system are being put in place. Data was collected at a 10 second averaging interval to resolve short term events associated with the rapidly changing conditions on the Borman expressway. Limited traffic data, averaged at 5 minute intervals, became available in June of 2001. The general objective of this study was to correlate the local air quality to events on the Borman and determine the overall effect of the ITS on the local air quality. An "event" on the Borman is defined as anything that impairs traffic conditions on the Expressway. Construction delays, lane restrictions, accidents, weather, and excessive demand are all capable of creating congestion and impairing the utility of the expressway.

\section{Findings}

Correlating local air quality to vehicle operating conditions is a complicated process. Individual vehicle emissions vary considerably with both speed and acceleration. Moving from the individual vehicle level to the roadway level complicates matters further because vehicles travel at a variety of speeds at varying densities. However if you step back from the details and consider the road as a means of conveyance for people and goods and consider the energy (fuel) required to move those people and goods, logical correlations begin to present themselves.
Pollution, (fine particulate matter, carbon monoxide, and others) is a by-product from the conversion of stored energy (gasoline and diesel fuel) to kinetic energy (vehicular motion). As a vehicle travels from point "A" to point " $B$ ", it encounters friction from the roadway, friction from internal moving parts, and drag (total drag is the sum of form drag and skin friction drag) from the air (wind resistance). All of these require energy to overcome and therefore produce pollution. If the vehicle is required to slow down during its trip, energy is dissipated via the brakes and/or engine (in the case of compression braking) as heat energy. To 
return to its prior speed, the vehicle must not only overcome the resistance previously described but accelerate as well, thereby requiring more energy and thus producing more pollution. In work previously demonstrated by Dr. Robert B. Jacko, acceleration has a pronounced effect on vehicular emissions.

Three general statements can be made at this point.

1.) At constant speed and all other factors equal, the more vehicles operating in a mile of roadway, the more pollution that will emanate from that roadway.

2.) Acceleration requires additional energy (fuel) input to vehicles beyond cruising and therefore produces additional pollution beyond that produced by cruising vehicles.

3.) Deceleration converts kinetic energy (vehicular motion) into heat that must eventually be replaced with more energy (via acceleration) if the vehicle is to return to its prior speed.

Therefore, the most efficient, and thus least polluting means of traveling between two points is one that minimizes acceleration.

How is this theory put into practice? Consider your own driving experience. When density (vehicles per mile) is very low and you are essentially the only individual on the road, you are free to drive at any speed you wish without having to change lanes or accelerate to pass individuals. Your vehicle is operating about as efficiently as it can given the average speed you have chosen to drive. Better fuel mileage may be achieved at a different speed, but you could do much worse if you had to accelerate and decelerate frequently to accommodate other vehicles.

Now consider a road where you're driving "at the speed of traffic". You may still be traveling at the same speed you were when the road was yours alone but you no longer have the option to travel any faster, and you can not decelerate without affecting traffic behind you. In this scenario, emissions from each individual vehicle are the same as they would have been if each of them were on the roadway alone. But because of the greater density of traffic on the roadway, the emissions from roadway into the local air are much greater than they were before when you were the only vehicle on the road.

As more vehicles demand use of the roadway, speeds begin to decline as drivers adjust to reduced vehicle spacing. Acceleration and deceleration increase as drivers must adjust vehicle speeds to accommodate other vehicles. As vehicle density increases, speeds decline and acceleration/deceleration cycles continue until jam density is reached and vehicles are moving very little if at all. Many different factors are in play in these operating conditions. As traffic density increases, velocity decreases therefore frictional energy and form drag demands decrease, so logically, pollutant emissions decrease, however, as traffic density increases acceleration/deceleration cycles increase therefore increasing energy input (and therefore pollution) into the system. Finally, as density increases you have more sources of pollution (vehicles) per mile.

One of the parameters available from the Borman ITS program is roadway occupancy. This is a ratio of the time any vehicle is over a sensor to total time, or the time the sensor is "occupied". This parameter is analogous to traffic density, the parameter discussed at length to this point. Our environmental measurements and measurements of traffic occupancy have shown that, as expected by the vehicle energy requirements just described, pollution flux near the Borman Expressway is well correlated with traffic occupancy.

A telling example of this is in comparing two scenarios varying only in density of traffic. Speed, flow, and density are three interrelated parameters useful in describing the operating conditions on a roadway. Flow is the number of vehicles per hour and is the product of the speed of the vehicles (in miles per hour) and the density of traffic (in vehicles per mile). At a given flow however, you may have more than one set of vehicle speed and density. You can have a high speed and low density or a low speed and high density. In real world terms, this would be a case where traffic might be heavy but moving along at a reasonable speed versus slower very congested traffic moving well below posted limits. 
In a similar real world case on the Borman Expressway, our research demonstrated that for the same number of vehicles moving through a segment (1600 veh/lane/hour), higher traffic occupancy (25\%) produced $16 \%$ to $34 \%$ more pollution (carbon monoxide and fine particulate matter) in the area near the roadway than did traffic at lower occupancy $(19 \%)$. This illustrates the environmental benefit of minimizing oversaturated traffic flow conditions. The same number of vehicles were moving through the segment, the only difference was in the density of them. If this traffic situation can be avoided or minimized, as ITS can do, then the air quality near the Borman will be improved.

In addition to the general relationships between flux and traffic occupancy, specific events (designated by Hoosier Helper responses to accidents), were studied. Local air pollution would frequently increase by a factor of 2 or 3 over pre-event (accident) pollution levels. An additional benefit of ITS is the reduction of accidents, particularly secondary accidents (accidents occurring within or at the end of a traffic queue from a prior accident). Obviously the reduction of accidents and secondary accidents by ITS would reduce the environmental impact of the Borman on local air quality.

One of the real benefits of this study is that for the first time we have quantifiable real-time road parameters that have been correlated to realtime environmental conditions. This will permit the development of traffic management tools that incorporate the environment. This is one of the goals of the implementation phase of this project.

\section{Implementation}

Correlations between flux and vehicle occupancy as well as between flux and traffic flow have shown that mitigating oversaturated traffic conditions can significantly reduce PM2.5 and $\mathrm{CO}$ in the area adjacent to the Borman Expressway. ITS is the unique tool for accomplishing this improvement in the air we breathe near the expressway. By monitoring realtime traffic conditions, the Borman ITS system will optimize the smooth flow of traffic. Rerouting scenarios including providing information to motorists regarding traffic conditions will allow drivers to make informed travel decisions and thereby avoid congested areas. Consequently, the Borman ITS program should result in improvement of the local air quality, as it will provide information for faster response by the Hoosier Helpers and other emergency vehicles thereby shortening traffic backups and subsequent pollution production. Keep in mind that the while the first phase of this project has shown how ITS can improve air quality near the Borman, the ITS system was not fully operational at the time of the completion of this phase. A follow-up phase will incorporate all of the ITS data and add substantially to the understanding of the environmental benefits of ITS.
The follow-up phase of the project will assess the effects of fleet mix, number and type of lane obstructions (moving lane closure, fixed lane closure, accidents), and duration of closure. A model will be developed and verified based on data from the site. This model and other work associated with the follow-up phase will be incorporated into a set of tables and/or a decision matrix that will assist planners and operators in making environmentally sound decisions regarding not only the Borman expressway but other expressways as well.

The benefits of ITS will be communicated in several ways including; A press release to be developed through the INDOT Office of Communication, talking points for public officials, and information sharing with Gary, Chicago, Milwaukee corridor officials. The information will also be incorporated into Trafficwise.org, a website that will offer information about traffic conditions including information gathered from intelligent traffic systems in the state of Indiana. These educational initiatives will help the public at large understand their role in keeping traffic moving smoothly and the environmental benefit of driving decisions made with the assistance of ITS systems. 


\section{Contacts}

For more information:

Prof. Robert B. Jacko

Principal Investigator

School of Civil Engineering

Purdue University

West Lafayette IN 47907

Phone: (765) 494-2199

Fax: (765) 496-1988
Indiana Department of Transportation

Division of Research

1205 Montgomery Street

P.O. Box 2279

West Lafayette, IN 47906

Phone: (765) 463-1521

Fax: (765) 497-1665

\section{Purdue University}

Joint Transportation Research Program

School of Civil Engineering

West Lafayette, IN 47907-1284

Phone: (765) 494-9310

Fax: (765) 496-1105 


\section{$\underline{\text { Table of Contents }}$}

List of Figures $\quad$ ii

List of Tables vi

List of Equations $\quad$ vii

1.0 INTRODUCTION 1

2.0 MATERIALS AND METHODS 2

2.1 Monitoring Site Selection 2

2.2 Measurements $\quad 5$

2.2.1 $\mathrm{PM}_{2.5} \quad 6$

2.2.2 Measuring $\mathrm{PM}_{2.5}$

2.2.3 Carbon Monoxide 9

2.2.4 Measuring Carbon Monoxide $\quad 10$

2.2.5 Meteorological Instrumentation 11

2.2.6 Sampling Interval $\quad 12$

2.2.7 Traffic Data 13

2.2.8 Collection Methods 14

2.2.9 Hoosier Helper Data 14

2.2.10 Data Management $\quad 15$

2.2.11 QA/QC 16

2.2.12 Explanation of "Flux" 18

2.3 Modeling 19

2.3.1 ISCST3 19

2.3.2 CALINE4 19

2.3.3 MOBILE5b \& Part5 20

2.3.4 Highway Capacity Manual 20

3.0 RESULTS \& DISCUSSION 20

3.1 Background and Site Characterization $\quad 20$

3.1.1 Bearings and Distances $\quad 20$

3.2 Borman Sensitivity 22

3.3 Seasonal Data and General Characterization 27

3.4 Background Determination by Sector Analysis 30

3.5 ISCST3 Background Estimates $\quad 39$

4.0 ANALYSIS OF TRAFFIC ENVIRONMENT RELATIONSHIPS 47

4.1 Aggregate Analysis 48

4.1.1 Predicted Aggregate Results $\quad 48$

4.1.1.1 Vehicle Speed, Density, and Flow 51

4.1.1.2 CALINE4 Predictions 54

4.1.2 Observed Aggregate Results $\quad 57$

4.2 Predicted Serial Results $\quad 60$

4.2.1 Accounting for Background Levels 61

4.2.2 Varying Wind Direction and Analysis $\quad 62$

4.2.3 Downstream Effects $\quad 63$

4.2.4 Upstream Effects $\quad 64$

4.3 Observed Serial Results $\quad 70$

5.0 CONCLUSIONS

ACKNOWLEDGEMENTS $\quad 90$

REFERENCES $\quad 91$ 


\section{List of Figures}

Figure \# $\quad \underline{\text { Caption }} \quad$ Page

2.1 East-Southeast View of Monitoring Site: Note "S" curve 3

2.2 Southeast View of Monitoring Station 4

2.3 North View of Monitoring Station 4

$2.4 \quad$ TEOM Control Unit 8

$2.5 \quad$ Size Selective Inlets 8

2.6 Carbon Monoxide Analyzer: CO Monitor TEI 48C 11

3.1 Monitoring Station Map Detail 21

3.2 Wind Vector and Resultant Concentration 23

3.3 Sensitivity of the Monitoring Station to the Borman 25

Expressway

3.4 Average Flux vs. Origin Direction Jan 1, 2001 to 26

November 30, 2001

3.5 Borman Exposure Flux Deviation from mean -90 to 110

degrees (270 to 110$)$

3.6 2001 Borman Monitoring Station Wind Rose 28

3.7 Seasonal Variations in $\mathrm{CO}$ and $\mathrm{PM}_{2.5}$ Concentration 30

3.8 Roads and General Background Surrounding the Borman 32

Expressway Monitoring Station.

3.9 Population Density surrounding the Monitoring Site on 33

the Borman Expressway 


\section{List of Figures}

Figure \# $\quad \underline{\text { Caption }} \quad$ Page

3.10 Aerial Photograph Directly over the Monitoring Site on 34

the Borman Expressway

3.11 Flux Emanating from 10 to 40 and 150 to 180 degree arcs. 35

3.12 Flux of Borman Origin and Relative Traffic Flow 36

3.13 Average Urban Mixing Height 37

3.14 Average Atmospheric Stability 38

3.15 CO Sources and Monitoring Station 40

3.16 $\mathrm{PM}_{2.5}$ Sources and Monitoring Station 40

3.17 ISCST3 Predicted Average Concentrations from Permitted 42

Point Source Origin

3.18 Predicted $\mathrm{PM}_{2.5}$ Concentration Due to Permitted Point Sources 44

at Monitoring site by Borman Intersecting Wind Direction

3.19 Average Measured Concentration of $\mathrm{PM}_{2.5}$ and $\mathrm{CO}$ By Wind 45

Direction Midnight to Midnight

3.20 Average Measured Concentration of $\mathrm{PM}_{2.5}$ and $\mathrm{CO}$ By Wind 46

Direction Midnight to 5 am

3.21 Predicted CO Concentration of Permitted Stationary Origin 47

4.1 Emission factor for Borman Fleet 75F 51

4.2 Estimated Traffic Flow and Speed Vs. Density 52

4.3 Estimated Traffic Flow, Speed, and Emissions vs. Density 53 


\section{$\underline{\text { List of Figures }}$}

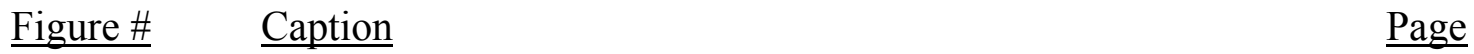

4.4 Combined Caline4 and ISCST3 Modeling Results and 56

Measured Results

4.5 $\quad \mathrm{CO}$ and $\mathrm{PM}_{2.5}$ Scatter Plot: Predicted vs. Measured Results $\quad 57$

4.6 Borman Exposure: Flux and Flow vs. Occupancy 59

4.7 Borman Exposure: Flux and Occupancy vs. Flow 60

4.8 Theoretical $\mathrm{PM}_{2.5}$ Pollution Profile along Roadway Segment 65

4.9 Theoretical CO Pollution Profile along Roadway Segment 66

4.10 Theoretical $\mathrm{PM}_{2.5}$ Upstream Monitoring Station Record 67

4.11 Theoretical CO Upstream Monitoring Station Record 68

4.12 Theoretical $\mathrm{PM}_{2.5}$ Downstream Monitoring Station Record 68

4.13 Theoretical CO Downstream Monitoring Station Record 69

4.14 April 4, 2001 Accident Response: Flux 71

4.15 April 4, 2001 Accident Response: Concentration 73

4.16 February 10, 2000 Accident Effect 74

4.17 August 24, 2001 Congestion Event: Flux 75

4.18 August 24, 2001 Congestion Event: Concentration 76

4.19 July 11, 2001 Accident / Congestion Event 78

4.20 July 8, 2001 Acceleration / Deceleration Event 79

4.21 August 23, 2001 Accident and Recovery with Congestion 81

Downstream $\mathrm{PM}_{2.5}$ Flux 


\section{$\underline{\text { List of Figures }}$}

Figure \# Caption $\quad$ Page

4.22 August 23, 2001 Accident and Recovery with Congestion 83 Downstream CO Flux

4.23 August 23, 2001 Accident and Recovery with Congestion 84

Downstream $\mathrm{PM}_{2.5}$ Concentration

4.24 August 23, 2001 Accident and Recovery with Congestion 85

Downstream CO Concentration

4.25 June 8, 2001 Extended Congestion Effects 86 


\section{$\underline{\text { List of Tables }}$}

$\underline{\text { Table\# }} \quad \underline{\text { Table Title }} \quad \underline{\text { Page }}$

$1.1 \quad$ Project Objectives 2

2.1 Summary of Error Between 1 Second Data and Longer 12

Averaging Intervals: Trial One

2.2 Summary of Error Between 1 Second Data and Longer 12

Averaging Intervals: Trial Two

3.1 Approximate Bearings and Distances From Monitoring Site 22

to Borman Expressway

3.2 Comparison of Measured Parameters to Environmental Standards 29

3.3 Highest Hourly $\mathrm{PM}_{2.5}$ Observations 29

3.4 Average Hourly Borman Component of Local Air Quality 39

from 10 to 40 degrees

4.1 Mobile5b Fleet Mix 49

4.2 Part5 Fleet Mix and Mean Vehicle Characteristics 50

4.3 Caline4 Modeling Parameters 55

5.1 Level of Service Effect on Local Air Quality 88 


\section{List of Equations}

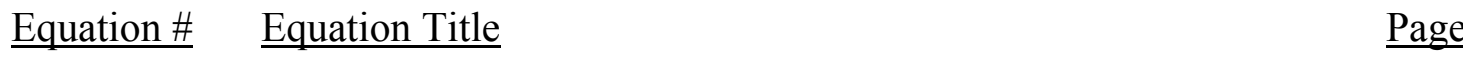

$\begin{array}{lll}2.1 & \text { Box Mixing Model } & 18\end{array}$

$\begin{array}{lll}4.1 & \text { Traffic Velocity } & 51\end{array}$

4.2 Traffic Flow $\quad 52$

4.3 Emissions Calculation 53

$\begin{array}{lll}4.4 & \text { Site Measurement Components } & 6\end{array}$ 


\section{$1.0 \quad$ INTRODUCTION}

The Borman Expressway is a 16-mile section of interstate I-80/94 in Lake county Indiana connecting the Indiana and Illinois Tollways. It is one of the most heavily traveled freeways in the United States. Heavy congestion and non-uniform speeds are prominent and consequently on road vehicular exhaust emissions are high thus adversely affecting local concentrations of carbon monoxide (CO) and fine particulate matter $\left(\mathrm{PM}_{2.5}\right)$.

The Indiana Department of Transportation recently began the installation of an intelligent transportation system (ITS) on the Borman expressway. This system combines numerous technologies to gather and process traffic data for distribution to motorists, police, safety officials, and assistance providers with the goal of reducing congestion, accidents, and enhancing the efficiency of the existing roadway.

The ITS project provided a unique opportunity to gather information about the effect of ITS on local air quality as the system was phased in. A proposal to monitor the effects of ITS on local air quality was accepted by the JTRP and work on this project began in March 1999. The objectives of this project are listed in table 1. 


\section{Table 1.1: Project Objectives}

1 Establish a mobile monitoring station near the Borman Expressway

2 Monitor $\mathrm{PM}_{2.5}$ (particulate matter less than 2.5 microns), Carbon

Monoxide (CO), and meteorological parameters.

3 Determine pollutant sources and background effects

4 Determine the Borman Expressway contributions to the local air quality

$5 \quad$ Collect ITS data as available

6 Determine pollutant build-up lag time.

$7 \quad$ Correlate traffic conditions with local air quality

8 Assess the seasonal variation of $\mathrm{CO}$ and $\mathrm{PM}_{2.5}$

\subsection{MATERIALS AND METHODS}

\subsection{Monitoring site selection}

Reconnaissance flights were made over the Borman Expressway to find potential monitoring locations. Three sites were considered. A pumping station located at the southeast corner of the Chase Street - Borman crossover, a pumping station located just south of the Borman expressway between the Kennedy and Cline Interchanges, and an open field north of the Borman Expressway just west of the Chase Street Crossover of the Borman Expressway. Borman proximity, security, utilities, meteorology, and local geography were deciding factors in selecting the monitoring station.

All three locations were close to the Borman but only the two pumping stations offered security and convenient utilities. The field north of the expressway offered 


\section{Table 1.1: Project Objectives}

1 Establish a mobile monitoring station near the Borman Expressway

2 Monitor $\mathrm{PM}_{2.5}$ (particulate matter less than 2.5 microns), Carbon

Monoxide (CO), and meteorological parameters.

3 Determine pollutant sources and background effects

4 Determine the Borman Expressway contributions to the local air quality

$5 \quad$ Collect ITS data as available

6 Determine pollutant build-up lag time.

$7 \quad$ Correlate traffic conditions with local air quality

8 Assess the seasonal variation of $\mathrm{CO}$ and $\mathrm{PM}_{2.5}$

\subsection{MATERIALS AND METHODS}

\subsection{Monitoring site selection}

Reconnaissance flights were made over the Borman Expressway to find potential monitoring locations. Three sites were considered. A pumping station located at the southeast corner of the Chase Street - Borman crossover, a pumping station located just south of the Borman expressway between the Kennedy and Cline Interchanges, and an open field north of the Borman Expressway just west of the Chase Street Crossover of the Borman Expressway. Borman proximity, security, utilities, meteorology, and local geography were deciding factors in selecting the monitoring station.

All three locations were close to the Borman but only the two pumping stations offered security and convenient utilities. The field north of the expressway offered 
access to prevailing winds but offered no security and no immediate access to phone and electricity. The Chase street pumping station, located immediately east of the Chase street overpass embankment, possessed utility access but western exposure was obstructed by the overpass grade. The Southeast Hessville site, located between Kennedy and Cline Avenues, was uniquely situated at a bend in the Borman thus exposing more than $180^{\circ}$, from approximately 270 to 110 degrees, to observation. The site between Kennedy and Cline avenues was selected, based on advantages in security, utilities, and local geography. Figures $2.1-2.3$ show the Southeast Hessville pumping station (the monitoring site) from the air. Figure 2.4 shows a map of the general area. The red circle indicates the general location of the monitoring station.

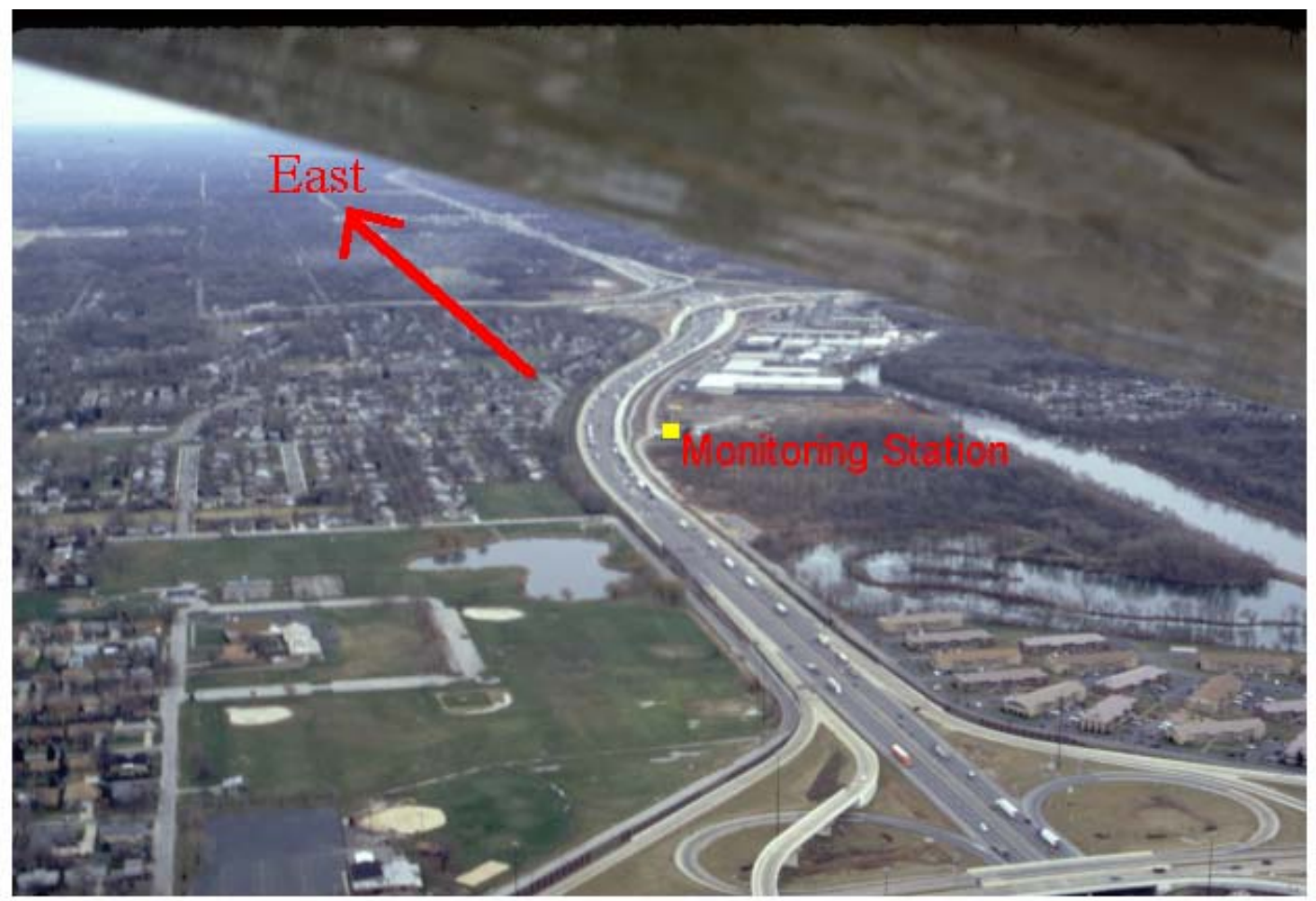

Figure 2.1: East-Southeast view of Monitoring Site. Note "S" Curve 


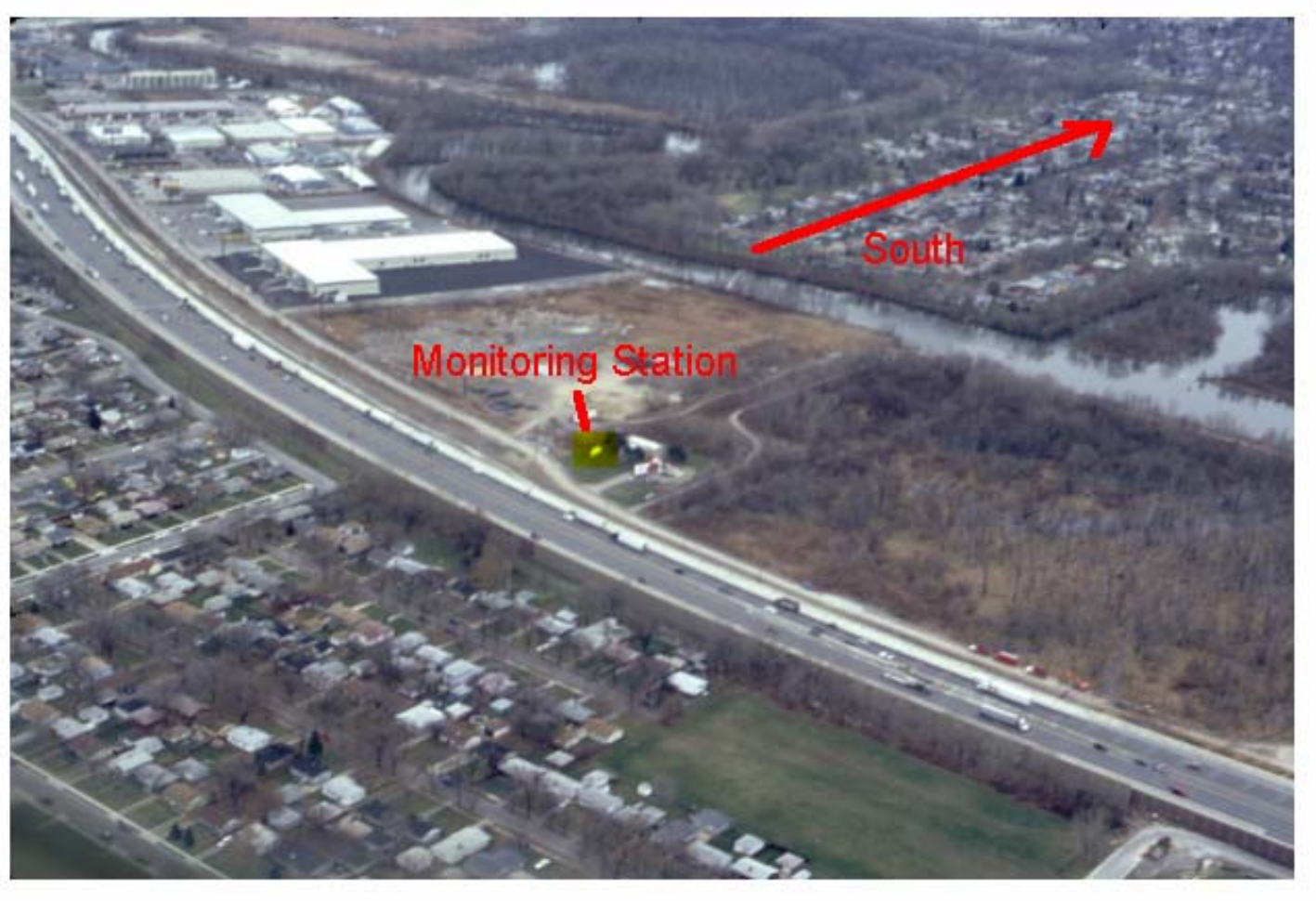

Figure 2.2: South East View of Monitoring Station

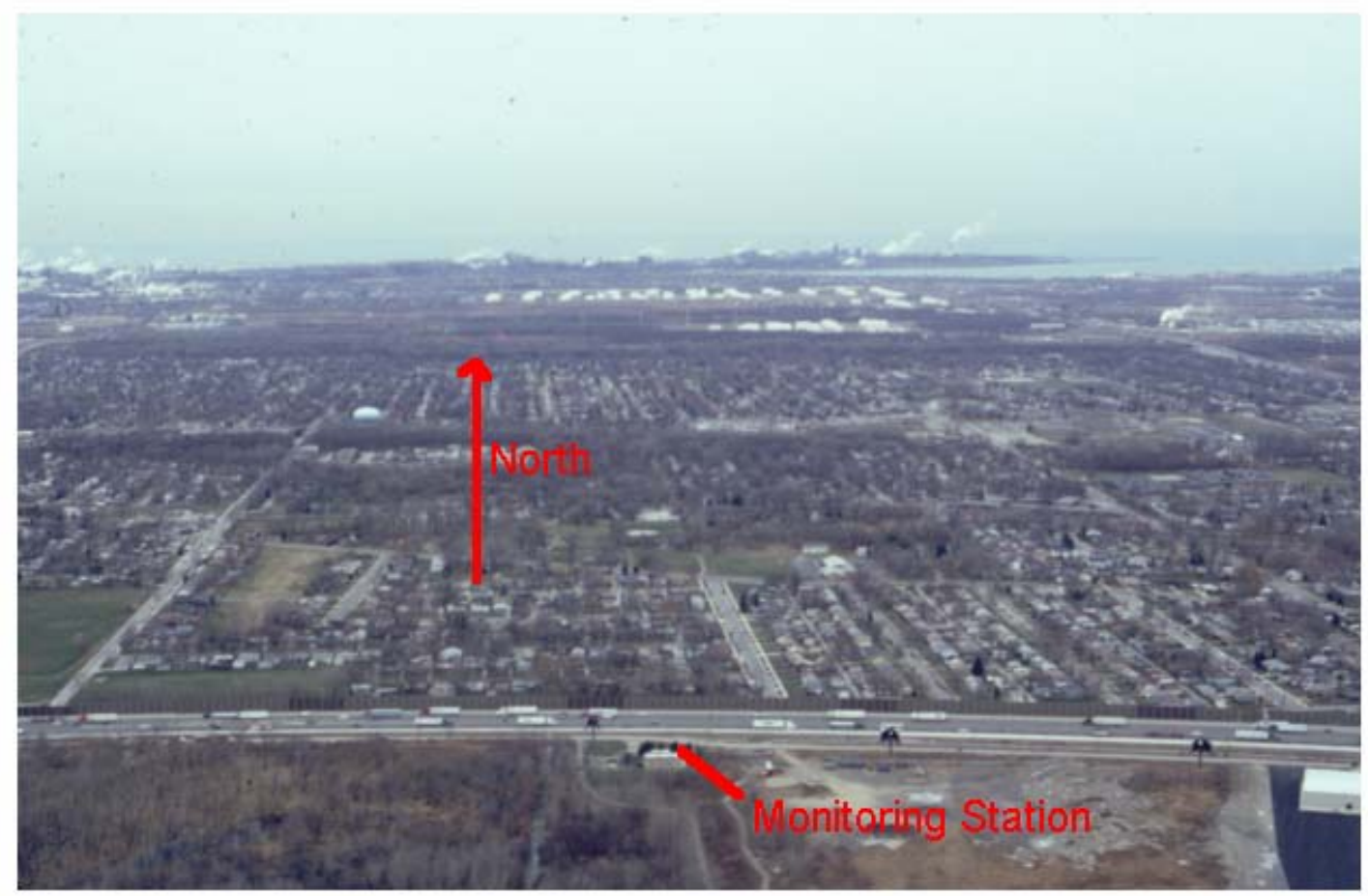

Figure 2.3: North View of Monitoring Station 


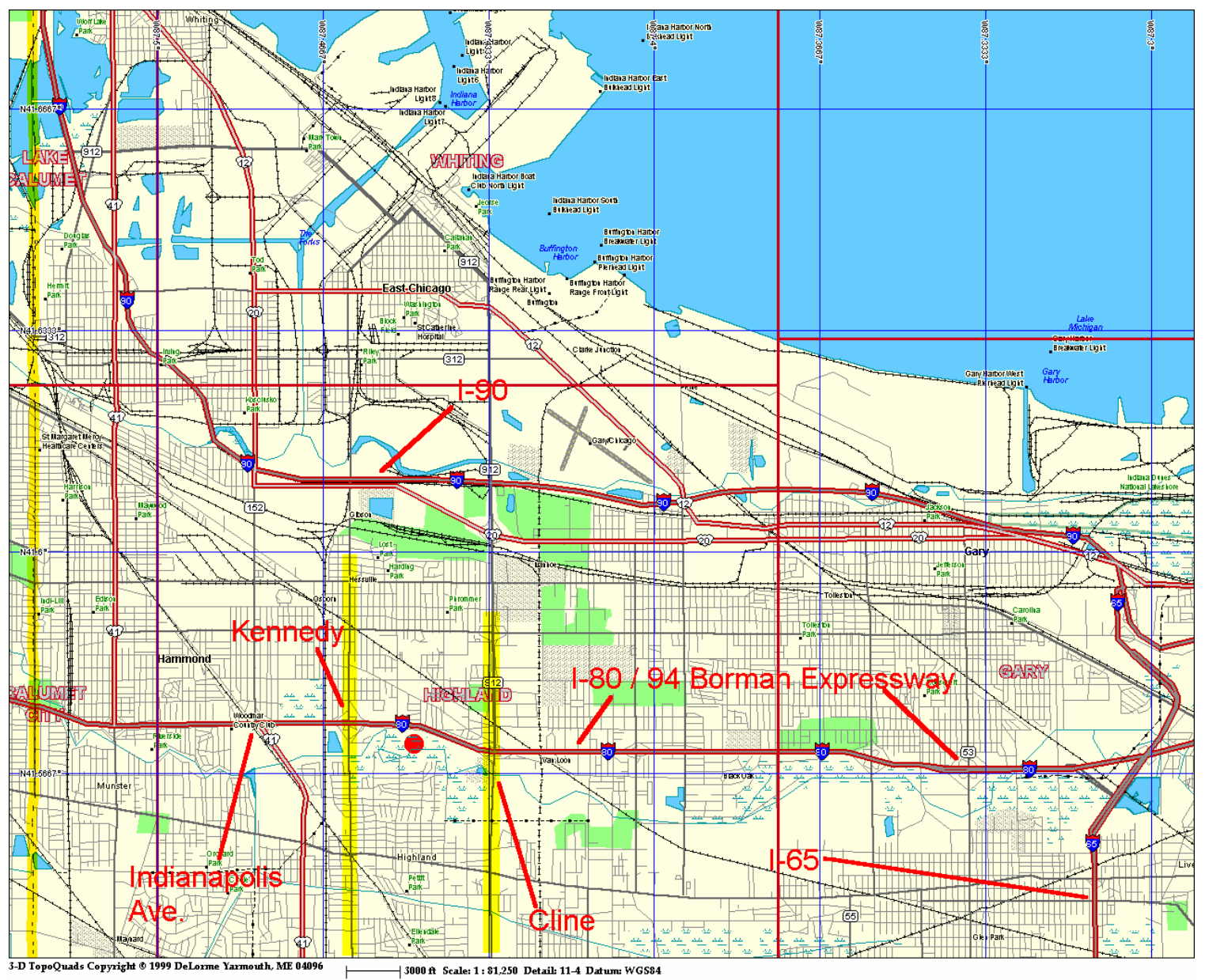

Figure 2.4: Borman Expressway (I-80/94) in Northwestern Indiana

\section{2 $\quad$ Measurements}

Two key parameters and 6 supporting parameters were monitored in the mobile sampling laboratory. Particulate matter, specifically particulate matter less than 2.5 microns in size $\left(\mathrm{PM}_{2.5}\right)$, and Carbon Monoxide $(\mathrm{CO})$ were the key pollutants of interest. Wind speed, wind direction, rainfall, ambient temperature, wet bulb temperature, and mobile laboratory temperature were recorded to provide context for the $\mathrm{PM}_{2.5}$ and $\mathrm{CO}$ data. 


\subsection{1 $\mathbf{P M}_{2.5}$}

In 1997 the Environmental Protection Agency proposed a revised National Ambient Air Quality Standard (NAAQS) for particulate matter that focused on $\mathrm{PM}_{2.5}$. Prior to this the particulate matter standard had been based on $\mathrm{PM}_{10}$ (particulate matter less than 10 microns). Recent research had suggested that the very fine fraction of particulate matter was more deleterious to health than larger particles. Smaller particles may be transported deeper into the respiratory system where they and the substances they carry are more likely to be absorbed into the bloodstream and less likely to be purged from the body by the lungs natural defense mechanisms.

The internal combustion engine is a major source of fine particulate matter. Diesel engines represent a significant source of $\mathrm{PM}_{2.5}$ within the category of internal combustion engines. Not long after the USEPA proposed the new particulate matter standards, the American Trucking Association (ATA) filed suit against the United States Environmental Protection Agency (USEPA) stating the agency's proposed new standards were unconstitutional. The ATA alleged that the USEPA had promulgated law without proper review by the legislature and that they were required to consider the economic impact of the proposed rules. The Supreme Court ruled in February 2001 that the USEPA had not acted unconstitutionally in promulgating the standards for particulate matter that the government had charged them with in the Clean Air Act Amendments. The court also ruled that the EPA was not required to assess the economic impact of the proposed new particulate matter standard.

The large volume of Heavy Duty diesel truck traffic in the Borman Expressway corridor, the recent focus on $\mathrm{PM}_{2.5}$ health effects, and the regulatory focus on $\mathrm{PM}_{2.5}$ made 
$\mathrm{PM}_{2.5}$ a pertinent parameter to monitor as an indicator of air quality near the Borman Expressway.

\subsubsection{Measuring $\mathbf{P M}_{2.5}$}

A Tapered Element Oscillating Microbalance (TEOM), manufactured by Rupprecht \& Patashnick, was used for measurement of $\mathrm{PM}_{2.5}$ in this study. The TEOM is capable of near-continuous measurement of particulate concentrations with very little user intervention. The TEOM can measure and average data over periods less than a second. It achieves this rapid measurement frequency by replacing gravimetric mass determination with change in frequency determination. A small filter is placed on the end of a vibrating hollow rod. A constant flow of air is pulled across the filter and through the vibrating hollow rod. The particles borne by the air stream are deposited on the filter. As more air is pulled across the filter the mass on the vibrating hollow rod increases. The increase in mass on the filter reduces the frequency at which the rod oscillates. The change in oscillating frequency is then used to calculate the change in mass on the filter. Concentration is calculated by dividing the mass change rate by the volume flow rate. Figure 2.4 shows the TEOM control unit. 


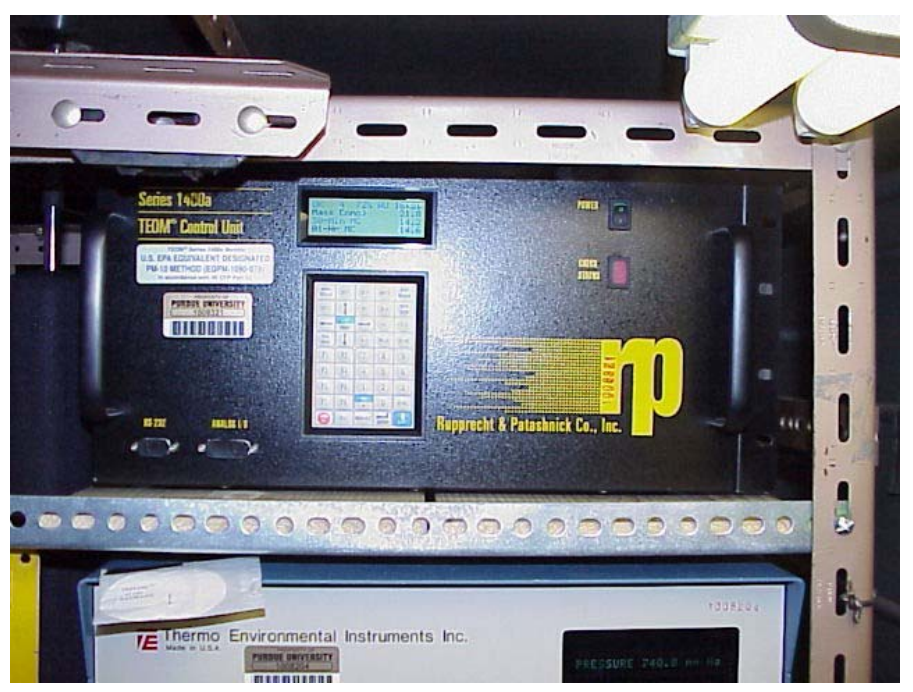

Figure 2.4: TEOM Control Unit

$\mathrm{PM}_{2.5}$ is selected from the ambient air prior to measurement by a $\mathrm{PM}_{10}$ impaction head followed by a $\mathrm{PM}_{2.5}$ sharp cut cyclone mounted outside of the laboratory on the roof. The $\mathrm{PM}_{2.5}$ air stream passes through a bulkhead in the laboratory ceiling and down to the mass transducer where the actual measurement takes place. Figure 2.5 shows the impaction head and sharp cut cyclone.

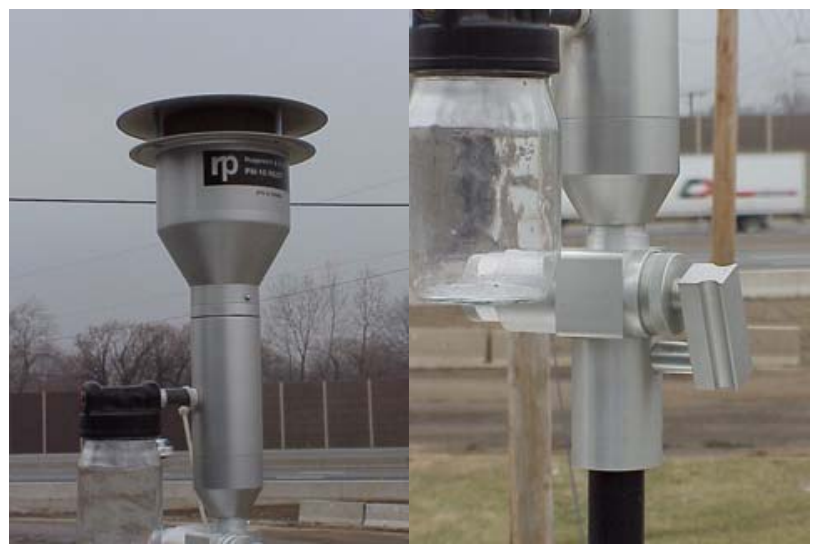

Figure 2.5 : Size Selective Inlets: $\mathbf{P M}_{10}$ Impactor on left, Sharp Cut Cyclone on right. 
Traditional gravimetric methods require extensive labor in recovering and processing samples. Typically, gravimetric methods average samples over 1 hour or 24 hours (i.e. A pre conditioned filter is exposed to the sample air stream for 1 to 24 hours. The filter is then taken to a laboratory where it is conditioned and then weighed). Monitoring ambient concentrations at intervals only as frequent as 10 minutes by manual methods would be very labor intensive. Ten minute averaging would require the processing of 144 filters per day.

The central tenant of this project is that the Borman Expressway is a major component of local air quality and that intelligent transportation systems present new opportunities to improve local air quality. Traffic jams and congestion can vary by the minute. Averaging samples over a 24 hour basis or even a 1 hour basis would miss much of the dynamic nature of the expressway and likewise miss much of the variability in local air quality near the expressway.

\subsubsection{Carbon Monoxide}

The Borman Expressway carries a significant number of gasoline powered vehicles in addition to heavy duty diesel trucks. Gasoline powered internal combustion engines produce significantly more $\mathrm{CO}$ than do diesel engines on a vehicle miles traveled basis. While the Borman carries a great number of heavy diesel trucks, it carries even more gasoline fueled vehicles.

Carbon monoxide is a significant component of local air quality. Inhalation of Carbon Monoxide produces carboxyhemoglobin in the bloodstream. Excess carboxyhemoglobin in the bloodstream can lead to asphyxiation while lower 
concentrations can produce headaches, loss of time interval discrimination, and loss of motor coordination (Amdur, Doull, Klaassen, 1991).

Carboxyhemoglobin formation is time and intensity dependant. Similar carboxyhemoglobin concentrations could be expected in subjects exposed to very high $\mathrm{CO}$ concentrations for a short time or lower concentrations of $\mathrm{CO}$ for a long time. In addition, physical activity accelerates the formation of Carboxyhemoglobin.

Knowing that diesel fueled vehicles produce relatively more $\mathrm{PM}_{2.5}$ and that gasoline fueled vehicles produce relatively more $\mathrm{CO}$ can be used to discern the effects of varying fleet mix on local air quality. The pairing of these two environmental components makes them especially useful for assessing the effect of an expressway on local air quality.

\subsubsection{Measuring Carbon Monoxide}

A Thermo Environmental Instruments Model 48C gas filter correlation Carbon Monoxide analyzer was used for carbon monoxide measurements (figure 2.6). This analyzer is widely used and is incorporated in federal reference methods for ambient CO determination. The analyzer was equipped with solenoid actuated zero and span valves that permitted frequent remote calibration of the analyzer. 


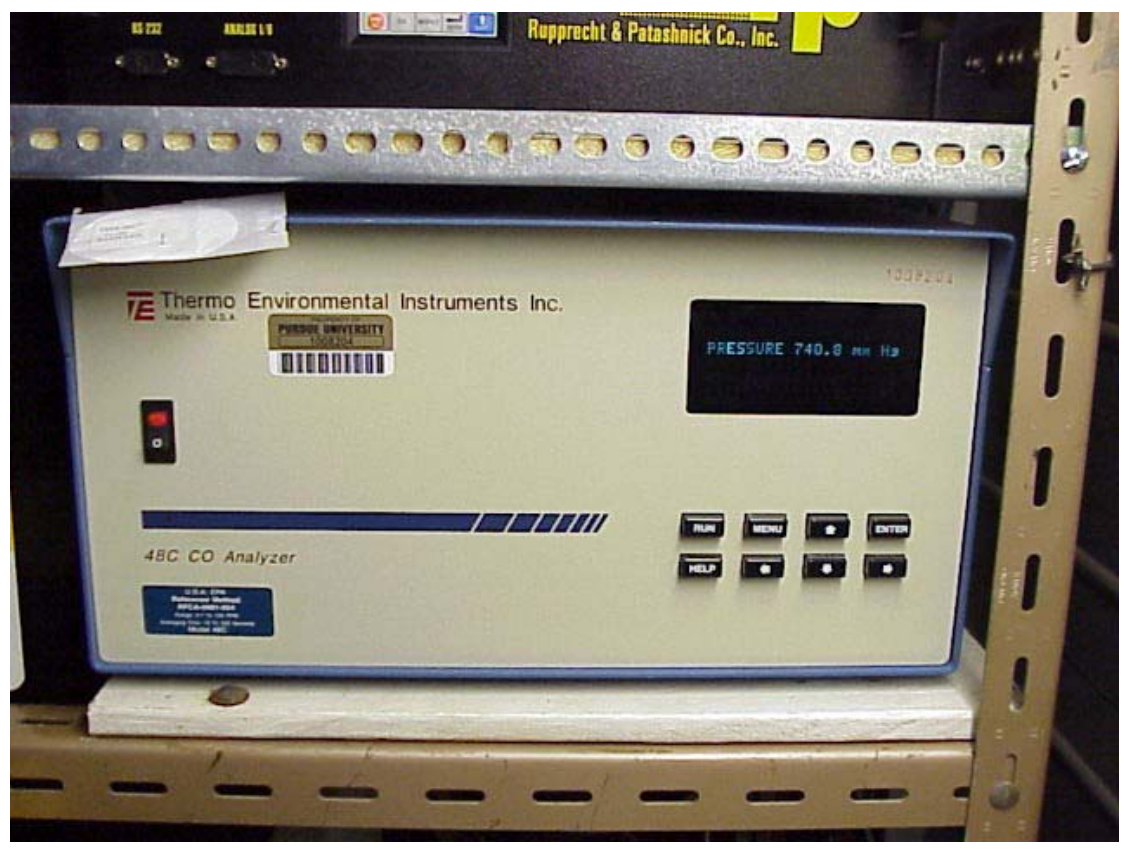

Figure 2.6: Carbon Monoxide Analyzer: CO Monitor TEI 48C

\subsubsection{Meteorological instrumentation}

Wind Speed and direction where monitored with a Met One Meteorological instrument set. The anemometer was a reed switch pulse count design. The wind vane was a gapless potentiometer design. Excitation, signal processing, and digital to analog conversion was performed by a Campbell Scientific $21 \mathrm{x}$ microdatalogger. The TEOM data management software was used to process the wind direction data thus avoiding error associated with the wind vane crossing north where the potentiometer crosses from maximum resistance to minimum resistance (i.e. from 359 degrees to 1 degree.). The anemometer calibration was checked in a Purdue Wind tunnel prior to use. 


\subsubsection{Sampling Interval}

A ten second averaging interval was selected as a compromise between resolution and the physical constraints of the equipment and data management system. Particulate and $\mathrm{CO}$ data was collected from the field at a 1 second averaging interval. The assumption was made that field $\mathrm{PM}_{2.5}$ concentrations would not vary significantly from 1 second to another. This in effect was the best approximation of truly continuous sampling. Longer averaging intervals were then simulated by averaging this data into coarser periods; 3 seconds, 5 seconds, 10 seconds, etc.. The absolute percent difference between the original data and these longer averaging periods was then calculated. Table 2 and 3 show the results of the two tests.

Table 2.1: Summary of Error Between 1 Second Data and Longer Averaging Periods: Trial One

Base Data: One Second Average Interval 4:40:10 pm to 5:35:40 pm 10/26/99

\begin{tabular}{|l|l|l|l|l|l|}
\hline Errors & 3 Sec. & 5 sec. & 10 sec. & 15 sec. & 30 sec. \\
\hline Max & $0.97 \%$ & $1.74 \%$ & $3.04 \%$ & $4.15 \%$ & $6.54 \%$ \\
\hline $95 \%$ tile & $0.50 \%$ & $0.63 \%$ & $1.14 \%$ & $1.57 \%$ & $2.62 \%$ \\
\hline $50 \%$ tile & $0.00 \%$ & $0.16 \%$ & $0.39 \%$ & $0.53 \%$ & $0.90 \%$ \\
\hline Average & $0.13 \%$ & $0.23 \%$ & $0.45 \%$ & $0.64 \%$ & $1.07 \%$ \\
\hline
\end{tabular}

Table 2.2: Summary of Error Between 1 Second Data and Longer Averaging Periods: Trial Two

Base Data: One Second Average Interval 5:35:42 pm to 6:20:14 pm 10/26/99

\begin{tabular}{|l|l|l|l|l|l|}
\hline Errors & 3 Sec. & 5 sec. & 10 sec. & 15 sec. & 30 sec. \\
\hline Max & $1.12 \%$ & $1.34 \%$ & $2.25 \%$ & $3.17 \%$ & $4.92 \%$ \\
\hline $95 \%$ tile & $0.49 \%$ & $0.65 \%$ & $1.11 \%$ & $1.53 \%$ & $2.65 \%$ \\
\hline $50 \%$ tile & $0.00 \%$ & $0.16 \%$ & $0.36 \%$ & $0.5 \%$ & $0.85 \%$ \\
\hline Average & $0.12 \%$ & $0.22 \%$ & $0.43 \%$ & $0.61 \%$ & $1.05 \%$ \\
\hline
\end{tabular}


A three second averaging interval was selected for trials but proved too fast for communication and too prodigious in data volume. A ten second averaging interval was found to be the minimum interval practical for the capabilities of the TEOM memory buffer and communication system As table 2 and 3 indicated, this averaging rate provided data that $95 \%$ of the time would be expected to be within $1.1 \%$ of the value that would have been measured at a 1 second averaging interval.

\subsubsection{Traffic Data}

A key element of the Borman Intelligent Transportation System is traffic data. Traffic data will be collected at numerous monitoring stations along the roadway, when completed. These stations will alert the traffic center of congestion and traffic anomalies. Video cameras along the roadway will be used to confirm the situation and assist roadway managers in dispatching the appropriate response. This response could be Hoosier Helpers, police, firemen, or medical assistance. Traffic data will also be used to inform the public of traffic conditions and alert motorists to alternate routes as conditions warrant.

The traffic data will eventually be available via internet to interested and authorized parties. Traffic data collection began for this project in June of 2001 with the closest functional monitoring stations available at the time. The communication system for these monitoring stations was not yet in place so in lieu of the internet connection a cellular modem system was installed for communications. A communication system was installed near mile marker 3.6 approximately 0.5 miles from the monitoring station. This station provided information on eastbound traffic only. An additional communication system was installed in October near Indianapolis Boulevard, approximately 1.5 miles 
from the station. The latter installation provided traffic information on both east and west bound lanes. It was installed too late for incorporation into this draft. The data will be analyzed and included in the final report. Traffic data from the eastbound lanes however has been incorporated into this report. Sensors in the immediate vicinity of the environmental monitoring station (near mile marker 4.2) were damaged during highway construction and data from these sensors was unfortunately not available for inclusion in this report.

\subsubsection{Collection Methods}

The traffic collection system consists of a micro inductive loop placed beneath the roadway. As vehicles pass over the sensor their presence and the duration of presence is recorded. The averaging interval was set to 5 minutes to maximize memory duration yet retain sufficient resolution. The five minute averaging interval is in contrast to the 10 second environmental averaging interval. Shorter grouping intervals wouldn't necessarily enhance the value of the traffic data. A typical flow of $120 \mathrm{veh} / \mathrm{lane} / 5$ minutes equates to a rate of 20 vehicles/lane/minute. However the sensor can only measure whole vehicles. Either there is a vehicle over the sensor or there isn't. Therefore the error introduced by one more or one less vehicles is considerably greater with the shorter averaging period (i.e. 120 vehicles $+/-1$ vehicle $=+/-0.83 \%, 20$ vehicles $+/-1$ vehicle $=+/-5 \%$ ).

\subsubsection{Hoosier Helper Data}

Information about traffic assistance and accidents was available prior to the installation of the any of the traffic monitoring equipment. The Hoosier Helpers program 
assists motorists in almost any means possible to keep the Borman Expressway clear and free of obstacles and safer for all who use it. These obstacles may be debris, truck tire treads, disabled vehicles, or accidents. The type of response, assistance given, type of vehicle involved, location along the expressway, direction of traffic, lanes obstructed, and many other parameters are recorded. Much of this data proved useful in discerning the source of significant environmental events near the Borman Expressway.

\subsubsection{Data Management}

The volume of data collected in this project was formidable. 2.1 million environmental data points were collected in an average month. 0.44 million traffic data points were collected once both traffic monitoring stations were being recorded. Approximately 55.4 Megabytes of storage was required each month. During the first two years of the project about 60.7 million data points consuming 1.3 gigabytes of storage as collected.

Data from all instruments at the mobile sampling laboratory was collected in the TEOM's internal storage buffer. This data was transferred at 4-hour intervals to a personal computer located at the site. The PC served as a buffer for data collection and could collect over a month of data unattended if needed. This was never the case however as the site was generally checked every other day to insure all systems were performing nominally. The TEOM and carbon monoxide analyzer have Microsoft Windows ${ }^{\mathrm{TM}}$ based interfaces. These permit total control of all functions via a personal computer. These functions were transferred back to Purdue by modem and PC Anywhere software. 
The data would be worthless without organization and careful management. Microsoft SQL Server 7.0 was used for data management, storage, and reporting. Redundant backups were created. An un-altered copy of each file as it was collected from each source was made and filed away. After inspection for spurious data the data file was archived in a master database. Automatic nightly backups of the database as well as all project related material were made via Purdue computer network. Additional backups of the core data were made intermittently by burning the information to compact disks. Finally the data was stored on a secondary personal computer that was refreshed at regular intervals.

\subsubsection{QA/QC}

A quality assurance and quality control plan was developed per 40 CFR 58 (code of federal regulations) and with the assistance and consultation of the Indiana Department of Environmental Management. The QA/QC plan for the $\mathrm{CO}$ analyzer was developed from the code of federal regulations. The QA/QC plan for the TEOM was based on the manufacturer's recommendations. This was recommended by the Indiana Department of Environmental Management as the TEOM is a relatively new technology and while it is an official alternate measurement technique, there are many such alternate methodologies. In such cases it is advised to follow the manufacturers recommendations and operating directions in developing a case specific QA/QC plan.

The carbon monoxide analyzer was checked approximately every two days remotely from Purdue University to make sure the zero and span had not drifted out of calibration. Minor adjustments to the calibration were made as needed. The sample flow 
rate and pressure were monitored for signs of obstruction. A precision check of the carbon monoxide monitor was made every two weeks. The precision checks consisted of a project team member challenging the monitor with a gas of known concentration and reporting the result. During these site visits the sampler inlets were inspected and filters were changed as needed. An accuracy audit was completed every quarter. An accuracy audit consists of challenging the monitor with three gases of known concentration and recording the value. The monitor passed all zero and span checks, precision checks, and accuracy audits without exception.

The TEOM analyzer and sample path was checked for leaks with every filter exchange, approximately once per month. The $\mathrm{PM}_{10}$ impaction head and the $\mathrm{PM}_{2.5}$ sharp cut cyclone were inspected and cleaned as needed with each filter exchange. Flow audits were performed every 3 months. These audits consisted of connecting a calibrated wet test meter to the instrument and confirming that air is being moved across the particle sizing devices and through the TEOM at the design rates and that the TEOM is accurately reporting these flows. The TEOM was never out of specification but subtle adjustments were made as needed to maintain consistent flow rates throughout the study. At least twice per year a mass verification audit was conducted on the Mass Transducer. This audit challenged the mass transducer with a precisely weighed filter provided by Rupprecht and Patashnick. This audit verified that that the mass transducer was accurately ascertaining the oscillating frequency and thus accurately measuring mass accumulation. 


\subsubsection{Explanation of "Flux"}

Many components factor into the concentration of pollutants ultimately measured at the monitoring station. Wind speed is a very important factor to consider when comparing one day to another or when attempting to correlate traffic conditions with environmental factors. Consider an idealized situation where the Borman Expressway traffic is completely uniform in all traffic parameters. Speed, fleet mix, traffic density, power input (i.e. no variation in road grade or traffic speed), and traffic flow are all constant. Given this constant source of $\mathrm{CO}$ or $\mathrm{PM}_{2.5}$, as wind velocity increases the concentration of pollutant in the air will decrease. As the wind velocity decreases the concentration of pollutant in the air will increase. The reason this occurs is because as wind velocity increases the flow rate of air across the Borman increases. So from equation 1, a simple box mixing model, we can see that given the mass emission rate is constant an increase in air flow rate will result in a lower pollutant concentration.

\section{Equation 2.1: Box Mixing Model}

$$
\text { Concentration }(\text { Mass/Volume })=(\text { Mass/time }) /(\text { Volume } / \text { time })
$$

This equation illustrates an origin of ambiguity in inter-day and even intra-day concentration comparisons. Measured concentrations will vary considerably dependant on wind velocity. To compensate for this mass flux is calculated. Flux is a rate of mass transport and in this case: concentration in air multiplied by air velocity. The units are mass / (area * time). Flux units relative to this project are $\mu \mathrm{g} / \mathrm{m}^{2} \mathrm{sec}$ and occasionally $\mu \mathrm{g} / \mathrm{cm}^{2} \mathrm{sec}$. 


\subsection{Modeling}

While this project involved extensive data collection, that did not preclude the use of models. Models were used to estimate background concentrations of pollution and to determine the sensitivity of the monitoring location to the Borman.

\subsubsection{ISCST3}

The Industrial Source Complex Short Term Model version 3 is a commonly used EPA Gaussian dispersion model used for the prediction of airborne pollutant transport. Multiple sources and receptors can be modeled. Northwestern Indiana has several industrial sources that are among the largest sources of $\mathrm{PM}_{2.5}$ and $\mathrm{CO}$ in the United States. ISCST3 was used to estimate these sources contribution to the air quality near the monitoring station

\subsubsection{CALINE4}

The California Line Source Model version 4 (CALINE4) is a Gaussian dispersion model for predicting $\mathrm{CO}$ concentration from mobile sources near roadways. The model includes a graphic interface that facilitates data entry. This model was used to estimate the contribution of the Borman Expressway to local air quality and to determine the sensitivity of the monitoring station to different wind directions. Emission factors for CALINE4 were determined from Mobile5b and Part5. Particulate Matter was treated as a conservative neutral buoyant pollutant allowing it to be modeled as CO. 


\subsubsection{MOBILE5b \& Part5}

MOBILE5b and PART5 were used to estimate $\mathrm{CO}$ and $\mathrm{PM}_{2.5}$ emissions from the Borman Expressway fleet. These models require information of fleet mix, fleet speed, fuel parameters, local policy parameters, and environmental parameters such as temperature and altitude and produce a mass emission rate in units of mass / mile. These models do not directly provide an estimate of air concentration in the local area. Mobile5 and Part5 estimate mass emission rates can be used in a dispersion model such as CALINE4 to predict local ambient air concentrations.

\subsubsection{Highway Capacity Manual}

Relationships between speed and density were estimated with the guidance of the 2000 Highway Capacity Manual. The interrelationship of traffic flow, speed, and density complicates the estimation of emissions from roadways. Roadways have a finite capacity and as this capacity is approached traffic speed tends to decrease. More cars traveling a roadway produce more emissions, however, as vehicle speeds decrease while demand on the road is increasing then the emission rate from each individual vehicle may change as well. This relationship was investigated and density specific emission factor curves were estimated.

\subsection{RESULTS \& DISCUSSION}

\subsection{Background and Site Characterization}

\subsubsection{Bearings and Distances}




\subsubsection{MOBILE5b \& Part5}

MOBILE5b and PART5 were used to estimate $\mathrm{CO}$ and $\mathrm{PM}_{2.5}$ emissions from the Borman Expressway fleet. These models require information of fleet mix, fleet speed, fuel parameters, local policy parameters, and environmental parameters such as temperature and altitude and produce a mass emission rate in units of mass / mile. These models do not directly provide an estimate of air concentration in the local area. Mobile5 and Part5 estimate mass emission rates can be used in a dispersion model such as CALINE4 to predict local ambient air concentrations.

\subsubsection{Highway Capacity Manual}

Relationships between speed and density were estimated with the guidance of the 2000 Highway Capacity Manual. The interrelationship of traffic flow, speed, and density complicates the estimation of emissions from roadways. Roadways have a finite capacity and as this capacity is approached traffic speed tends to decrease. More cars traveling a roadway produce more emissions, however, as vehicle speeds decrease while demand on the road is increasing then the emission rate from each individual vehicle may change as well. This relationship was investigated and density specific emission factor curves were estimated.

\subsection{RESULTS \& DISCUSSION}

\subsection{Background and Site Characterization}

\subsubsection{Bearings and Distances}


Figure 3.1 is a map of the immediate vicinity of the monitoring station. Kennedy Avenue is to the west and Cline Avenue is to the east.

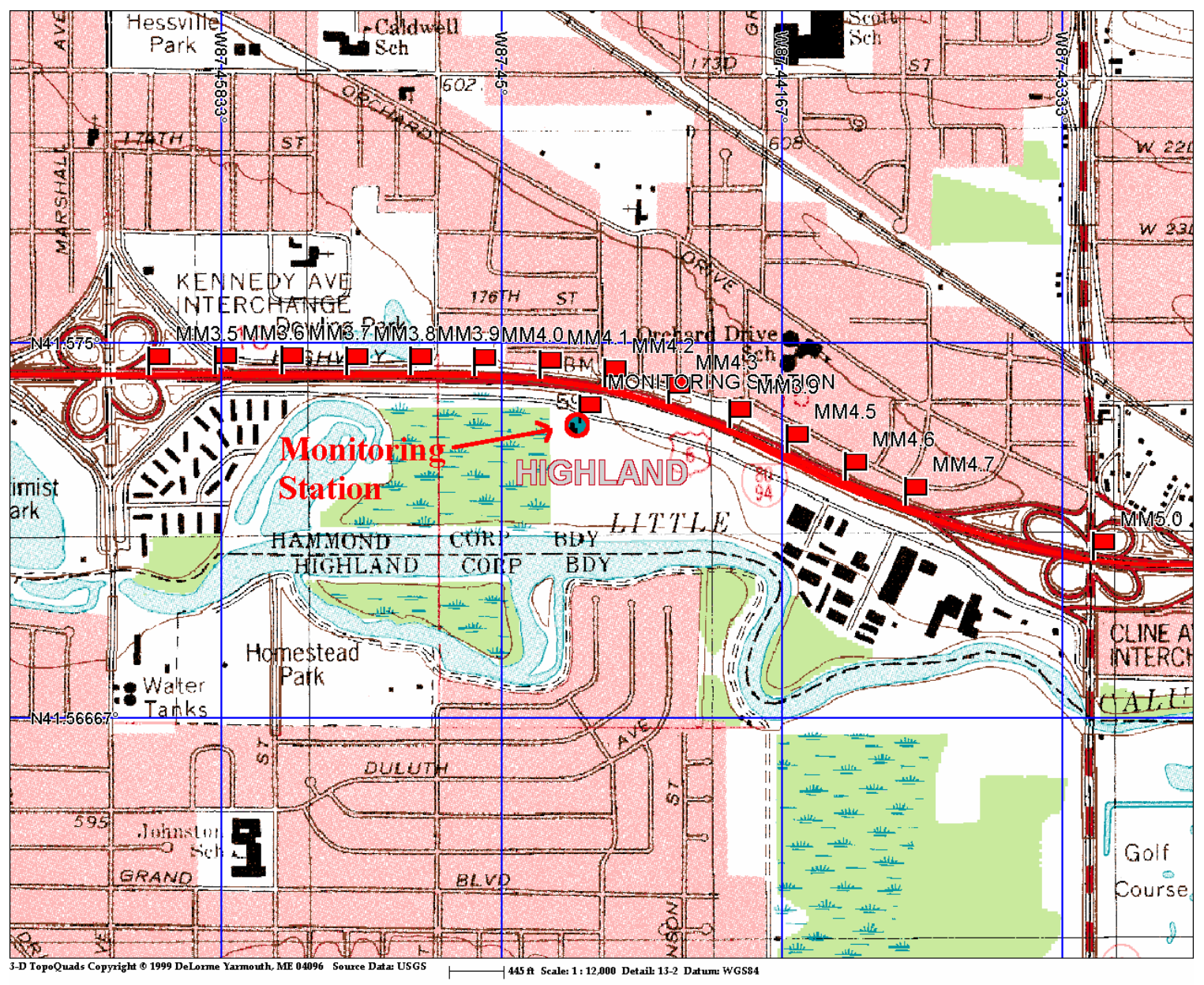

Figure 3.1: Monitoring Station Map Detail

Table 3.1 contains bearings and distances from the site to mile markers along the Expressway. This information was acquired from 3D Topoquads ${ }^{\circledR}$ by DeLorme.

Note as the distance from the site increases the length of exposure (Distance across the Borman) increases except just beyond Cline Avenue bend are where exposure distance briefly decreases. 
Table 3.1: Approximate Bearings and Distances From Monitoring Station to

Borman Expressway.

\begin{tabular}{|c|c|c|c|c|c|}
\hline $\begin{array}{l}\text { Mile } \\
\text { Marker }\end{array}$ & $\begin{array}{l}\text { Bearing } \\
\text { (degrees) }\end{array}$ & $\begin{array}{l}\text { Straight line } \\
\text { Distance To Center } \\
\text { of Borman (miles) }\end{array}$ & $\begin{array}{l}\text { To Near } \\
\text { Side } \\
\text { (miles) }\end{array}$ & $\begin{array}{l}\text { To Far } \\
\text { Side } \\
\text { (miles) }\end{array}$ & $\begin{array}{l}\text { Distance } \\
\text { Across the } \\
\text { Borman (feet) }\end{array}$ \\
\hline 0.5 & 272.2 & 3.65 & & & \\
\hline 1 & 271 & 3.16 & & & \\
\hline 1.5 & 271.4 & 2.67 & & & \\
\hline 2 & 271.9 & 2.17 & & & \\
\hline 2.5 & 272.5 & 1.66 & & & \\
\hline 3 & 273.6 & 1.16 & & & \\
\hline 3.5 & 276.1 & 0.665 & & & \\
\hline 3.6 & 277.3 & 0.564 & 0.497 & 0.624 & 670 \\
\hline 3.7 & 278.7 & 0.462 & 0.417 & 0.503 & 455 \\
\hline 3.8 & 281.5 & 0.365 & 0.332 & 0.382 & 263 \\
\hline 3.9 & 285 & 0.269 & 0.239 & 0.291 & 273 \\
\hline 4 & 292.5 & 0.174 & 0.149 & 0.192 & 226 \\
\hline 4.1 & 317.8 & 0.086 & 0.072 & 0.097 & 130 \\
\hline 4.2 & 38.2 & 0.062 & 0.050 & 0.073 & 124 \\
\hline 4.3 & 80.8 & 0.140 & 0.121 & 0.152 & 168 \\
\hline 4.4 & 93.1 & 0.230 & 0.199 & 0.256 & 302 \\
\hline 4.5 & 99 & 0.323 & 0.285 & 0.350 & 339 \\
\hline 4.6 & 102.8 & 0.420 & 0.370 & 0.458 & 463 \\
\hline 4.7 & 104.8 & 0.517 & 0.445 & 0.655 & 1105 \\
\hline 5 & 105.2 & 0.816 & 0.455 & 0.885 & 2269 \\
\hline 5.5 & 99.9 & 1.31 & 1.26 & 1.36 & 528 \\
\hline 6 & 94.2 & 1.80 & & & \\
\hline 6.5 & 95.8 & 2.30 & & & \\
\hline 7 & 94.8 & 2.80 & & & \\
\hline 7.5 & 94.1 & 3.30 & & & \\
\hline 8 & 93.6 & 3.80 & & & \\
\hline 8.5 & 93.2 & 4.30 & & & \\
\hline 9 & 93.5 & 4.80 & & & \\
\hline 9.5 & 94.2 & 5.29 & & & \\
\hline 10 & 93.9 & 5.79 & & & \\
\hline
\end{tabular}

All measurements taken off maps and are therefore approximate. 


\subsection{Borman Sensitivity.}

Credibly associating change in local air quality with change in Borman Expressway traffic was the overriding theme of the data analysis. As previously discussed, flux was used to account for the effect of wind on concentration. The angle of exposure to the Borman expressway affects the concentration at the site as well. Figure 3.2 illustrates this effect. In this idealized example wind vectors A and B are of identical magnitude but different direction. Any volume of air associated with Vector A is exposed to the roadway segment considerably longer than a parcel of air associated with Vector B. This means that under identical traffic and environmental conditions, with exception for wind direction, the concentration measured under condition " $\mathrm{A}$ " would be greater than the concentration measured when winds are perpendicular to traffic flow as in condition "B".

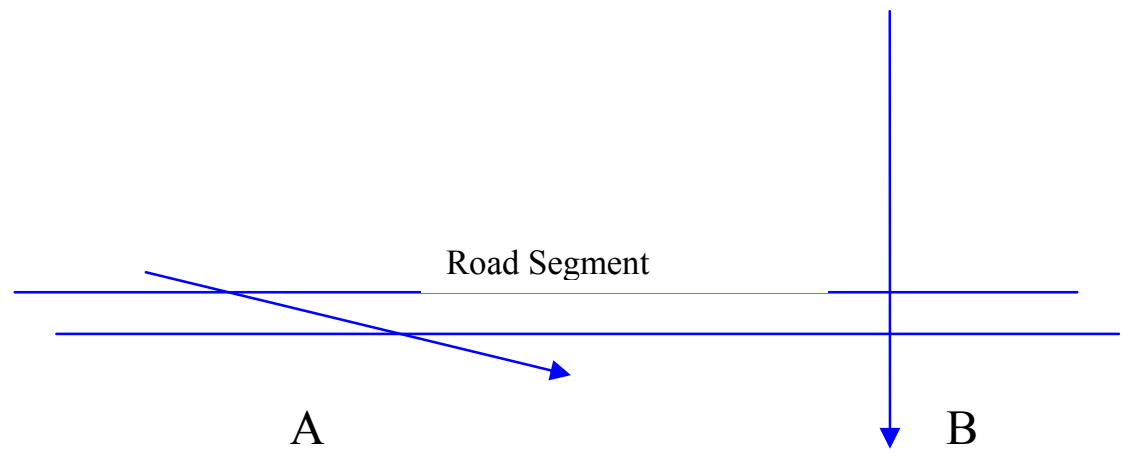

Figure 3.2: Wind Vector and Resultant Concentration 
CALINE4 was used to estimate the sensitivity of the site to varying wind directions. The Borman expressway near the monitoring station was carefully plotted into the model. Special attention was paid to curves near the site. Average traffic and environmental conditions were selected and held constant with the exception of wind direction, which was varied across the region of Borman exposure. The results were normalized by comparing each value to the mean of all values and then plotted. As figure 3.3 shows the site should be very sensitive to winds from 100 degrees. The figure shows the relative magnitude of difference to be expected by change in wind direction. For example; if winds changed from -40 degrees (320 degrees) to 10 degrees and no other factors changed a $14.2 \%$ drop in concentration would be expected. This is useful because if during a traffic incident, environmental parameters changed by $100 \%$ but the change coincided with a shift in winds, environmental variation could still be attributed to the traffic incident as the wind direction alone would not produce a change of such magnitude. 


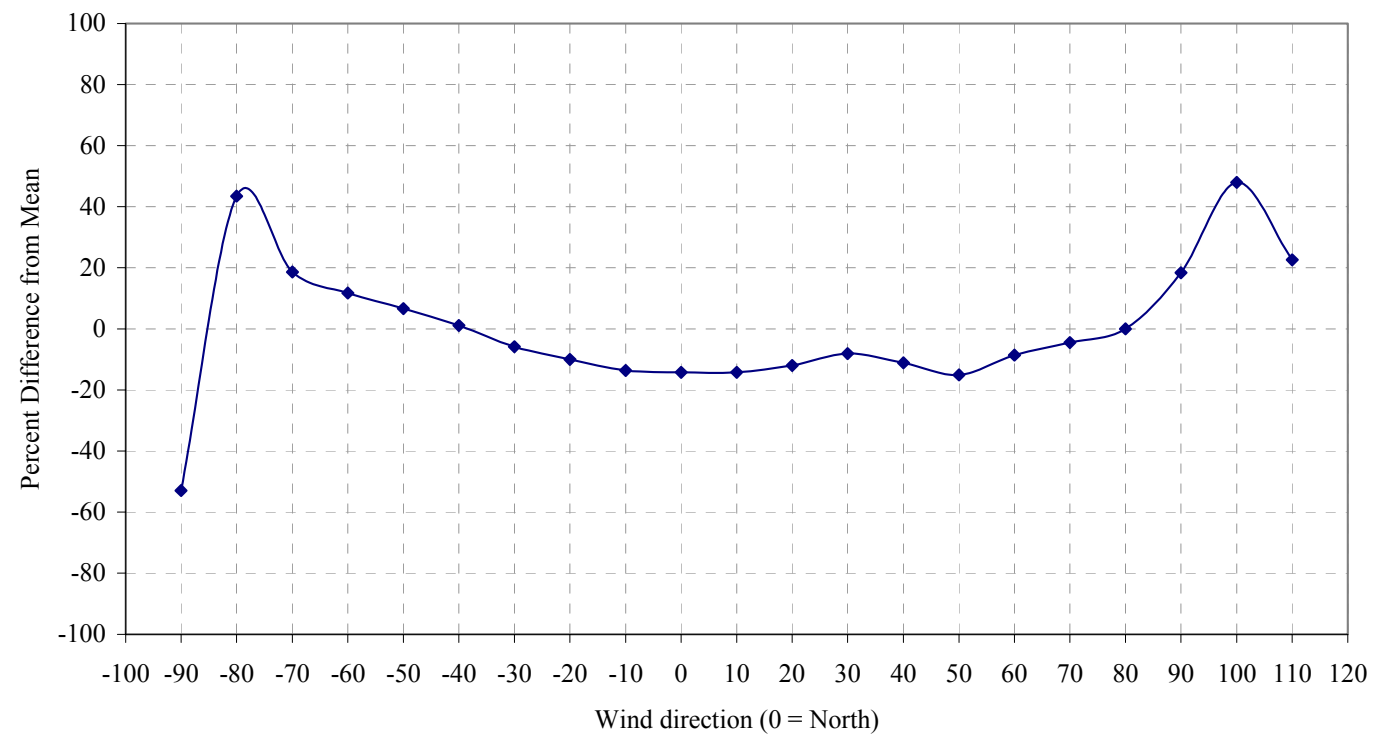

Relative Sensitivity is an estimate of what the monitoring station would measure given all variables are held constant except for the wind direction. For example if a PM2.5 concentration of $10 \mathrm{ug} / \mathrm{m}^{\wedge} 3$ was measured when the winds were from -40 degrees ( 310 degrees) then under identical conditions with winds from 10 degrees a concentration of $10+(-14.2 \% * 10)=8.58 \mathrm{ug} / \mathrm{m}^{\wedge} 3$ would be measured. This is important to consider when interpreting incidents where the wind is shifting signifcantly during the event. The site is most sensitive to winds from around 100 degrees. The site is not symmetrically sensitive because it is located near an "S" curve where the alignment of the Borman Expressway shifts.

\section{Figure 3.3: Sensitivity of the monitoring station to the Borman Expressway}

The sensitivity graph of the monitoring station can also be used as a fingerprint of traffic effects. At any given moment traffic conditions over the Borman Expressway can vary considerably. Over a long period of time however the mean traffic conditions on any bearing from the monitoring station would gradually approach the same mean assuming the overall demand on the Borman is the same. Therefore if the Borman is substantially contributing to the local air quality it would be reasonable to expect that a trace of the sensitivity graph might be evident in data collected from the site.

Figure 3.4 is a plot of the average concentration and flux measured from Jan 1, 2001 to November 30, 2001. In general, flux is greater from northerly directions than from southerly directions. This suggests that the Borman does indeed affect the local air 
quality but it doesn't address the issue of other non-Borman sources such as local streets, industrial sources, etc.

The Borman Exposure region of $\sim 270$ degrees to $\sim 110$ degrees in figure 3.5 shares some features with the sensitivity graph. The carbon monoxide trace shows distinct double peaks at oblique angles to the Borman but both peaks are closer to north than was predicted in the sensitivity graph. The $\mathrm{PM}_{2.5}$ trace doesn't show both of these humps but it does have a peak near the predicted high sensitivity area of $\sim 100$ degrees.

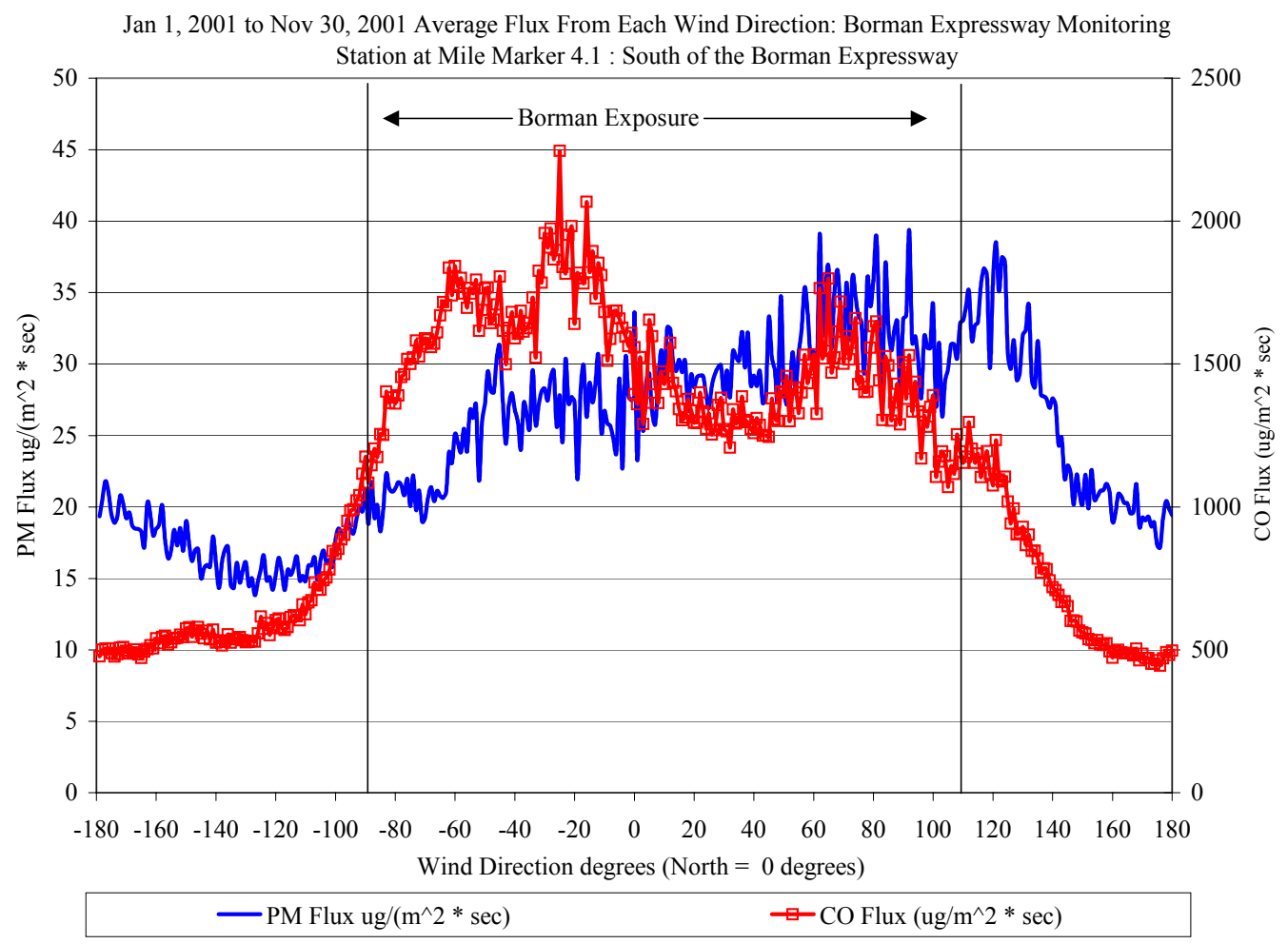

Figure 3.4: Average Flux vs. Origin Direction: January 12001 - November 30, 2001

Data from the Borman exposure region was normalized by calculating the difference from the mean of data in the arc from 272 degrees to 110 degrees, similar to 
what was done in the sensitivity graph. In figure $3.5 \mathrm{CO}$ emissions appear to more closely resemble the sensitivity predictions than do the $\mathrm{PM}_{2.5}$ measurements.

Jan 1,2001 to Nov 30, 2001 Borman Exposure Only

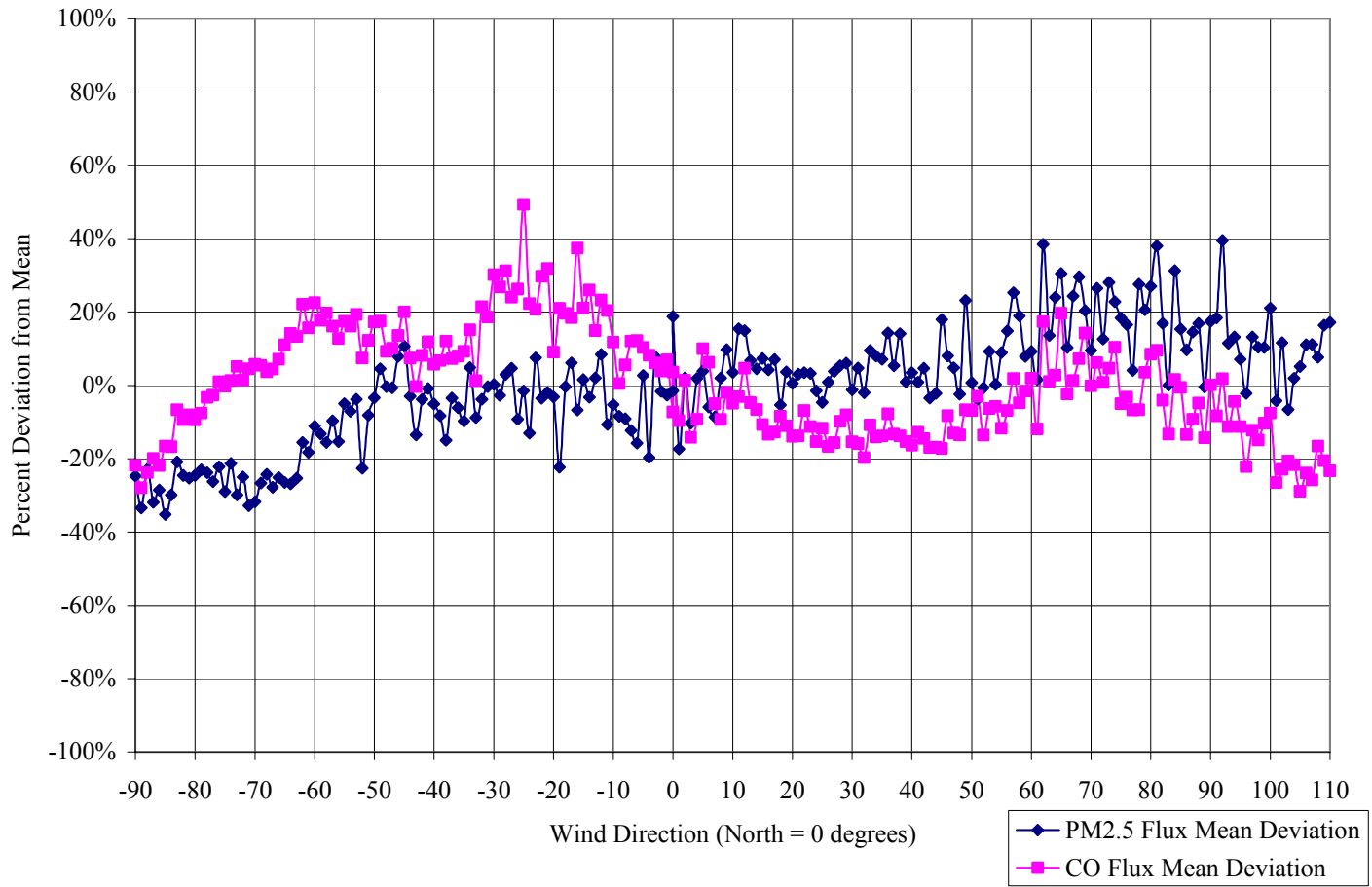

Figure 3.5: Borman Exposure Flux Deviation from Mean -90 to 110 degrees (270 to 110)

\subsection{Seasonal Data and General Characterization}

Given the monitoring stations location south of the Borman Expressway it is not in a location to receive the prevailing winds. As figure 3.6 shows, the prevailing winds are from the south. However, the approximately $37 \%$ of winds were from between 270 degrees to 360 degrees and between 0 degrees and 110 degrees, angles providing influence by or exposure to the Borman expressway. This exposure has been sufficient to permit substantial analysis. 


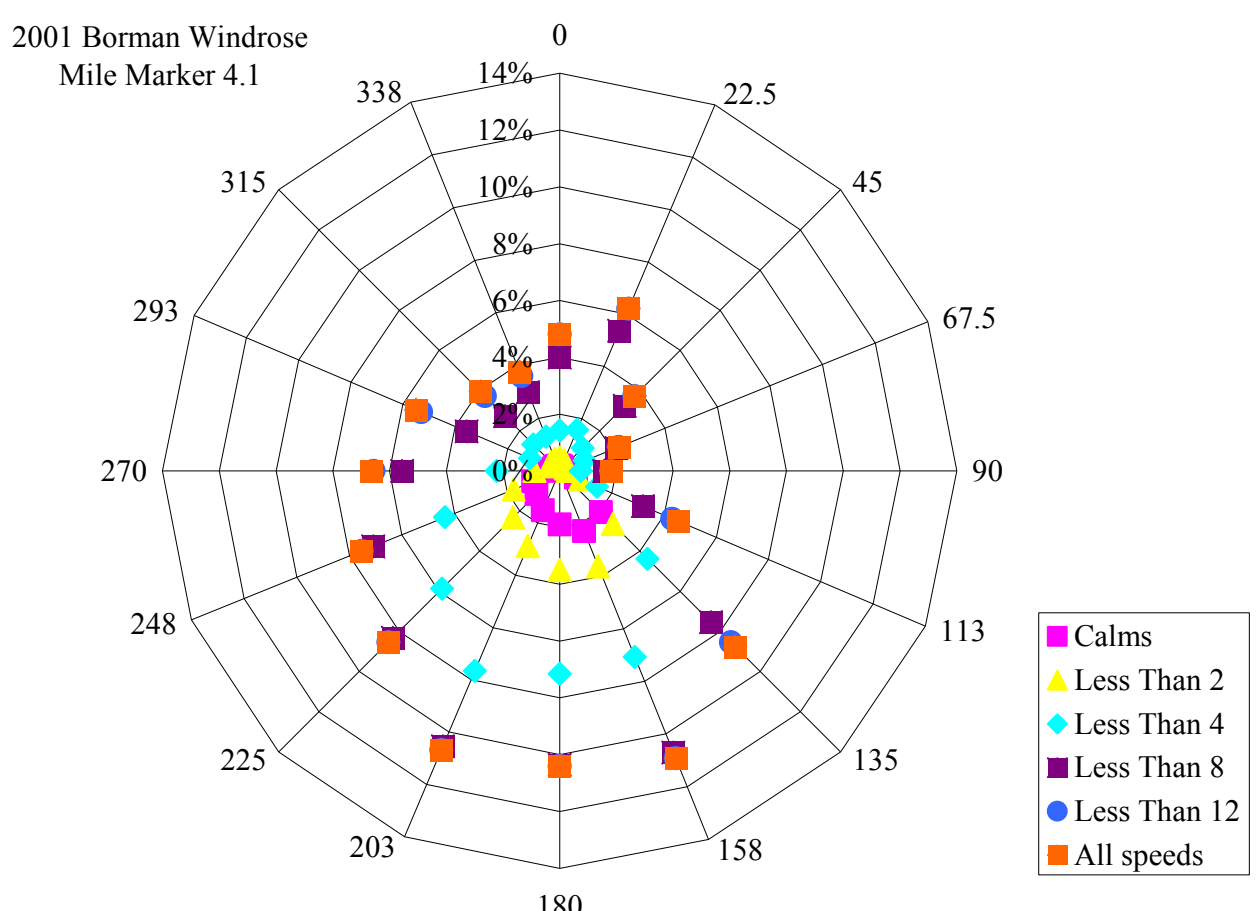

Figure 3.6: 2001 Borman Monitoring Station Wind Rose

The area near the Borman monitoring site does not routinely experience $\mathrm{CO}$ values near NAAQS standards of 35 PPM hourly average and 9 PPM 24 hour average. Measured $\mathrm{PM}_{2.5}$ concentrations have been considerably closer to the standard of $15 \mu \mathrm{g} / \mathrm{m}^{3}$ annual and $65 \mu \mathrm{g} / \mathrm{m}^{3}$ hourly. While there is no 1-hour standard for $\mathrm{PM}_{2.5}$ several very high hours were measured in 2000 and 2001 around Independence Day evening. These were most likely attributable to pyrotechnics and not the Borman Expressway. Table 3.2 and 3.3 summarize these measurements. 
Table 3.2: Comparison of Measured Parameters to Environmental Standards

\begin{tabular}{|l|l|l|}
\hline Standard & Value & Borman Expressway \\
\hline 1 Hour CO & 35 PPM & 4.2 PPM 2000, 2001 YTD \\
\hline 24 Hour PM 2.5 & $65 \mu \mathrm{g} / \mathrm{m}^{3}$ & $200038,36,32 \mu \mathrm{g} / \mathrm{m}^{3}$ \\
& & $200144,38,36 \mu \mathrm{g} / \mathrm{m}^{3}$ \\
\hline Yearly $\mathrm{PM}_{2.5}$ & $15 \mu \mathrm{g} / \mathrm{m}^{3}$ & $12.6 \mu \mathrm{g} / \mathrm{m}^{3} 2000$ \\
& & $12.2 \mu \mathrm{g} / \mathrm{m}^{3} 2001$ \\
\hline
\end{tabular}

Table 3.3: Highest Hourly $\mathbf{P M}_{2.5}$ Observations

\begin{tabular}{|l|l|l|}
\hline Date & Time & PM $_{2.5}$ \\
\hline July 4, 00 & $9: 00$ PM & $144.9 \mu \mathrm{g} / \mathrm{m}^{3}$ \\
\hline July 4, 00 & $10: 00$ PM & $106.5 \mu \mathrm{g} / \mathrm{m}^{3}$ \\
\hline July 4, 01 & $9: 00$ PM & $102.5 \mu \mathrm{g} / \mathrm{m}^{3}$ \\
\hline July 4, 01 & $10: 00$ PM & $135.9 \mu \mathrm{g} / \mathrm{m}^{3}$ \\
\hline July 4, 01 & $11: 00$ PM & $174.9 \mu \mathrm{g} / \mathrm{m}^{3}$ \\
\hline July 5, 01 & $12: 00$ AM & $127.4 \mu \mathrm{g} / \mathrm{m}^{3}$ \\
\hline
\end{tabular}

Seasonal Variation in $\mathrm{CO}$ and $\mathrm{PM}_{2.5}$ is illustrated in figure 3.7. $\mathrm{PM}_{2.5}$ concentrations are highest in late spring and into summer and appear be at their lowest in winter. Analysis of 2001-2002 winter data will continue and be included in the final report. $\mathrm{CO}$ concentrations do not exhibit the same obvious trend as $\mathrm{PM}_{2.5}$. Note the apparent correlation of $\mathrm{PM}_{2.5}$ concentration with ambient temperature. 


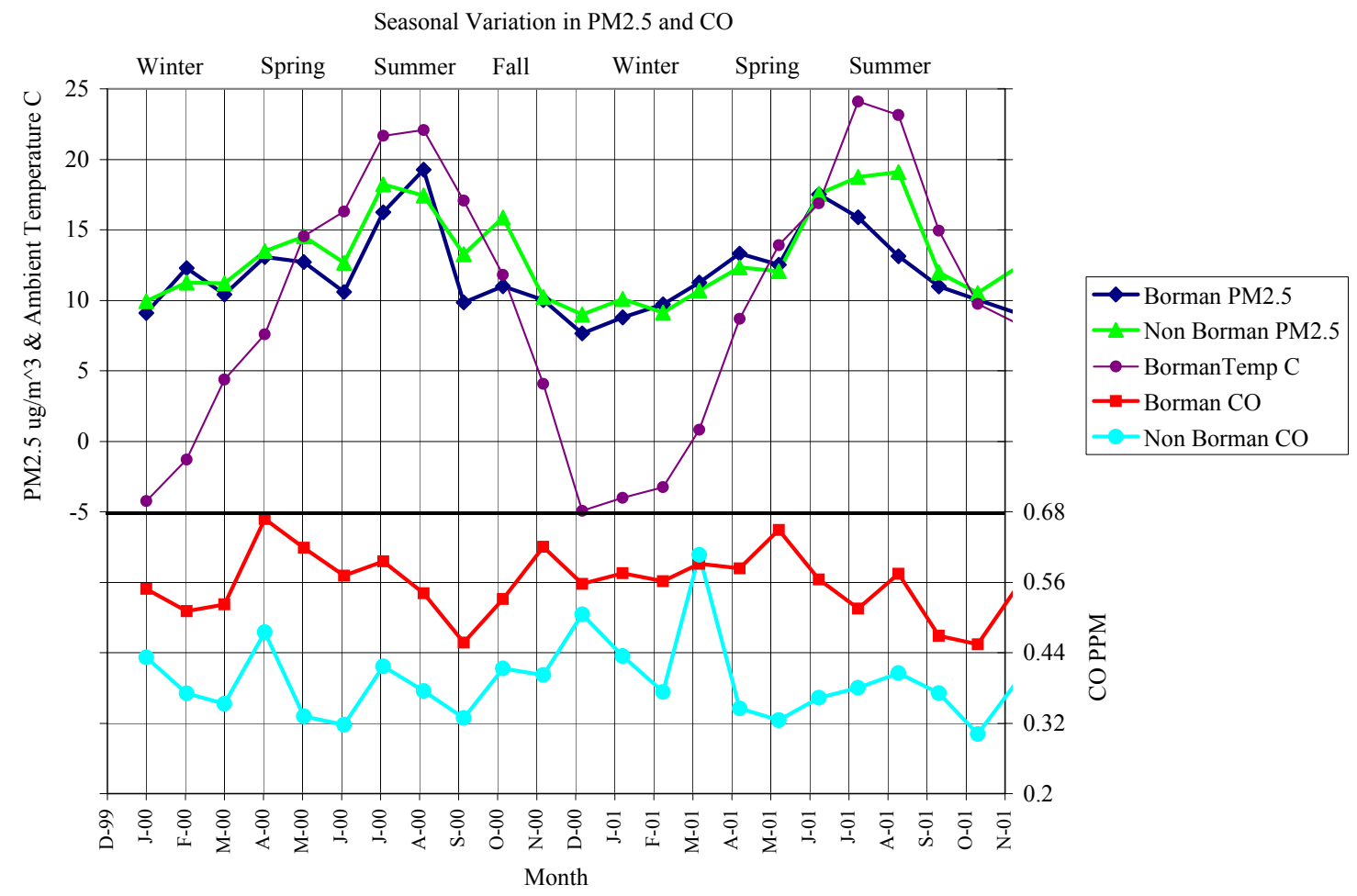

Figure 3.7: Seasonal Variations in $\mathrm{CO}$ and $\mathrm{PM}_{2.5}$ Concentration

\subsection{Background determination by sector analysis}

It has been demonstrated that the Borman is detectable in the local air quality.

However, the measurements from the northerly direction include pollutants emanating from both the Borman and from non-Borman background sources. Ambient monitoring stations in the region were not located close enough to our monitoring site to prove useful for our data needs. Placing an additional station on the northern side of the Borman was logistically and economically unfeasible so clever analytical methods had to be devised to estimate the background component of northerly measurements. 
Two 30 -degree sectors $\left(10^{\circ}-40^{\circ}\right.$ and $\left.150^{\circ}-180^{\circ}\right)$, one northerly and one southerly, were selected from the Borman area for comparison and estimation of the background component. Two sectors of similar development and population should have similar background emissions. If the sectors are carefully selected to avoid inclusion of major industrial sources such as steel mills the only other substantial difference between the two sectors would be the presence or absence of the Borman Expressway. The difference in average flux measurements between the two sectors would represent the Borman portion of the local air quality.

Figure 3.8 shows the sectors chosen for inclusion in analysis. The sectors were chosen to minimize inclusion of permitted industrial sources and avoid the three large steel mills to the north and northeast. Preference was given to sectors that contained similar population density as figure 3.9 shows. Figure 3.10 provides a visual sense of the development around the Borman monitoring station. These three figures show that the sectors of $10^{\circ}-40^{\circ}$ and $150^{\circ}-180^{\circ}$, though not perfectly identical, are similar enough to permit comparison. One of the researchers did a driving inspection of the communities in the area a verified the similarity of these sectors. 


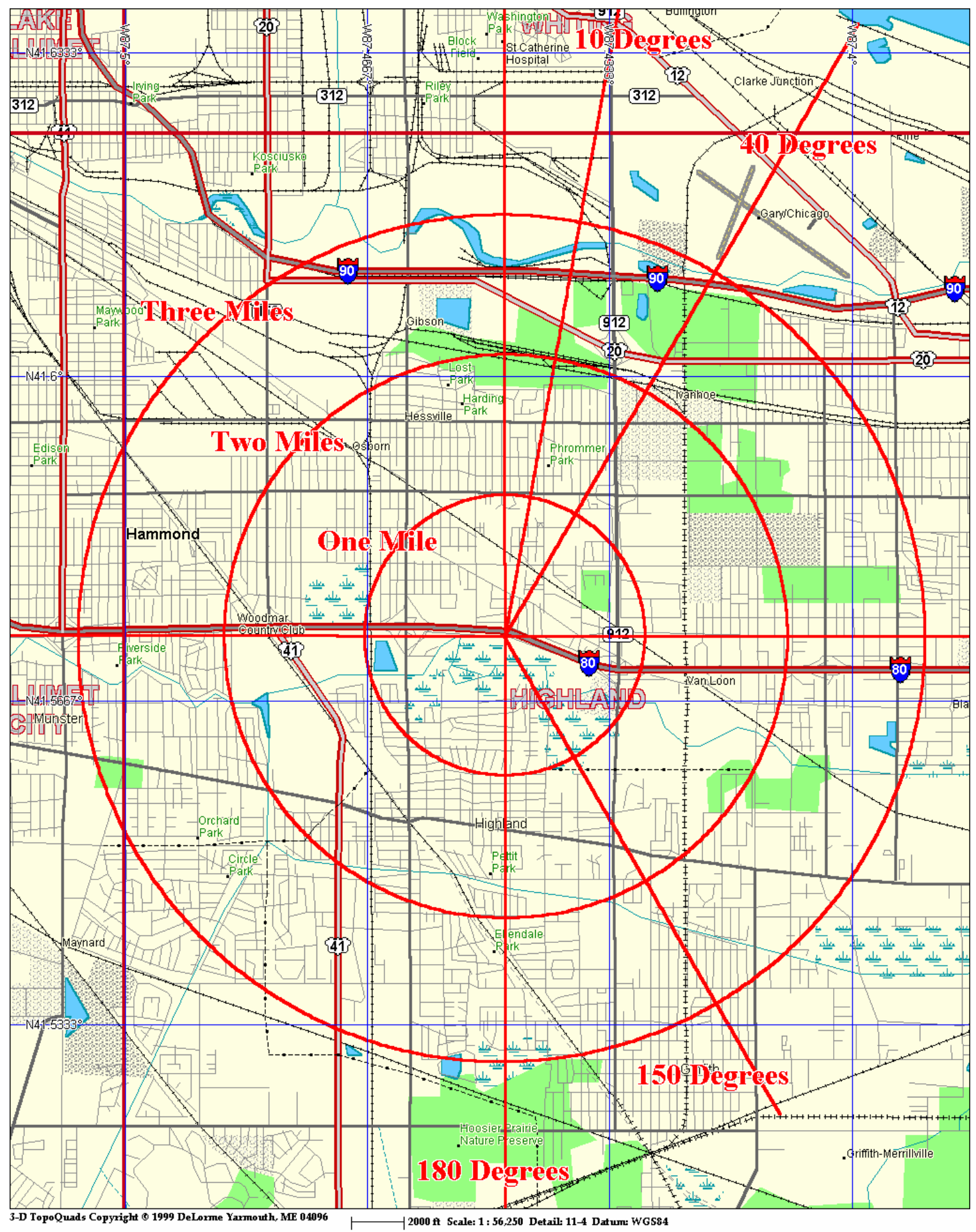

Figure 3.8: Roads and General Background Surrounding the Borman Expressway Monitoring Station 


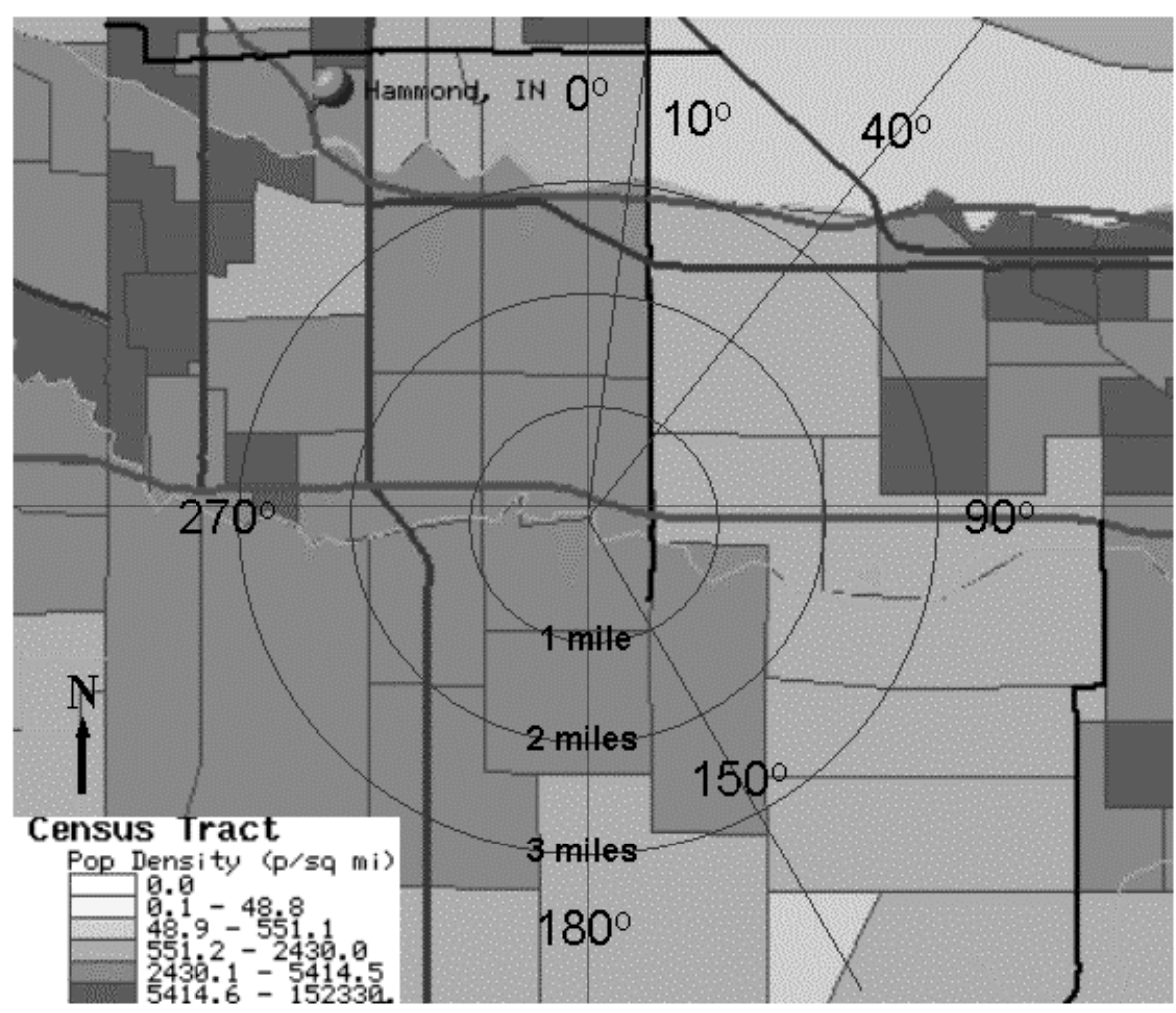

Figure 3.9: Population Density Surrounding the Monitoring Site on the Borman Expressway (United States Census Bureau. 1990) 


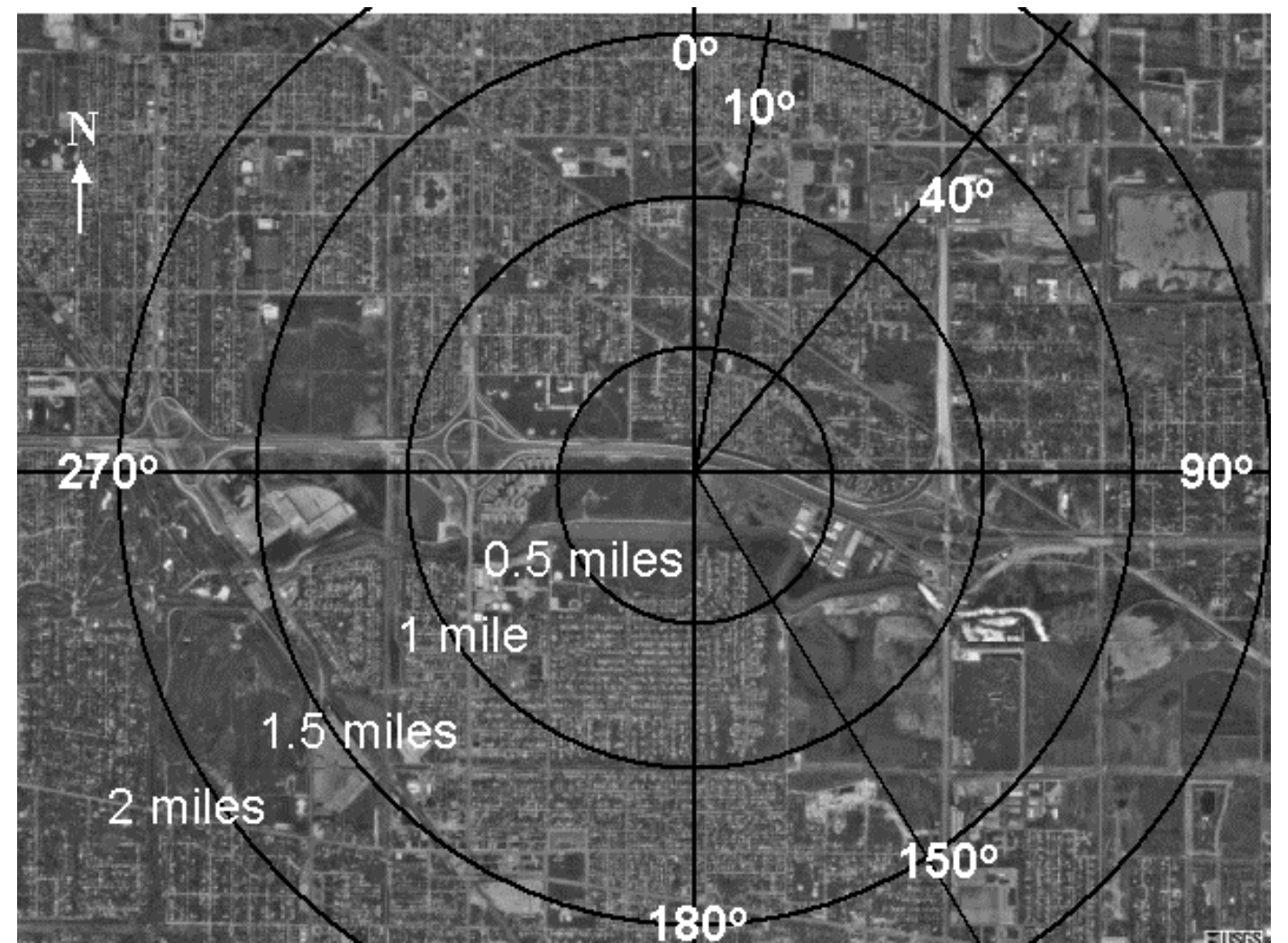

Figure 3.10: Aerial Photograph Directly Over the Monitoring Site on the Borman Expressway (Hammond, Indiana United States. From TerraServer

Average $\mathrm{PM}_{2.5}$ and CO Flux from January 1, 2000 to November 30, 2001

originating from each arc was calculated and was plotted in figure 3.11. Carbon

monoxide flux from the northern arc was greater than $\mathrm{CO}$ flux from the southern arc at all

times. $\mathrm{PM}_{2.5}$ flux from the south was greater than $\mathrm{PM}_{2.5}$ flux from the north during late evening and early morning hours when traffic flow would typically be lower. This is evidence that the sectors are not absolutely identical in terms of $\mathrm{PM}_{2.5}$ emissions.

Subtracting the southerly flux from the northerly flux produces a negative flux, not possible of course. Using the remaining positive flux values would be overly conservative in estimating the portion of northern flux due to the Borman expressway. 
Adjusting the difference between the northerly and southerly flux by the greatest negative difference leaves one hour where 0 percent of the local $\mathrm{PM}_{2.5}$ is of Borman origin and the remaining hours with some portion of Borman origin. This is still conservative, because at any hour of the day there is traffic on the Borman expressway and some part of the local $\mathrm{PM}_{2.5}$ is of Borman origin.

North (10 to 40 degrees) and South (150 to 180) degrees Flux: Borman Expressway Mile 4.1 January 1, 2000 to November 30, 2001.

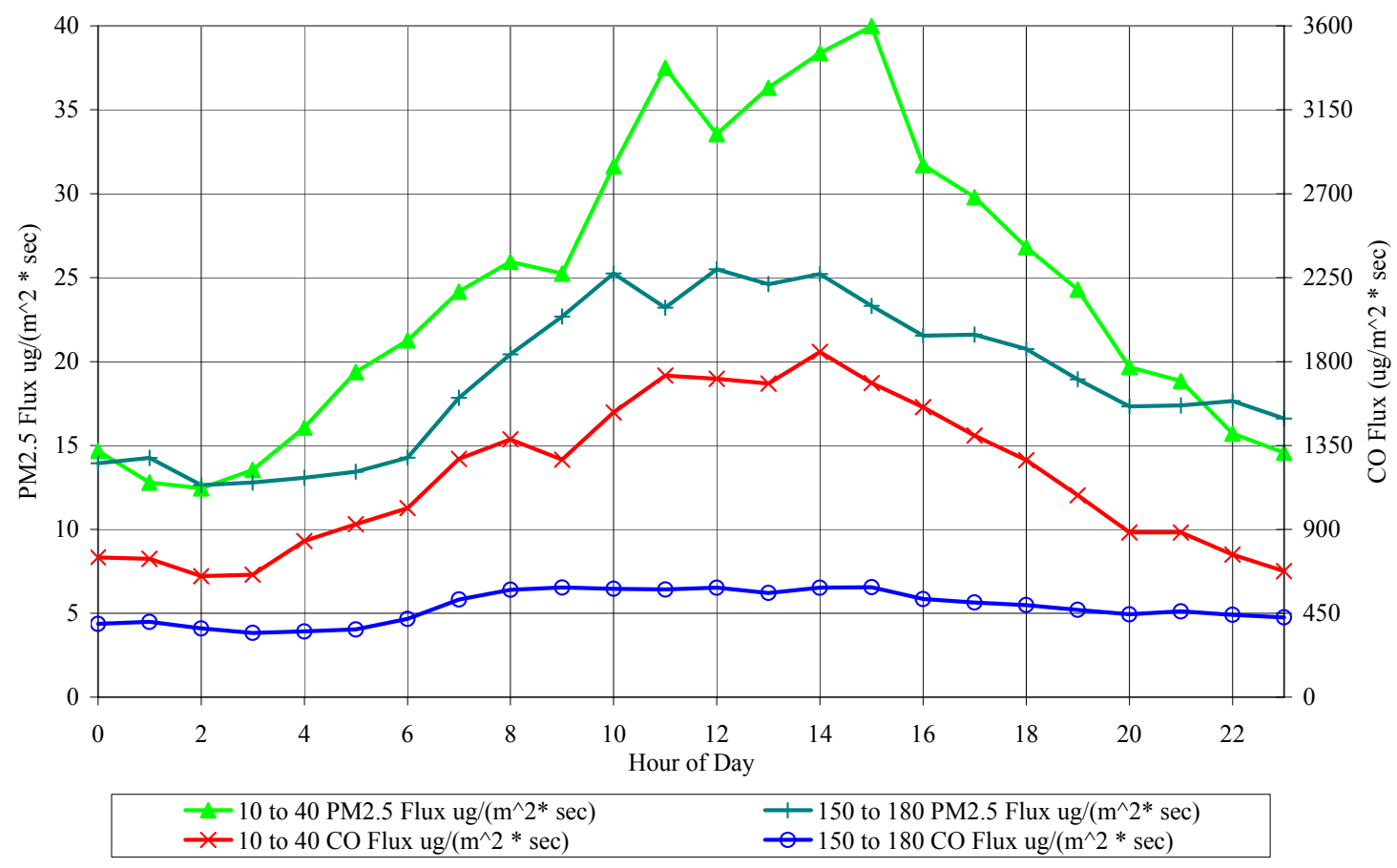

Figure 3.11: Flux Emanating from 10 to 40 and 150 to 180 degree ares

Figure 3.12 shows the difference between the two northern and southern flux curves as well as the respective traffic flow occurring in this period. The traffic distributions are based on a sensor located just east of the Borman Expressway I-65 interchange. These values do not reflect the exact mix of vehicles along the expressway but were the best representation available of the patterns in fleet mix. 
Flux of Borman Origin and Traffic Flow January 1, 2000 - November 30, 2001

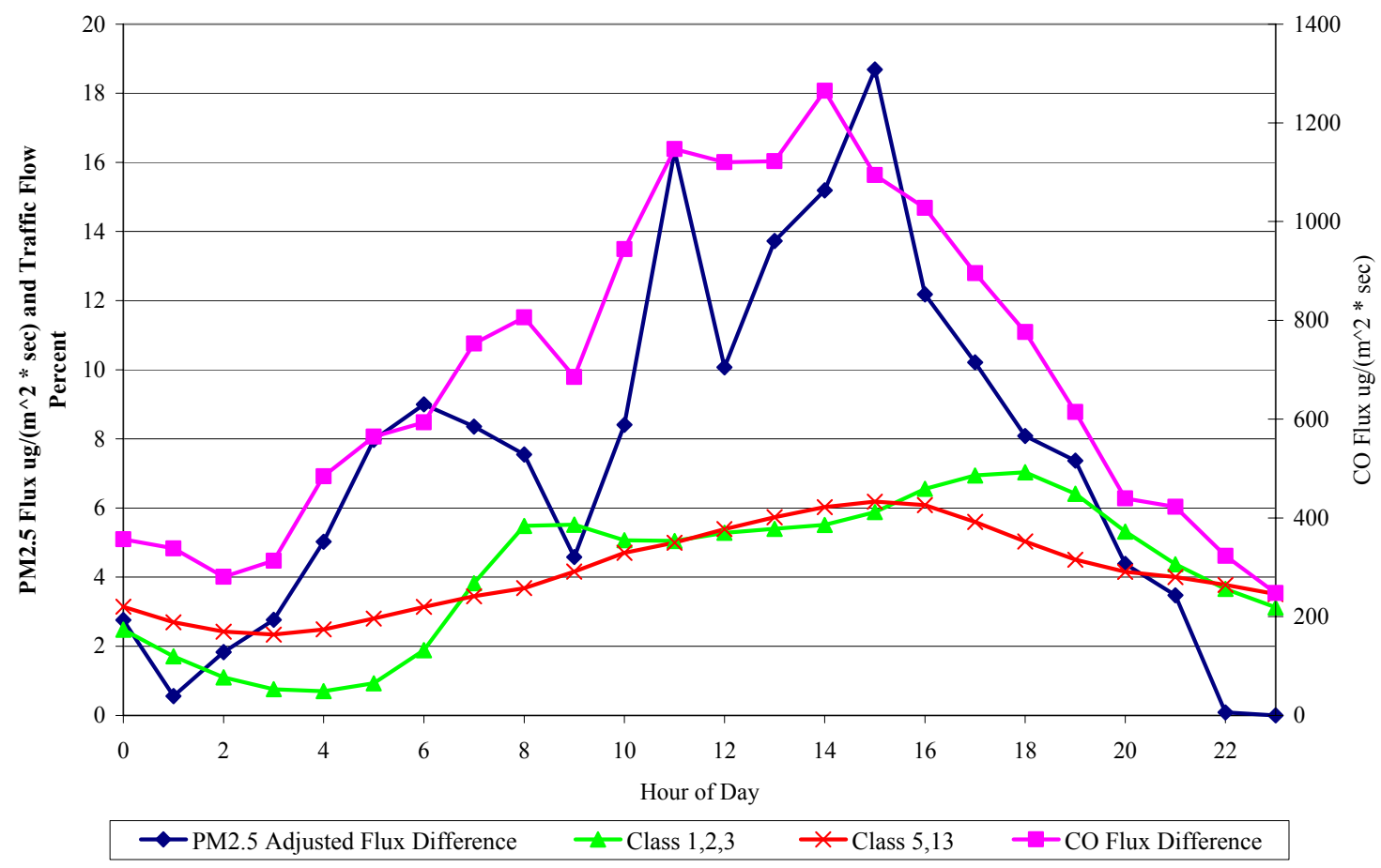

Figure 3.12: Flux of Borman Origin and Relative Traffic Flow

The difference in vehicular flow patterns is evident as is its implication in local air quality. Gasoline fueled (Class 1, 2, \& 3) vehicle flow declines much more in the early morning hours as compared to diesel fueled (Class 5 \& 13) vehicles. The peak in $\mathrm{PM}_{2.5}$ at 6 am not seen in the carbon monoxide emissions is indicative of this difference in flow pattern.

Atmospheric stability and mixing height are also in a factor at this point. Figures 3.13 and 3.14 show that the atmosphere is generally most stable and mixing heights are lowest in the hours prior to dawn and therefore dispersion is generally at its minimum at this point. (Atmospheric stability is a measure of the atmosphere's resistance or enhancement of vertical mixing. In figure 3.14 a higher numerical stability value implies 
a more stable atmosphere thus the atmosphere is generally most resistant to vertical mixing in the early morning hours.) This explains why the $\mathrm{PM}_{2.5}$ peak is of substantial magnitude even though diesel fueled vehicular flow between 2:00 and 8:00 hours is 1/3 to 2/3 of the peak flow at 15:00 hours.

Average Urban Mixing-height 1984-1991

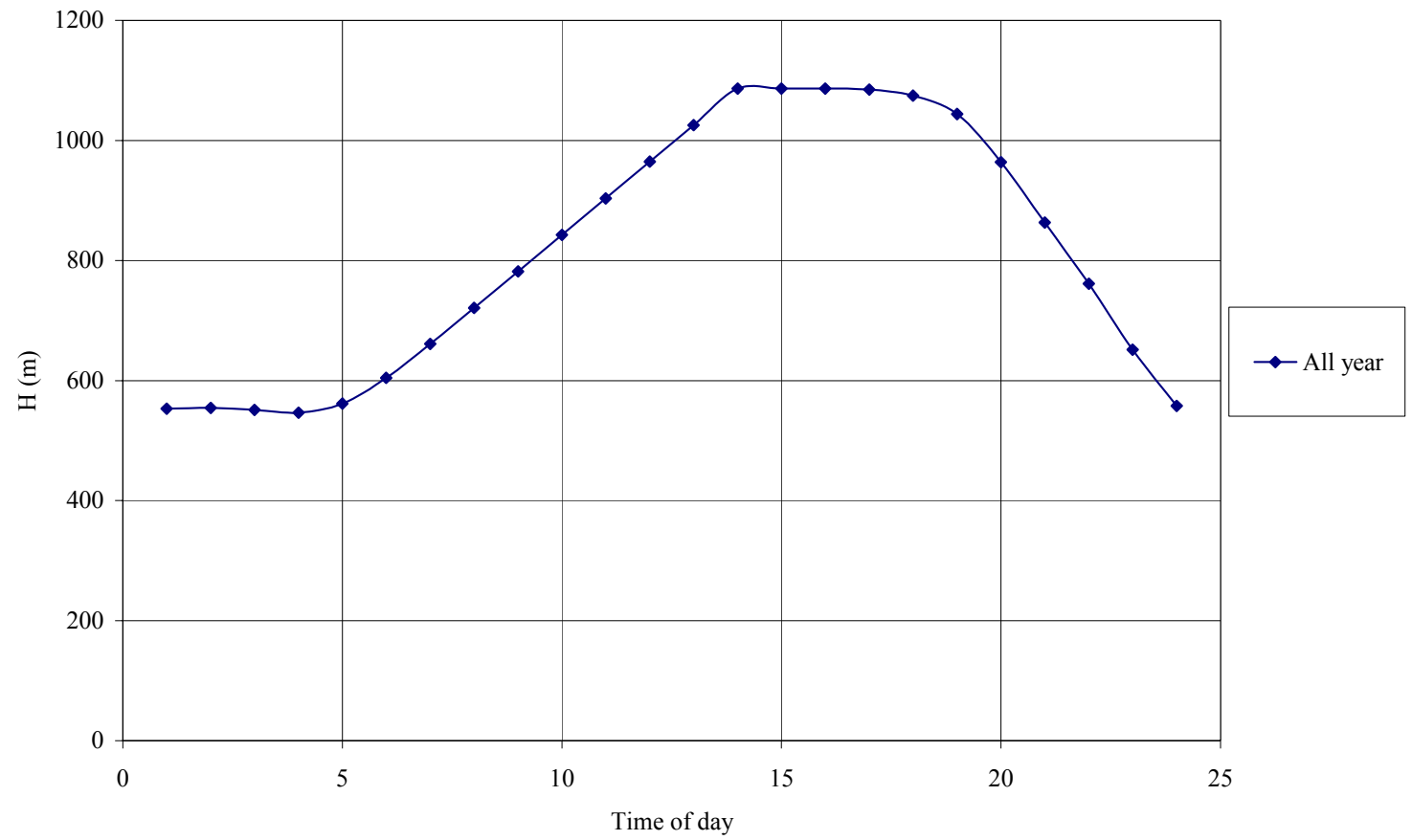

Figure 3.13: Average Urban Mixing Height. Peoria, Illinois 
Stability averaged from 1984-1991

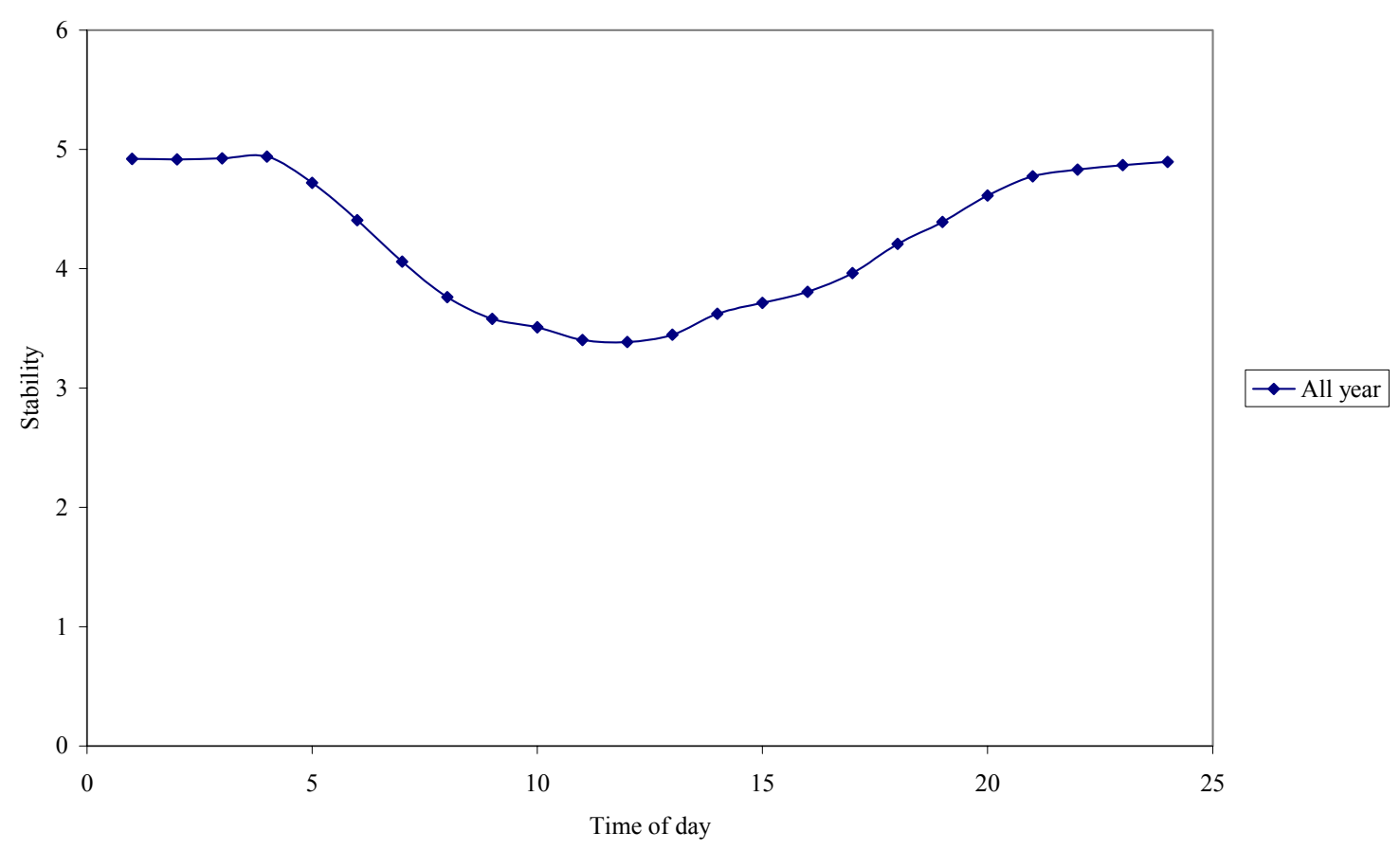

Figure 3.14: Average Atmospheric Stability: Chicago (Ohare), Illinois

An average Borman component of local air quality was calculated by dividing the difference in northern and southern flux by the northern flux. The average Borman component of the local $\mathrm{PM}_{2.5}$ ranged from 0 to $47 \%$ with an average of $27 \%$. The average Borman component of local CO ranged from $37 \%$ to $68 \%$ with a net average of $56 \%$ when winds were from 10 to 40 degrees (table 3.4 ). Obviously the Borman expressway contributes some $\mathrm{PM}_{2.5}$ to the local air quality. The $0 \%$ value at hour 23 is an artifact of the slight difference between the northern and southern arcs, refer to figure 3.12. The values represented here are conservative in respect to this. 
Table 3.4: Average Hourly Borman Component of Local Air Quality From 10 to 40 degrees. January 1, 2000 to November 30, 2001

\begin{tabular}{|r|r|r|r|r|r|}
\hline \multicolumn{6}{|c|}{ Flux emanating from Borman Expressway 10-40 Degrees } \\
\hline Hour & PM $_{\mathbf{2 . 5}}$ & $\mathbf{C O}$ & Hour & $\mathbf{P M}_{\mathbf{2 . 5}}$ & $\mathbf{C O}$ \\
\hline 0 & $19 \%$ & $48 \%$ & 12 & $30 \%$ & $66 \%$ \\
\hline 1 & $4 \%$ & $46 \%$ & 13 & $38 \%$ & $67 \%$ \\
\hline 2 & $15 \%$ & $43 \%$ & 14 & $40 \%$ & $68 \%$ \\
\hline 3 & $20 \%$ & $48 \%$ & 15 & $47 \%$ & $65 \%$ \\
\hline 4 & $31 \%$ & $58 \%$ & 16 & $38 \%$ & $66 \%$ \\
\hline 5 & $41 \%$ & $61 \%$ & 17 & $34 \%$ & $64 \%$ \\
\hline 6 & $42 \%$ & $59 \%$ & 18 & $30 \%$ & $61 \%$ \\
\hline 7 & $35 \%$ & $59 \%$ & 19 & $30 \%$ & $57 \%$ \\
\hline 8 & $29 \%$ & $58 \%$ & 20 & $22 \%$ & $50 \%$ \\
\hline 9 & $18 \%$ & $54 \%$ & 21 & $18 \%$ & $48 \%$ \\
\hline 10 & $27 \%$ & $62 \%$ & 22 & $1 \%$ & $42 \%$ \\
\hline 11 & $44 \%$ & $67 \%$ & 23 & $0 \%$ & $37 \%$ \\
\hline
\end{tabular}

As previously shown in figure 3.3 , the $10^{\circ}-40^{\circ}$ and $150^{\circ}-180^{\circ}$ azimuth of Borman exposure is likely to be among the least sensitive to traffic among the range of 272 to 110 degrees. Any other arc would likely have an even larger Borman Component in the local air quality.

\subsection{ISCST3 background estimates}

Major industrial emission sources were intentionally avoided in estimating the Borman portion of the local air quality. The area has several major sources of both $\mathrm{PM}_{2.5}$ and $\mathrm{CO}$. Figures 3.15 and 3.16 show the location of $\mathrm{PM}_{2.5}$ and $\mathrm{CO}$ sources in the area. 
CO-Sources and Site

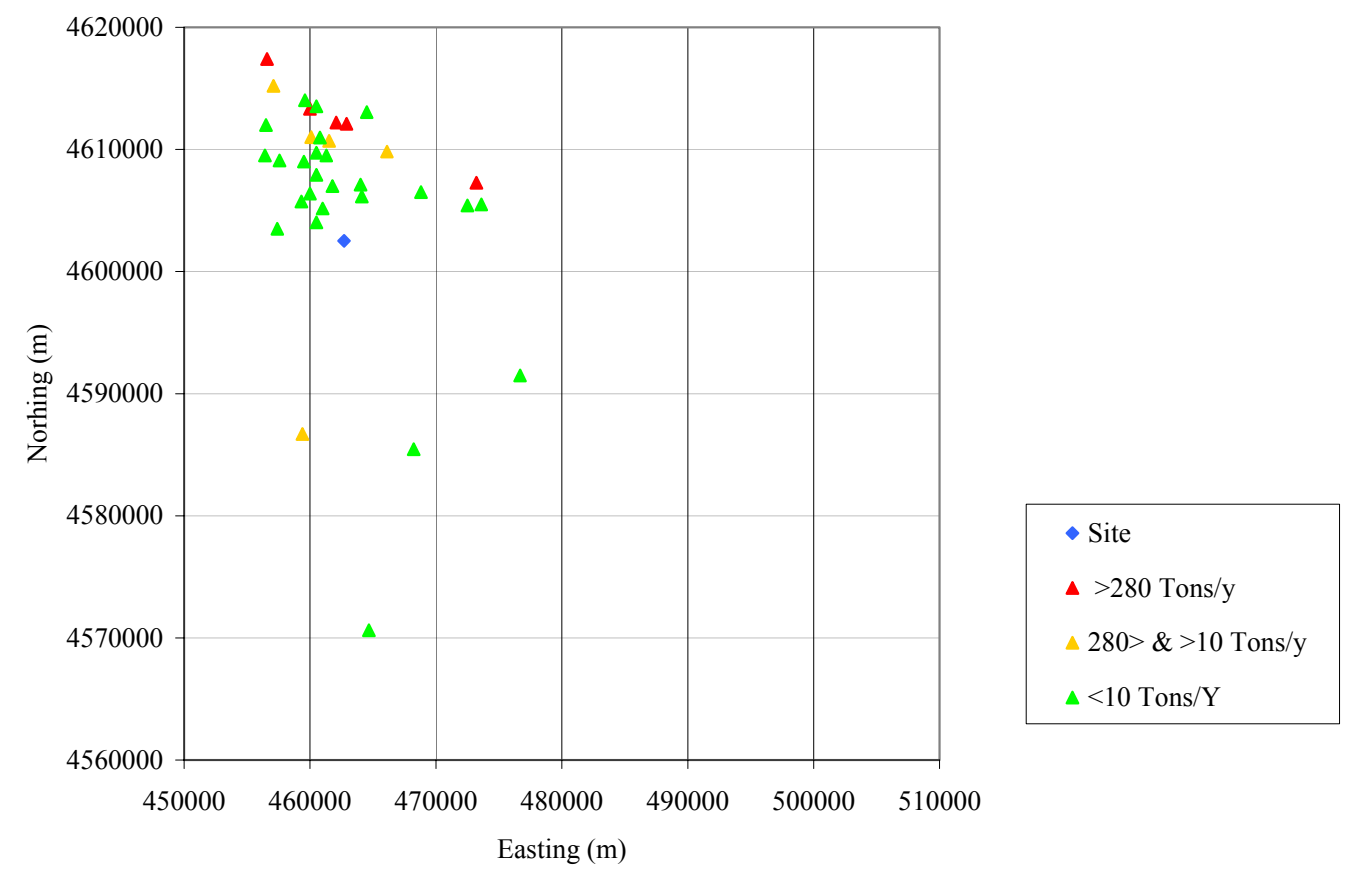

Figure 3.15: CO Sources and Monitoring Station

PM2.5 Stationary Sources

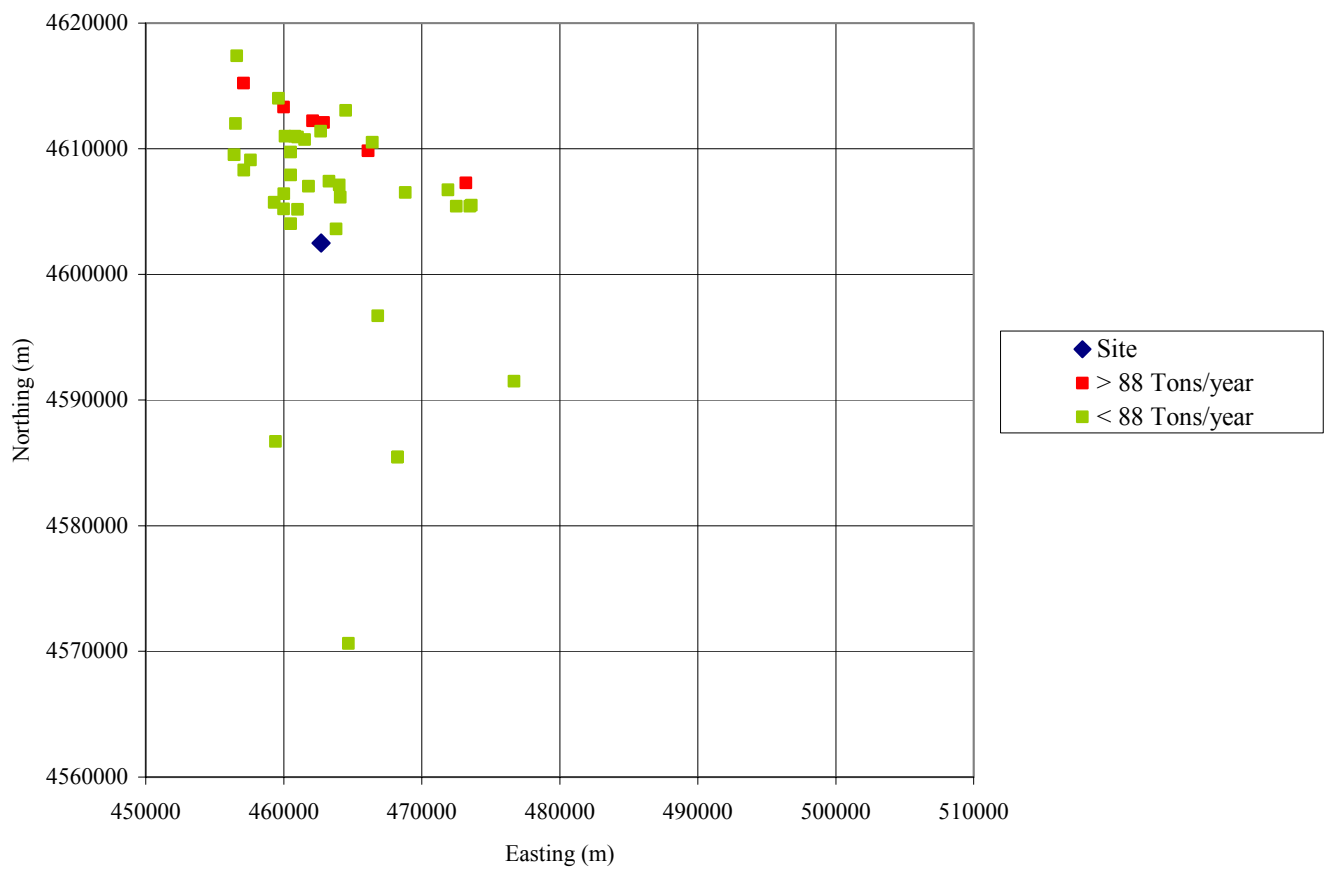




\section{Figure 3.16: $\mathbf{P M}_{2.5}$ Sources and Monitoring Station}

As figures 3.15 and 3.16 show, measurements during wind directions from the north-northwest could be under the influence of industrial sources. The locations and emissions from these sources were entered into the EPA Industrial Source Complex model. Location data and emission data was acquired from the EPA Aerometric Information Retrieval System (AIRS). Model runs were made with meteorological and mixing height data from 1986 to 1991 . From these runs meteorological data from 1984 and 1986 were found to produce the highest average $\mathrm{CO}$ and $\mathrm{PM}_{2.5}$ concentrations respectively at the monitoring station. Remaining analysis was based on these years, the worst average years.

The predicted average year round concentration of $\mathrm{PM}_{2.5}$ and $\mathrm{CO}$ of permitted point source origin is shown in figure 3.17. Figure 3.17 represents the average concentration predicted year round and includes winds from all directions. 
ISCST3 Predicted Average Conditions at Monitoring Station in the Borman Region due to emissions from Permitted Point Sources

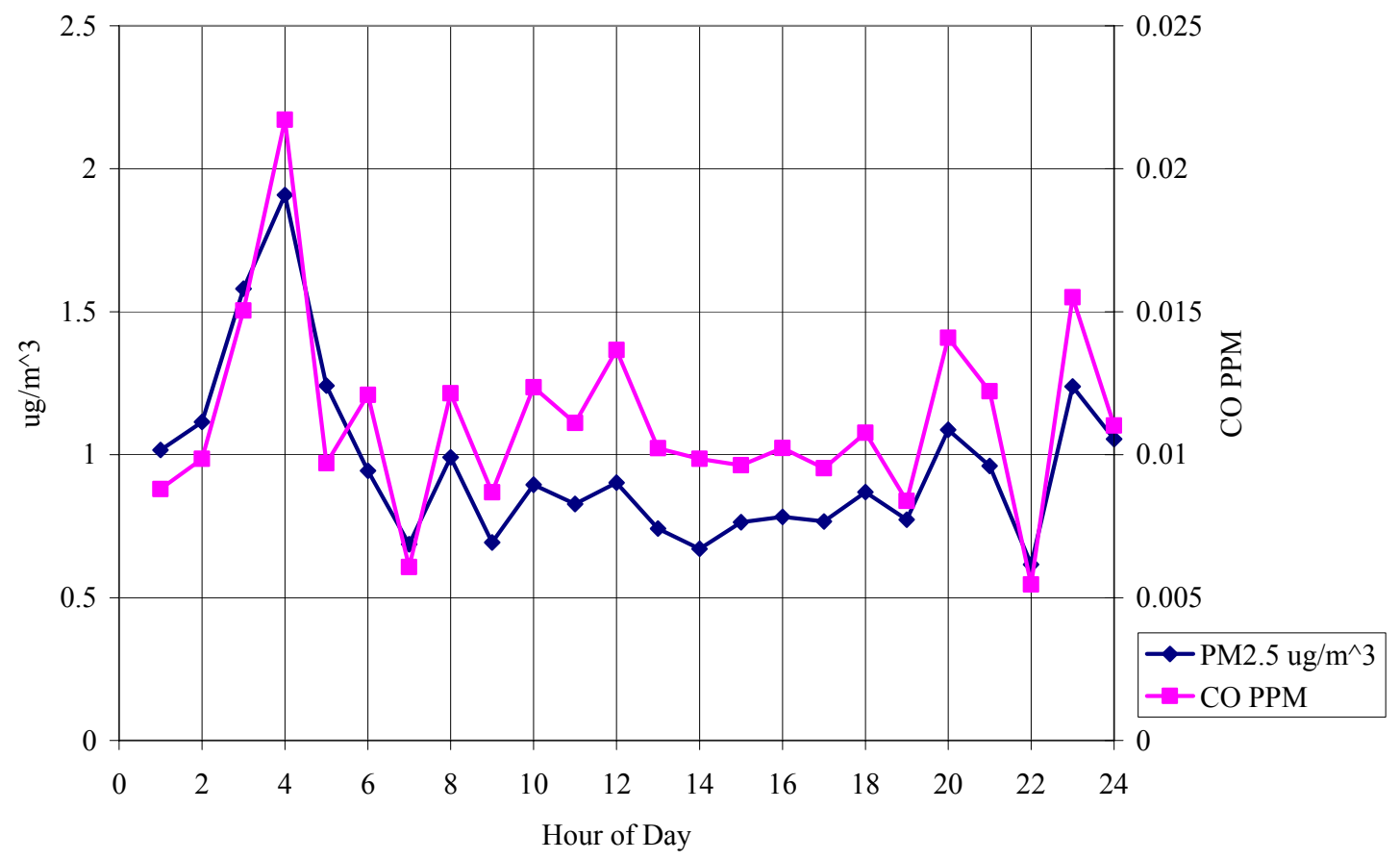

Figure 3.17: ISCST3 Predicted Average Concentrations from Permitted Point Source Origin

As figures 3.15 and 3.16 previously showed, several major industrial sources are northwest and east northeast of the monitoring station. Figure 3.18 shows the distribution of predicted $\mathrm{PM}_{2.5}$ concentrations at Borman intersecting wind directions. Arcs of -10 to 5 degrees and 60 to 75 degrees present regions of considerable predicted $\mathrm{PM}_{2.5}$ and must be considered cautiously when reviewing data. However, these predictions overestimate the magnitude of impact considerably as shown in figure 3.19. On first in inspection figure 3.19 suggests that most of the $\mathrm{PM}_{2.5}$ measured in the affected arcs is of point source origin. However, if this were true then there would be a precipitous drop in the concentration measured at the site to either side of the affected arcs. This is not the case, 
and while point sources do contribute to the local air quality, ISCST3 overestimates the magnitude in this case. Even when compared to measured conditions observed between midnight and 5 am (when traffic flows are generally least) the predicted magnitude of impact on measured concentrations is not seen (figure 3.20). These predictions were based on emissions estimates that sometimes represent the maximum potential emissions from a source. The modeling estimate also assumes that the source was actually operating during a period where the wind was blowing toward the site. They are useful in suggesting areas that require additional attention when interpreting serial traffic - environmental events.

The percentage of observations in the arcs of -10 to 5 and 60 to 75 degrees is $6.5 \%$ and $7.4 \%$ respectively leaving $86.1 \%$ of Borman exposure relatively unaffected by $\mathrm{PM}_{2.5}$ from permitted point sources. For $\mathrm{CO}$, the percentage of predictions in the -18 to 8 degree and 55 to 76 degree range are $10.7 \%$ and $9.9 \%$ respectively, this arc includes a considerable span where concentrations would be relatively low, $<0.025$ PPM (figure 3.21). Affected arcs above a 0.025 PPM threshold span include -4 to 6 degrees and 56 to 76 degrees. These arcs span $4.2 \%$ and $9.1 \%$ of predictions leaving a total of $86.7 \%$ of Borman exposure relatively unaffected by permitted point source $\mathrm{CO}$ emissions. 
PM2.5 conc at Site, Based on 1986 Meteorology

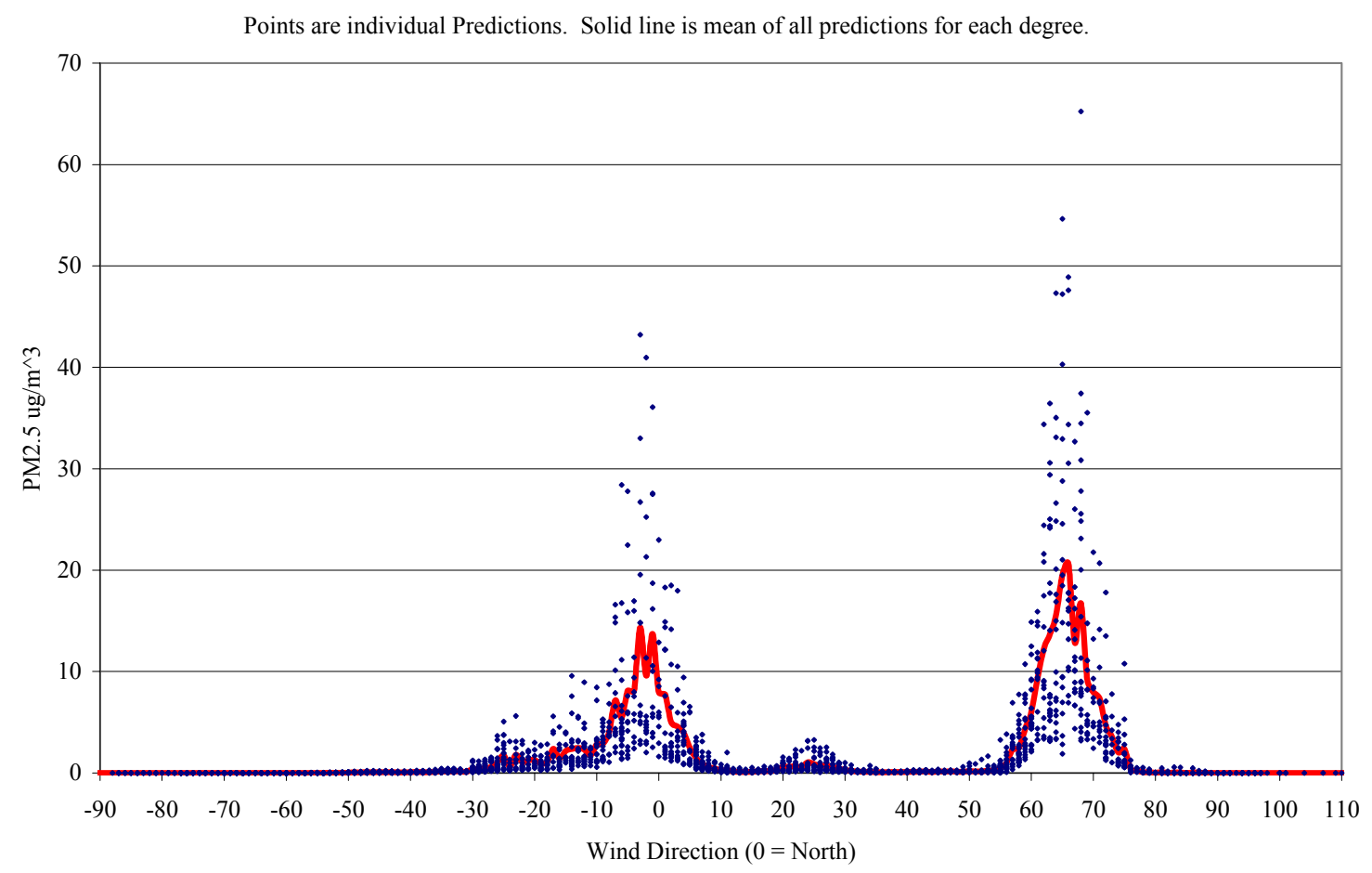

Figure 3.18: ISCST3 Predicted Average Concentrations from Permitted

\section{Point Source Origin}




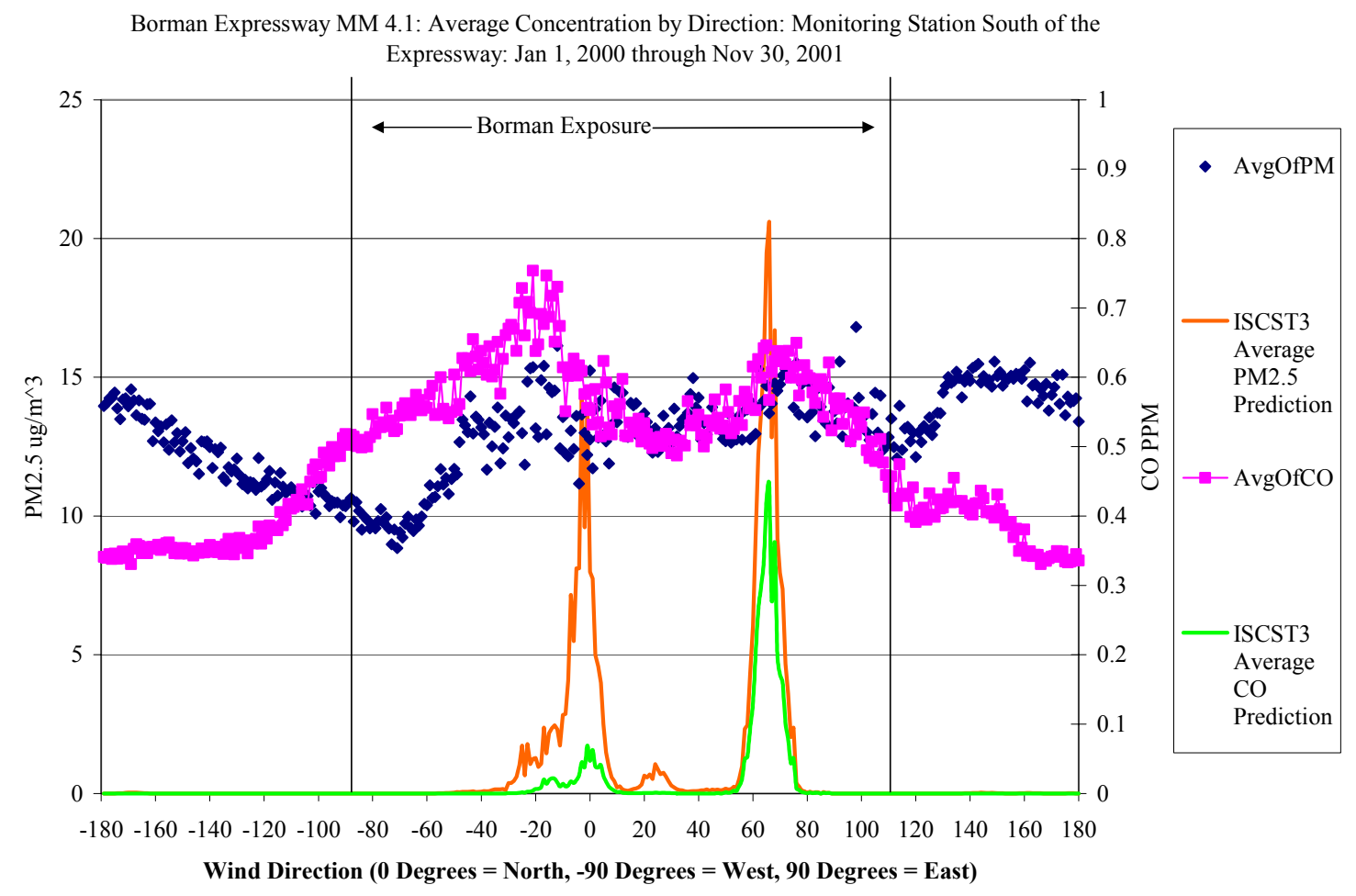

Figure 3.19: Average Measured Concentration of $\mathrm{PM}_{2.5}$ and CO By Wind Direction: Midnight to Midnight 
Borman Expressway Average Concentration Measured Between Midnight and 5 am Jan 2000 to November 2001

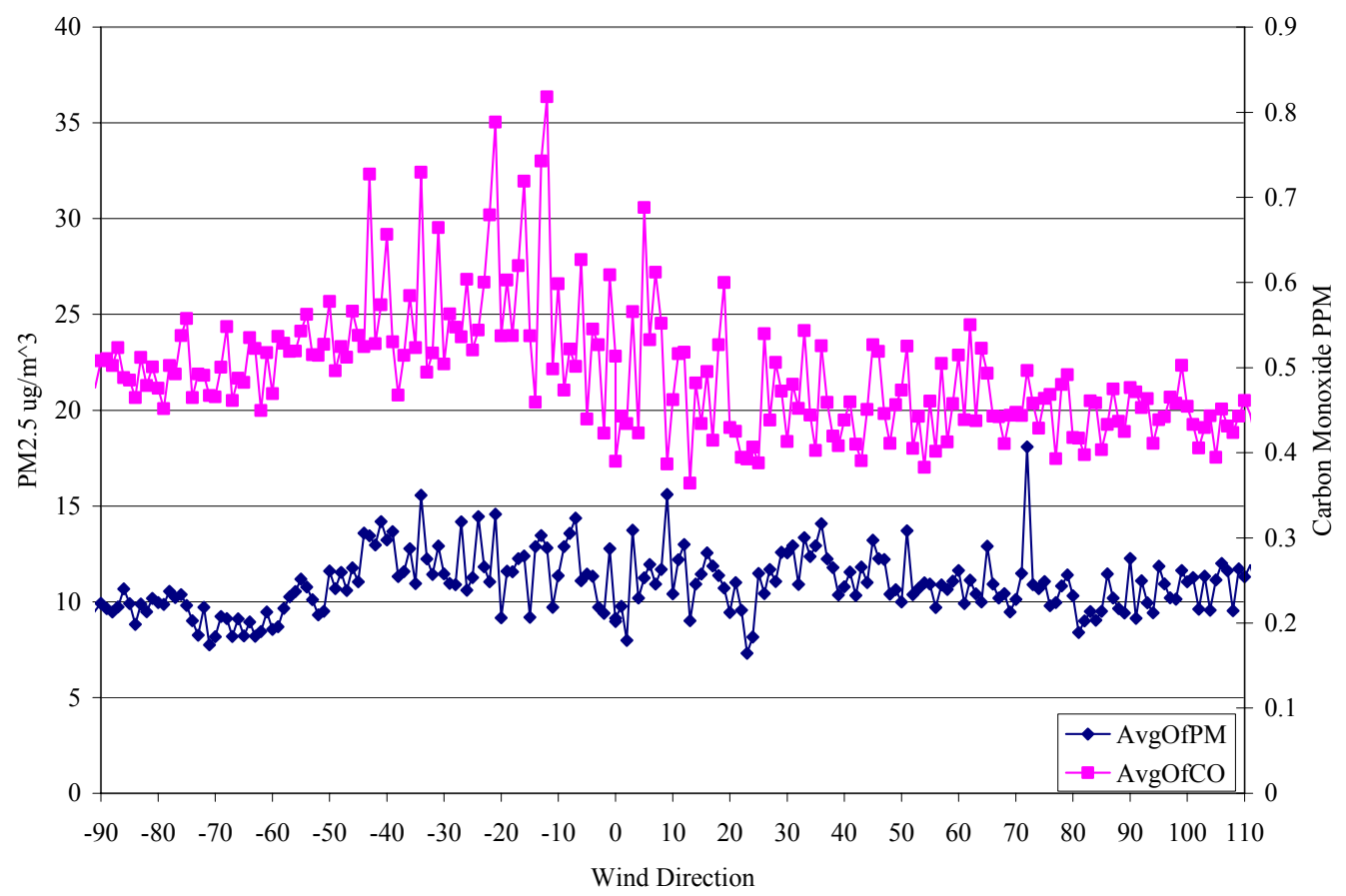

Figure 3.20: Average Measured Concentration of $\mathrm{PM}_{2.5}$ and $\mathrm{CO}$ By Wind

\section{Direction Midnight to 5 am}




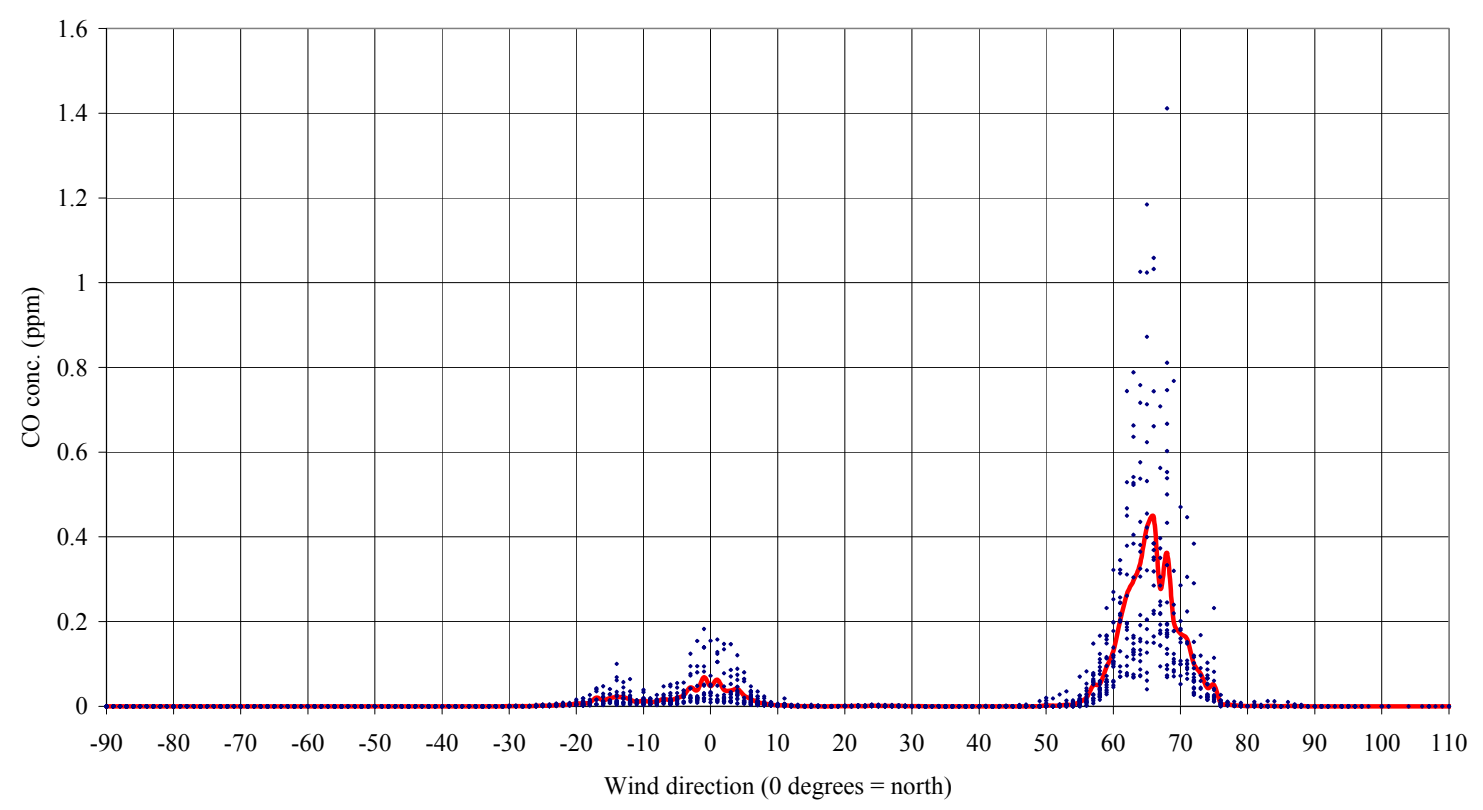

Figure 3.21: Predicted CO concentrations of Permitted Stationary Source Origin

\subsection{ANALYSIS OF TRAFFIC ENVIRONMENT RELATIONSHIPS}

Two general approaches can be taken in analyzing detailed data collected over a long period of time, an aggregate or a serial approach. An aggregate approach seeks correlation between groups of time and environmental conditions i.e. between 6 am and 10 am during weekdays pollutant levels are generally observed to rise. With a serial

approach events are analyzed in the order that they occurred (i.e. at $5 \mathrm{pm}$ on June the $5^{\text {th }}$ an accident occurred and $\mathrm{PM}_{2.5}$ concentrations rose sharply at 5:15 pm and remained elevated until the accident cleared). The former is useful in observing overall trends. The latter is useful for assessing the specific benefit of the actions of ITS components such as the Hoosier Helpers or variable message boards. 


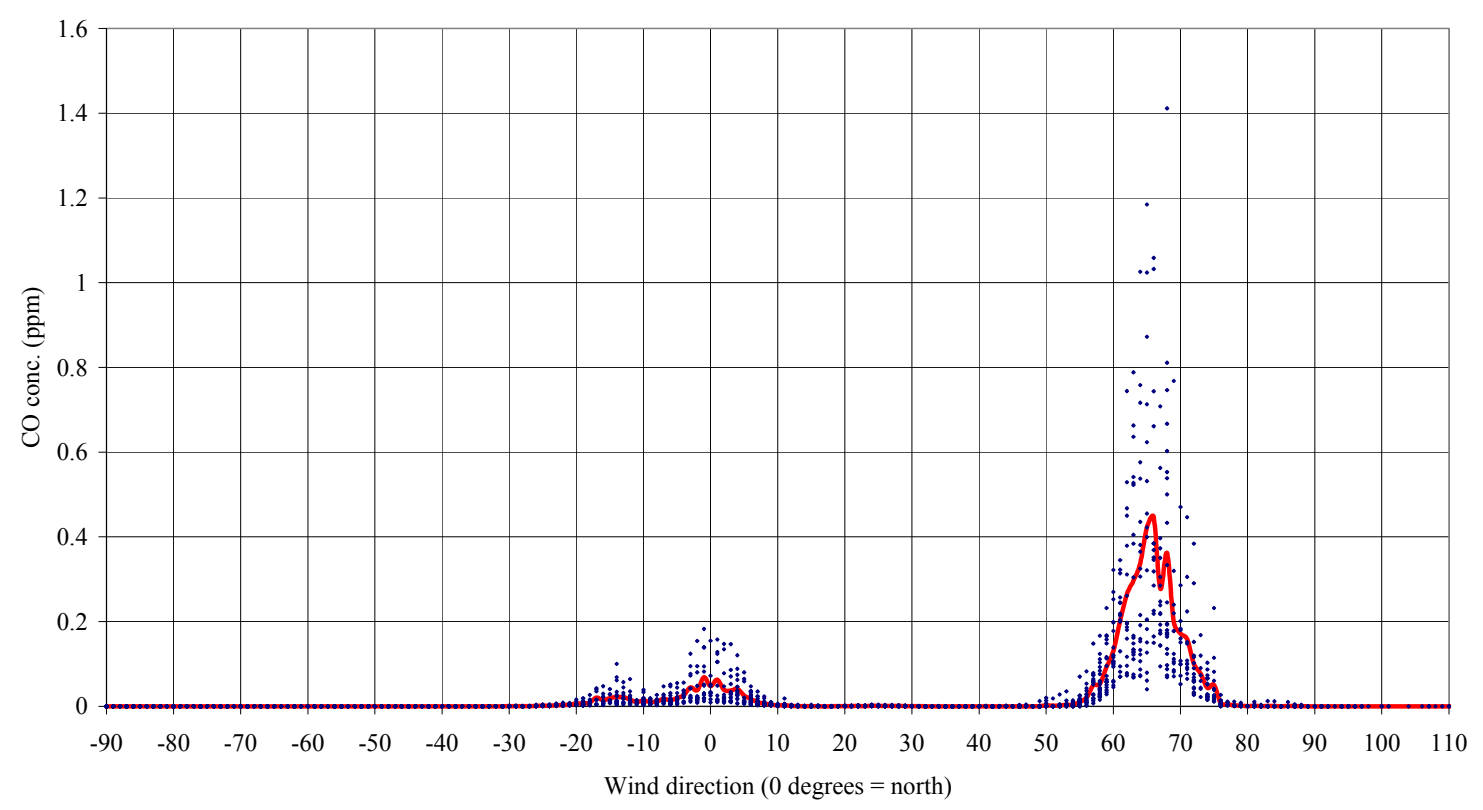

Figure 3.21: Predicted CO concentrations of Permitted Stationary Source Origin

\subsection{ANALYSIS OF TRAFFIC ENVIRONMENT RELATIONSHIPS}

Two general approaches can be taken in analyzing detailed data collected over a long period of time, an aggregate or a serial approach. An aggregate approach seeks correlation between groups of time and environmental conditions i.e. between 6 am and 10 am during weekdays pollutant levels are generally observed to rise. With a serial

approach events are analyzed in the order that they occurred (i.e. at $5 \mathrm{pm}$ on June the $5^{\text {th }}$ an accident occurred and $\mathrm{PM}_{2.5}$ concentrations rose sharply at 5:15 pm and remained elevated until the accident cleared). The former is useful in observing overall trends. The latter is useful for assessing the specific benefit of the actions of ITS components such as the Hoosier Helpers or variable message boards. 


\section{1 $\quad \underline{\text { Aggregate Analysis }}$}

\subsubsection{Predicted Aggregate Results}

Emission Factors were calculated using PART5 and MOBILE5b emissions modeling programs. The factors were combined with traffic classification data to determine the approximate $\mathrm{CO}$ and $\mathrm{PM}_{2.5}$ emissions from highways operating at a continuum of vehicle densities.

Emissions from a roadway may be estimated given the speed of vehicles, density of traffic, local temperature, emission factors, and average fleet vehicle composition. Several of these factors are interrelated and complicate the estimation of emissions. Speed is generally inversely related to emissions per mile from a vehicle. Emissions per

mile decrease as speed increases. The exception to this is at the upper region of operating speeds where emissions per mile begin to rise. Emissions per mile rise because the energy (fuel) input increases exponentially with velocity.

Speed is also related to vehicle density. Most drivers will attempt to maintain a following distance that will provide adequate time to react to traffic. Following distance is proportional to speed, as speed increases following distance increases and therefore traffic density decreases. Conversely, if following distance is decreased speed will decrease and traffic density increases. 
The appropriate emission factors were calculated based on the approximate fleet mix on the Borman Expressway. In contrast to the national fleet average, the Borman Expressway has considerably more Heavy Duty Diesel Vehicles (HDDV) and fewer Light Duty Gas Vehicles (LDGV) (Tables $4.1 \& 4.2)$. These tables are based on data acquired at the WIM (Weight In Motion) Station located east of the Borman Expressway interchange with I65. Note that Mobile5b and Part5 segregate vehicle classes differently thus two vehicle distributions were determined.

Table 4.1: Mobile 5b Fleet Mix

\begin{tabular}{lrr}
\hline & $\begin{array}{c}\text { National Fleet } \\
\text { Average } \\
\text { Distribution }\end{array}$ & $\begin{array}{c}\text { Borman Approximate } \\
\text { Fleet Average }\end{array}$ \\
\hline LDGV & $69.3 \%$ & $40.02 \%$ \\
LDGT1 & $11.6 \%$ & $20.12 \%$ \\
LDGT2 & $8.5 \%$ & $3.99 \%$ \\
HDGT & $1.5 \%$ & $0.70 \%$ \\
LDDV & $3.5 \%$ & $2.06 \%$ \\
LDDT & $1.7 \%$ & $1.00 \%$ \\
HDDV & $2.9 \%$ & $30.47 \%$ \\
MC & $1.0 \%$ & $1.64 \%$ \\
\hline
\end{tabular}

Based on Jan - Jun 2000 fleet distribution At station on Borman, east of I-65 interchange. 
Table 4.2: Part5 Fleet Mix and Mean Vehicle Length.

\begin{tabular}{|l|l|r|r|r|r|r|r|}
\hline $\begin{array}{l}\text { Vehicle } \\
\text { Class }\end{array}$ & $\begin{array}{l}\text { FHA } \\
\text { Scheme } \\
\text { for Part5 }\end{array}$ & $\begin{array}{l}\text { FHWA } \\
\text { Scheme }\end{array}$ & Percent & $\begin{array}{l}\text { Mean } \\
\text { Weight }\end{array}$ & $\begin{array}{l}\text { Fraction } \\
\text { Weight } \\
\text { pounds }\end{array}$ & $\begin{array}{l}\text { Equivalent } \\
\text { Length }\end{array}$ & $\begin{array}{l}\text { Fractional } \\
\text { Length }\end{array}$ \\
\hline LDGV & 1 & 2 & $40.02 \%$ & 3200 & 1281 & 1.0 & 0.400 \\
\hline LDGT & 2 & 3 & $20.12 \%$ & 4000 & 805 & 1.0 & 0.201 \\
\hline LDGT2 & 3 & 5 & $3.99 \%$ & 7250 & 290 & 1.0 & 0.040 \\
\hline HDGV & 4 & $5 \& 6$ & $0.70 \%$ & 10000 & 70 & 1.0 & 0.007 \\
\hline MC & 5 & 1 & $1.64 \%$ & 800 & 13 & 1.0 & 0.016 \\
\hline LDDV & 6 & $5 \& 6$ & $2.06 \%$ & 5000 & 103 & 1.0 & 0.021 \\
\hline LDDT & 7 & $5 \& 6$ & $1.00 \%$ & 7250 & 73 & 1.5 & 0.015 \\
\hline LHDDV & 9 & 7 & $0.09 \%$ & 14750 & 13 & 1.5 & 0.001 \\
\hline MHDDV & 10 & 8 & $0.98 \%$ & 26250 & 257 & 1.5 & 0.015 \\
\hline HHDDV & 11 & $9-13$ & $28.97 \%$ & 50000 & 14484 & 1.5 & 0.435 \\
\hline BUSES & 12 & 4 & $0.44 \%$ & 20000 & 87 & 1.5 & 0.007 \\
\hline & & & & & & & \\
\hline & & & $100.00 \%$ & $\begin{array}{l}\text { Mean } \\
\text { Wt. }\end{array}$ & 17,474 & $\begin{array}{l}\text { Mean Veh } \\
\text { Length }\end{array}$ \\
\hline
\end{tabular}

The Borman fleet distributions in tables 4.1 and 4.2 were combined with emission factors from Mobile5b and Part5 to calculate weighted average emission factors for the Borman Expressway. Mobile5b was run assuming all vehicles at equilibrium operating conditions and all trips were greater than 50 minutes. This simplification simulates conditions where most of the traffic was through-bound and operating at consistent speeds. Figure 4.1 illustrates the speed dependency of $\mathrm{CO}$ emissions. $\mathrm{PM}_{2.5}$ emissions according to Part5 are speed insensitive. The $\mathrm{PM}_{2.5}$ emission factor for the average Borman Fleet Mix was 0.268 grams/vehicle/mile. 
Mobile $5 \mathrm{~b}$ CO Emission factor for Borman Fleet $75 \mathrm{~F}$

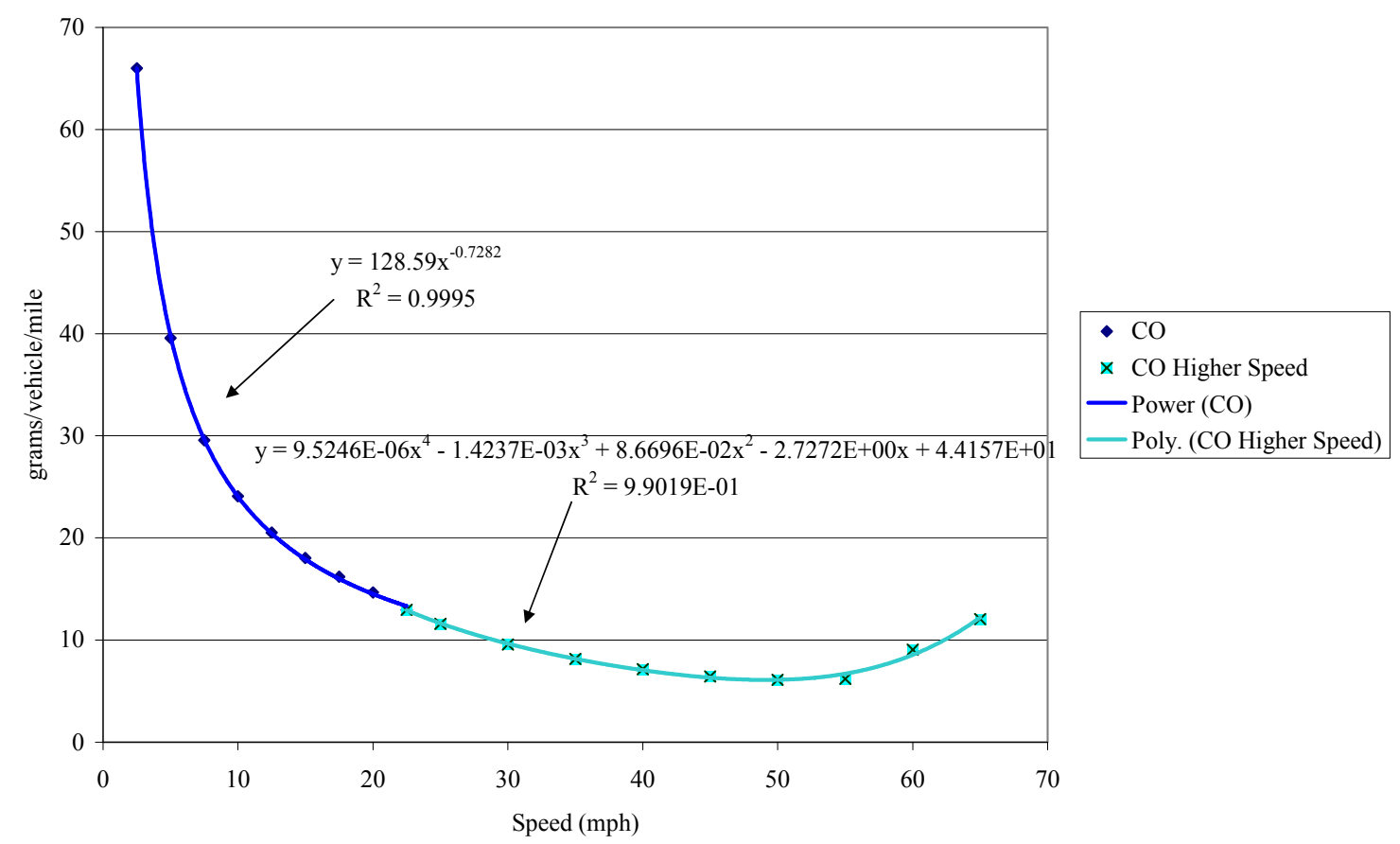

Figure 4.1: Mobile5b CO Emission Factor for Borman Fleet @ 75F

\subsubsection{Vehicle Speed, Density, and Flow}

As stated previously, vehicle speed and density are interrelated. Assuming a Free Flow Speed (FFS) of $65 \mathrm{mph}$, speed can be estimated for a given flow by equation 4.1.

\section{Equation 4.1: $\quad$ Traffic Speed}

Adapted from Highway Capacity Manual 2000

For Free Flow Speeds (FFS) between 55 and $70 \mathrm{mph}$ and for flow rates $\left(V_{p}\right)$ between (3400-30FFS) and (1700+10FFS)

$S=F F S-\left[\frac{1}{9}(7 F F S-340)\left(\frac{V_{p}+30 F F S-3400}{40 F F S-1700}\right)^{2.6}\right]$

For Free Flow Speeds (FFS) between 55 and $75 \mathrm{mph}$ and for flow rates $\left(V_{p}\right)$ less than $(3400-30 F F S)$

$\mathrm{S}=\mathrm{FFS}$ 
Given speed and flow, density can be determined by dividing flow by speed (equation 4.2).

\section{Equation 4.2: Traffic Density}

$k($ density $)=F($ TrafficFlow $) / V$

$($ Vehicles $/$ hour $/$ lane $) /($ miles $/$ hour $)=($ Vehicles $/$ mile $/$ lane $)$

Figure 4.2 shows how speed and traffic flow vary with density.

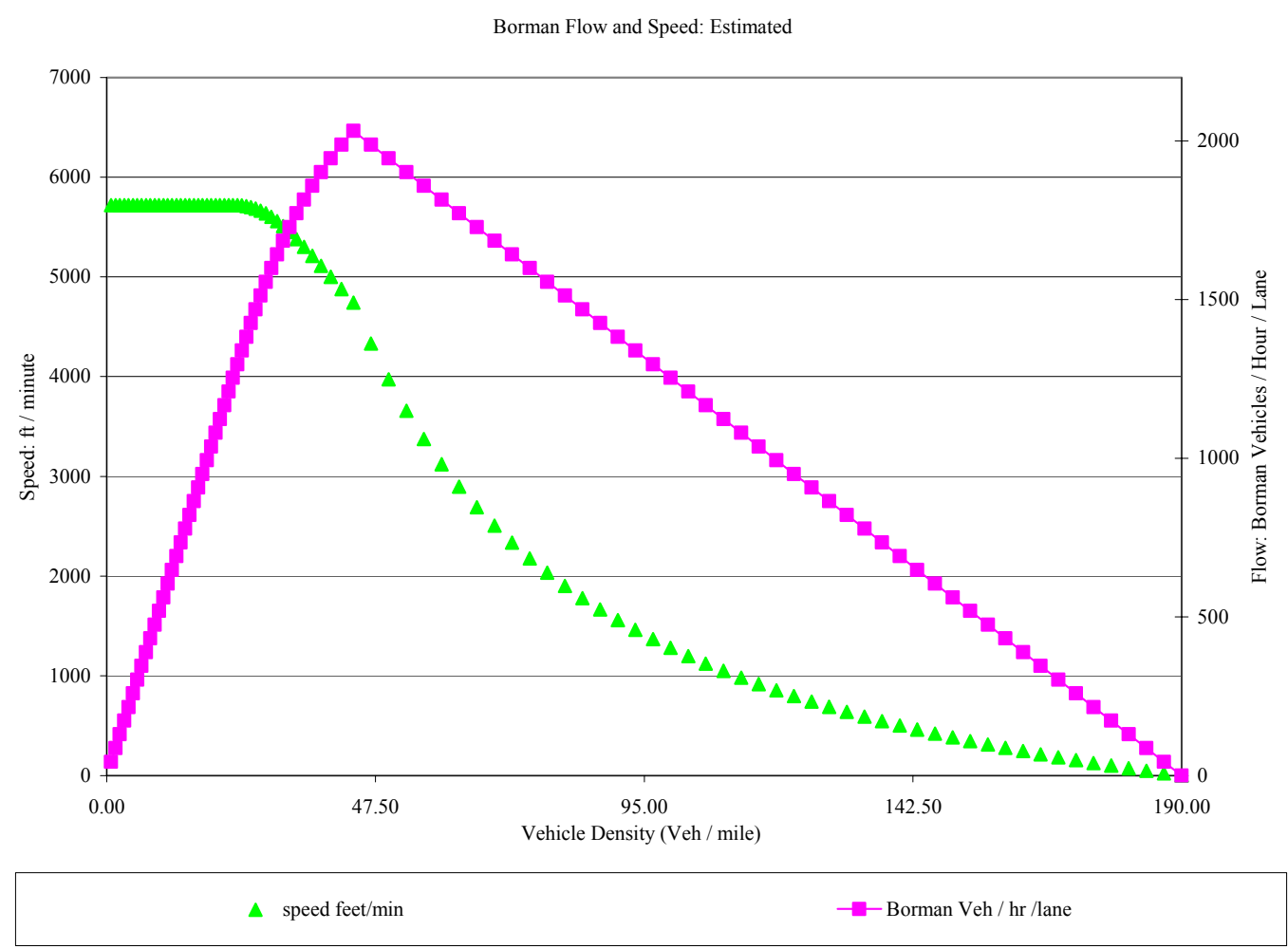

Figure 4.2: Estimated Traffic Flow and Speed Vs. Density

Figure 4.2 demonstrates that as density increases speed decreases and that flow increases to a peak near 2000 Vehicles/hour/Lane and then decreases. As previously stated, emissions/mile generally increase as speed decreases. Therefore emissions/mile are expected to increase as density increases for two reasons. First, the greater the density is, the greater the number of vehicles emitting pollutants in each mile; and 
second, as density increases speed decreases and therefore the emissions per vehicle / mile increase. Equation 4.3 shows how the emissions per mile per lane factor is calculated.

\section{Equation 4.3: Emissions Calculation}

$E=F^{*} E F$

Where

$E=$ Grams $/\left(\right.$ Mile $^{*}$ Lane $*$ Hour $)$

$F=$ Vehicles $/($ Lane $*$ Hour $)$

$E F=$ Grams $/($ Mile $*$ Vehicle $)$

* Note that EF refers to a speed specific emission factor

The relationship between vehicle density and emissions is illustrated in Figure 4.3.

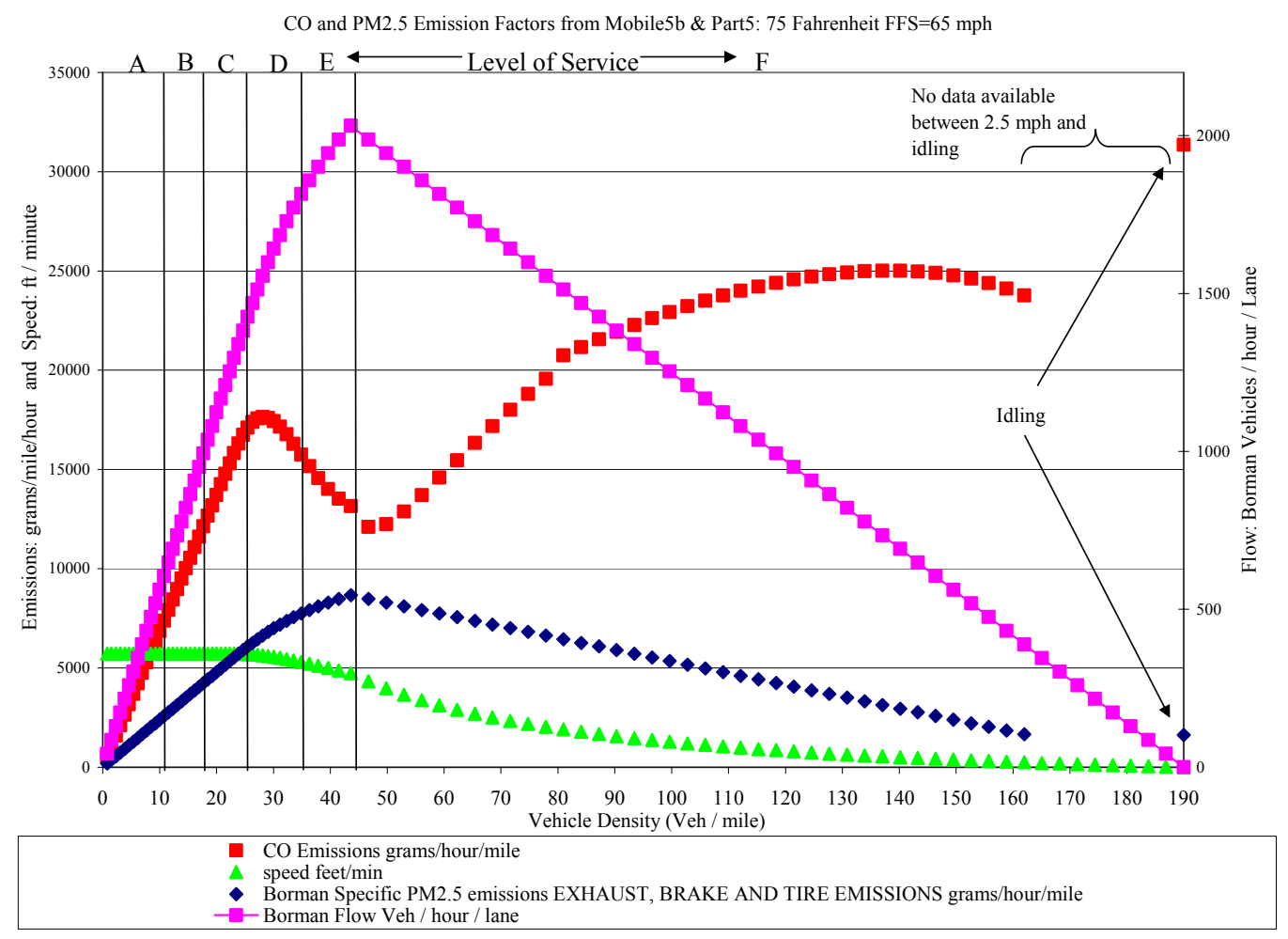

Figure 4.3 Estimated Traffic Flow, Speed, and Emissions vs. Density 


\subsubsection{CALINE4 Predictions}

The $\mathrm{CO}$ emission factor shown in figure 4.1 and the average $\mathrm{PM}_{2.5}$ emission factor were combined with traffic data from the eastbound Kennedy monitoring station to estimate Borman expressway contributions of $\mathrm{PM}_{2.5}$ and $\mathrm{CO}$ in the local air quality. The Borman component of local air quality was added to the previously predicted point source contributions to calculate a total mobile source and permitted point source estimate.

Emission factors were selected from figure 4.1 depending on speed, which was estimated from flow. The Borman was under construction with lane closures in this time period and so a four lane mixing width was assumed. Average meteorological inputs were selected from the Borman monitoring station with the exception of mixing height data and stability data. Mixing height and stability data were collected from the nearest observation stations in Peoria and Chicago, Illinois. Table 4.3 lists the factors used in the model at each hour. 
Table 4.3 Model Parameters for CALINE4 modeling

\begin{tabular}{|c|c|c|c|c|c|c|c|}
\hline Hour & $\begin{array}{c}\text { Total } \\
\text { Vehicles/ } \\
\text { Hour }\end{array}$ & $\begin{array}{c}\text { CO } \\
\text { Emissions / } \\
\text { veh / mile }\end{array}$ & $\begin{array}{c}\text { PM }_{2.5} \\
\text { Emissions / } \\
\text { veh / mile }\end{array}$ & $\begin{array}{c}\text { Average } \\
\text { Wind } \\
\text { speed } \\
\text { meters/sec }\end{array}$ & $\begin{array}{c}\text { Stability } \\
\text { from 1 to 7 }\end{array}$ & $\begin{array}{c}\text { Mixing } \\
\text { Height } \\
\text { meters }\end{array}$ & $\begin{array}{c}\text { Mean } \\
\text { Temp. }\end{array}$ \\
\hline 1 & 2263 & 12.06 & 0.268 & 1.9 & 5.33 & 520 & 19.4 \\
\hline 2 & 1670 & 12.06 & 0.268 & 1.9 & 5.32 & 526 & 18.9 \\
\hline 3 & 1711 & 12.06 & 0.268 & 2.1 & 5.33 & 527 & 18.6 \\
\hline 4 & 1962 & 12.06 & 0.268 & 1.4 & 5.34 & 527 & 18.3 \\
\hline 5 & 3173 & 9.06 & 0.268 & 2.0 & 4.90 & 561 & 18.0 \\
\hline 6 & 4816 & 9.06 & 0.268 & 2.7 & 4.29 & 642 & 17.8 \\
\hline 7 & 5579 & 9.06 & 0.268 & 1.4 & 3.77 & 738 & 19.0 \\
\hline 8 & 5938 & 6.19 & 0.268 & 1.7 & 3.43 & 834 & 21.0 \\
\hline 9 & 6160 & 6.19 & 0.268 & 2.6 & 3.22 & 930 & 22.9 \\
\hline 10 & 6305 & 6.19 & 0.268 & 3.0 & 3.14 & 1026 & 24.3 \\
\hline 11 & 6146 & 6.19 & 0.268 & 2.3 & 2.96 & 1122 & 25.3 \\
\hline 12 & 6031 & 6.19 & 0.268 & 2.8 & 2.94 & 1218 & 26.1 \\
\hline 13 & 6124 & 6.19 & 0.268 & 3.0 & 3.04 & 1314 & 26.3 \\
\hline 14 & 6165 & 6.19 & 0.268 & 3.0 & 3.38 & 1410 & 26.5 \\
\hline 15 & 6160 & 6.19 & 0.268 & 2.3 & 3.47 & 1410 & 26.9 \\
\hline 16 & 5892 & 6.19 & 0.268 & 2.9 & 3.58 & 1410 & 26.8 \\
\hline 17 & 5815 & 6.19 & 0.268 & 2.0 & 3.73 & 1410 & 26.5 \\
\hline 18 & 5774 & 6.19 & 0.268 & 2.1 & 4.05 & 1407 & 26.0 \\
\hline 19 & 5399 & 6.19 & 0.268 & 1.7 & 4.30 & 1375 & 25.1 \\
\hline 20 & 5325 & 6.19 & 0.268 & 1.6 & 4.78 & 1243 & 23.7 \\
\hline 21 & 4838 & 6.19 & 0.268 & 1.6 & 5.10 & 1059 & 22.0 \\
\hline 22 & 4253 & 6.19 & 0.268 & 1.7 & 5.20 & 882 & 21.0 \\
\hline 23 & 3785 & 6.19 & 0.268 & 1.2 & 5.27 & 689 & 20.3 \\
\hline 24 & 3160 & 9.06 & 0.268 & 2.0 & 5.30 & 527 & 19.9 \\
\hline
\end{tabular}

As figure 4.4 shows, there is fair agreement between measured data and predicted values. The model predicts the general trend but predicts absolute peaks rather poorly. The predicted average Borman monitoring station $\mathrm{CO}$ concentration was 0.309 PPM compared to the measured 90 to 110 degree azimuth concentration of $0.470 \mathrm{PPM}$, a difference of $34.7 \%$. The average of the absolute deviation at each hour was $29.8 \%$. The predicted average Borman monitoring station $\mathrm{PM}_{2.5}$ concentration was $12.6 \mu \mathrm{g} / \mathrm{m}^{3}$ 
compared to the measured 90 to 110 degree azimuth concentration of $21.2 \mathrm{ug} / \mathrm{m}^{3}$, a difference of $40.5 \%$. The average of the absolute deviation at each hour was $63 \%$. This particular sector, 90 to 110 degrees azimuth represents an area that has few other nonBorman sources and an extensive exposure to the Expressway. Other sectors such as the 300 to 330 degree azimuth sector may show less agreement as would be expected since the span of exposure is less and there are obviously other sources in the background as was shown in figure 3.15 and 3.16. An analysis of this sector is underway at the time of this draft.

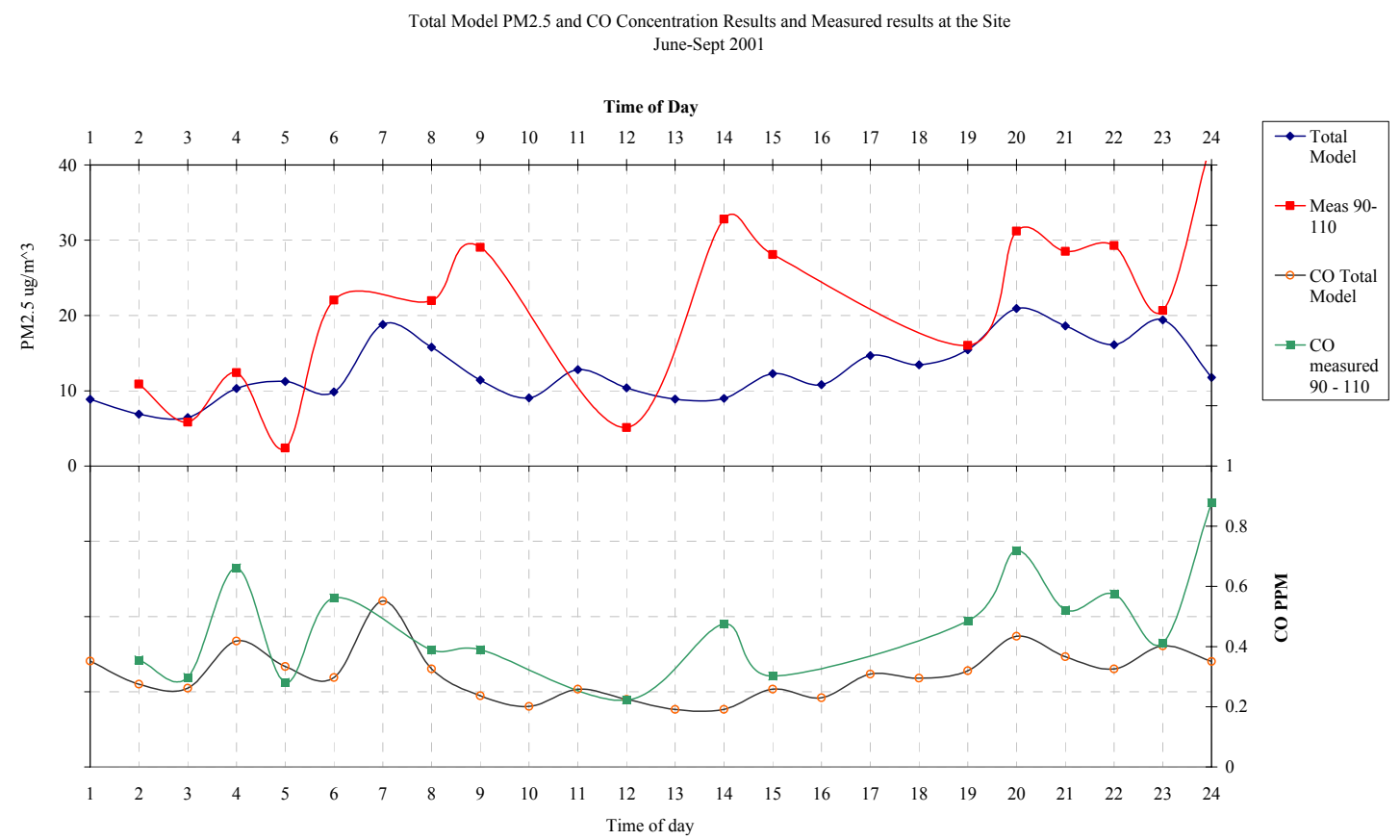

Figure 4.4: Combined Caline4 and ISCST3 Modeling Results and Measured Results

A scatter plot of modeled concentration versus measured concentration shows reasonable agreement (figure 4.5). The coefficient of simple determination and 
correlation as well as the descriptive linear equation are shown on the graphs. Note that the $\mathrm{R}$ values of $39.5 \%$ and $57.8 \%$ for $\mathrm{PM}_{2.5}$ and $\mathrm{CO}$ respectively are in relative agreement with the previous Arc flux analysis. Average background components by the arc flux method were $27 \%$ and $57 \%$. The agreement with $\mathrm{CO}$ is particularly noteworthy.

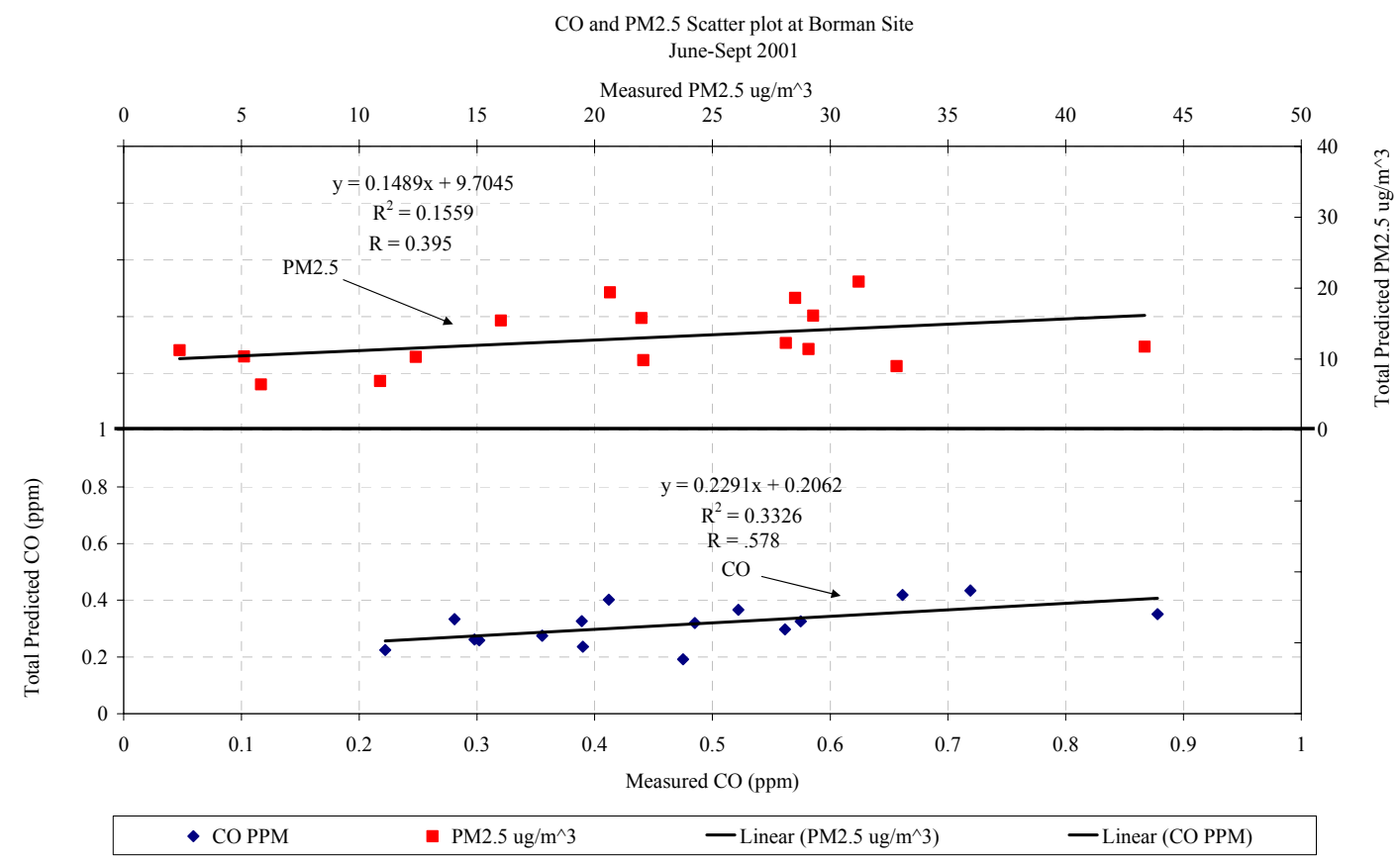

Figure 4.5: $\mathrm{CO}$ and $\mathrm{PM}_{2.5}$ Scatter Plot: Predicted vs. Measured Results

\subsubsection{Observed Aggregate Results}

Traffic data from the eastbound center lane "B" lane sensor at Kennedy Avenue was joined with environmental data. The "B" lane was selected because as previously mentioned the Borman was under construction in this period and the "B" lane was the lane most consistently in use. Environmental data in this analysis is during periods of Borman intersecting winds only.

Figure 4.6 illustrates the relationship between flux, flow, and lane occupancy. Only values where at least 300 minutes $(60,5$ minute periods) of data were available 
were included. As data collection proceeds, additional values will be added to the graph at the very low and the very high end of occupancy. Note the expected relationship between flow and lane occupancy is seen. Traffic flow peaks around $22 \%$ occupancy after which it begins to decline. $\mathrm{PM}_{2.5}$ flux correlates with occupancy in a near linear relationship while CO flux has a polynomial or "curvilinear" relationship with lane occupancy.

Pollutant background flux can be determined by extrapolating each best fit curve through "zero" or " $0 \%$ occupancy or " 0 flow". Then the average speed is used to back calculate the equivalent concentration since these points represent the average conditions at each flow rate. Overall background $\mathrm{PM}_{2.5}$ concentrations were calculated at $8.5 \mu \mathrm{g} / \mathrm{m}^{3}$ and $\mathrm{CO}$ background concentrations were calculated as 0.159 PPM. 
Borman Flux and Flow vs. Lane Occupancy June 8, 2001 to Oct 31, 2001

Average Wind Speed: $4.8 \mathrm{mph}$

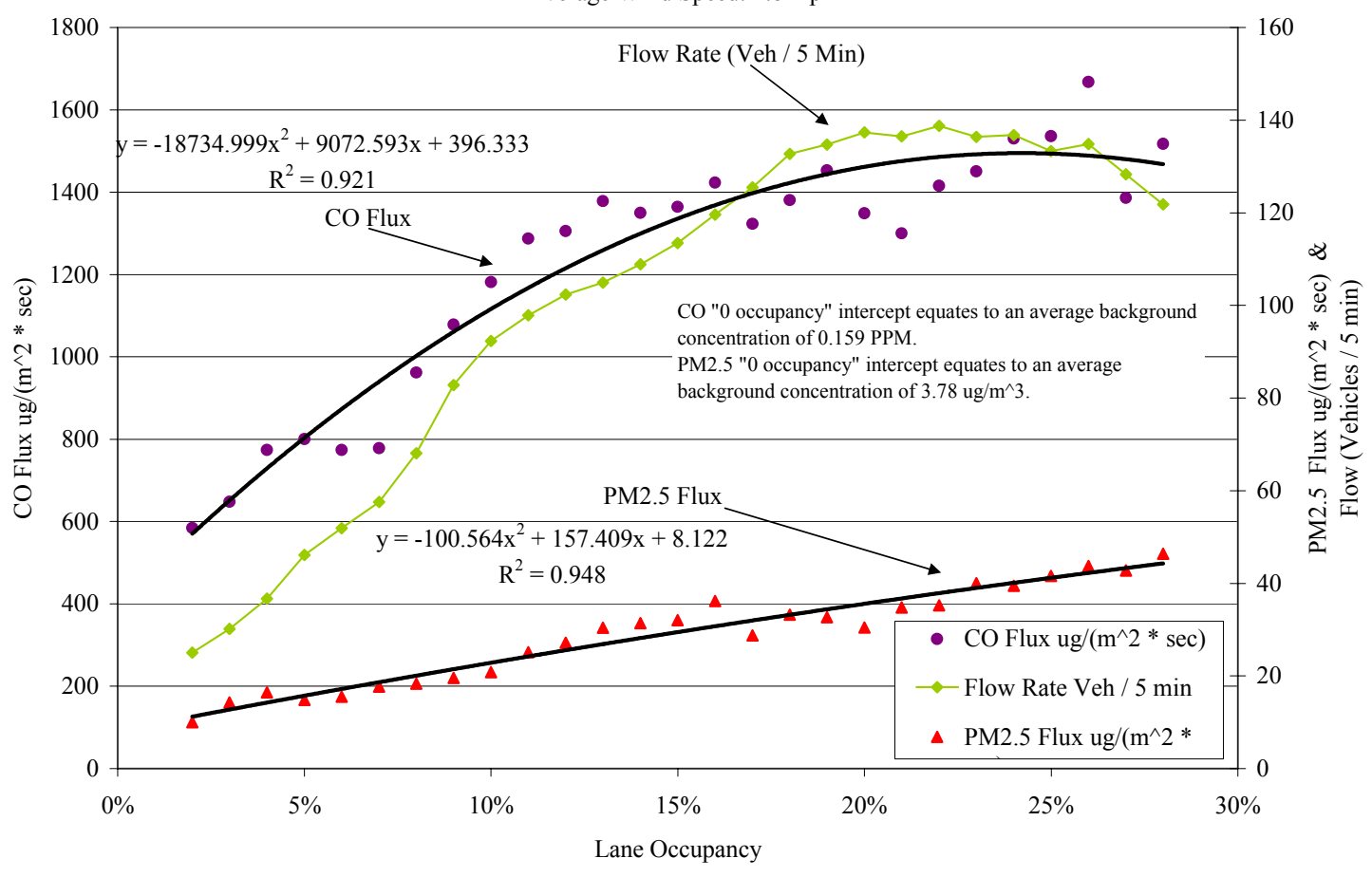

Figure 4.6: Borman Exposure: Flux and Flow vs. Occupancy

Figure 4.7 shows the dependency of $\mathrm{PM}_{2.5}, \mathrm{CO}$, and Occupancy on flow. As with the previous figure only flow rates where at least 300 minutes of data was available were included in the figure. As with traffic occupancy, $\mathrm{R}^{2}$ values are high, greater than 0.9 for both. The ambiguity between flow and occupancy on either side of capacity flow is not seen in this data. As more data in oversaturated conditions is collected it may begin to appear. In this case there was less than 300 minutes of data at conditions above saturated occupancy so this is not yet seen. 
CO, PM2.5, Occupancy Vs Flow: Borman Expressway MM 4.1 Winds Intersecting Borman

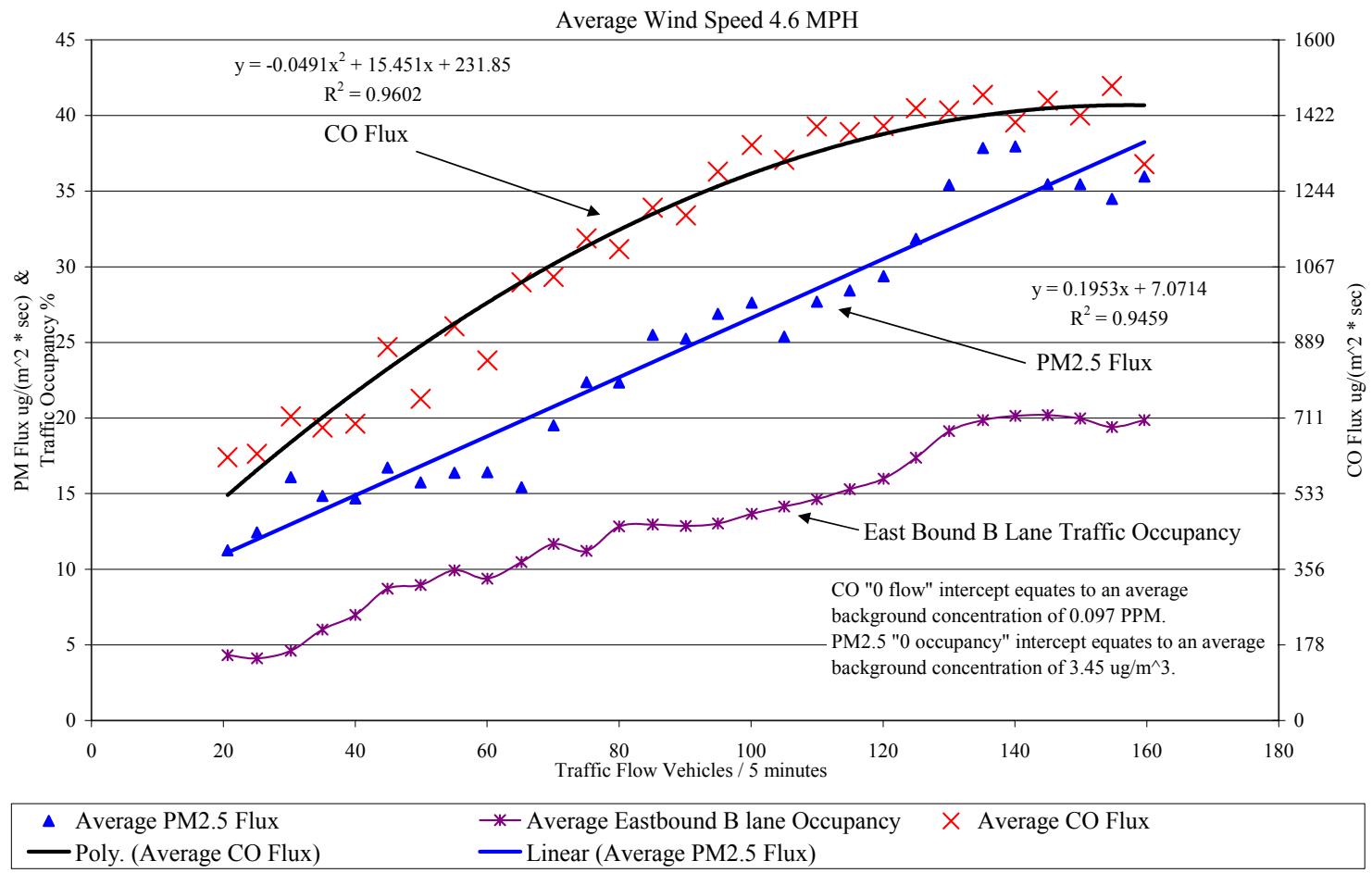

Figure 4.7: Borman Exposure: Occupancy and Flux vs. Flow

In figure 4.7 the " 0 " flow background estimate of 0.097 PPM CO and $3.45 \mu \mathrm{g} / \mathrm{m}^{3}$

$\mathrm{PM}_{2.5}$ is lower than the "0" occupancy estimate calculated in figure 4.6. This discrepancy is likely to decrease as the data set becomes larger.

\section{2 $\quad$ Predicted Serial Results}

It is important to note that any incident that significantly disturbs traffic flow should have some effect, perceptible or not, on local air quality. A simple mass balance 
around the local environment would show this to be true. The effect, positive or negative, location, and magnitude is what this section will elucidate.

The effect of a traffic incident on local air quality is dependant on many factors. These factors include the direction of the wind, wind velocity, separation distance of incident and receptor (source -receptor distance), duration of incident, and atmospheric mixing height. The effects of wind velocity, source - receptor distance, and mixing height are straightforward. Given a constant mass emission rate at ground level, pollutant concentrations in air will decrease with increasing wind velocity, source - receptor distance, or mixing height. The distinction of ground level emission source is made because pollutant concentrations from elevated sources, i.e. smoke stacks, generally increase with distance from the stack to some maximum and then decrease with distance.

\subsubsection{Accounting for Background Levels}

As the flux analysis and modeling work have shown, a major component of pollution in the local area is the Borman Expressway. Immediate information about the background concentration at the time of a specific event can be gathered from the data record at the site. To understand how this is possible, consider that the concentration measured at the site can never be lower than the background concentration.

The pollutant concentration at the site is the sum of the background concentration and the emissions from the roadway. In simple box model terms the concentration is determined by the following equation: 


\section{Equation 4.4: Site Measurement Components}

$\mathrm{C}_{\mathrm{s}}=\mathrm{C}_{\mathrm{b}}+\mathrm{M}_{\mathrm{B}} / \mathrm{Qm}_{\mathrm{m}}$

where

$\mathrm{C}_{\mathrm{s}}=$ concentration at the site

$\mathrm{M}_{\mathrm{B}}=$ the Mass emission rate from the Borman

$\mathrm{Q}_{\mathrm{m}}=$ the Flow of air that the Emissions are dispersed in.

A more sophisticated model would more accurately predict the emissions at the site but regardless of the model, if there is no source of mobile mass emissions then there is no Borman Component to the local air quality at the site. Therefore, if an incident or incidents occur that significantly interrupts traffic flow and removes most of the traffic from the path of air across the roadway, the monitoring instruments will be measuring the pollutant concentration in air that is largely unaffected by the Borman.

In general practice the Borman is seldom totally empty. However, given this understanding of what composes the measurements being made at the site, the background concentration on any given day can then be assumed to be less than or equal to the minimum concentration measured in a given data set over a short period of time.

\subsubsection{Varying Wind Direction and Analysis}

Varying wind direction affects the travel distance and source exposure duration of roadway emissions. For example, when the winds are from the north there is very little distance (time) for dispersion, so the pollutant can't be diluted, but the air stream has very little residence over the source of pollution, so there isn't much time for $\mathrm{CO}$ or $\mathrm{PM}_{2.5}$ 
entrainment. On the other hand, when winds are from $\sim 100$ degrees there is considerable distance (time) for dispersion, but the air path crosses the Borman on two occasions providing both two opportunities for pollutant entrainment and extended exposure. Wind from 100 degrees crosses the Borman are at mile 4 and 5 at a distance of 0.3 and 1.3 miles respectively. The effect of wind direction and incident duration cannot be conveniently categorized. Conditions must be applied to the effect of wind direction and incident duration on local air quality.

\subsubsection{Downstream Effects}

If the receptor is receiving wind downstream of the incident then pollutant concentrations will likely decrease as the incident upstream in traffic has cut off or reduced traffic flow thus reducing the number of pollutant sources passing through the path of air that is being carried to the receptor. When the incident clears, pollutant concentrations will likely increase as vehicles return to previous travel conditions. How much local pollutant concentrations rise after incident clearance is dependant on the path of the air stream that the receptor receives. If the receptor's air stream passes through the acceleration zone downstream of the incident then concentrations are likely to rise sharply to above pre incident levels. If the receptor's air-stream crosses traffic several miles downstream of the incident where speeds have stabilized then the rise in concentration will be less significant. If pre-incident densities were characterized by class a or b conditions and the queue release produced class $\mathrm{c}, \mathrm{d}$, or e conditions then the resultant rise would be greater than pre incident conditions. If the pre-incident traffic conditions were $\mathrm{c}, \mathrm{d}$, or e, no increase above pre-incident concentrations would be 
perceived. Finally and perhaps ironically, if traffic flow was already impaired prior to the incident, i.e. class $\mathrm{F}$, an incident upstream may well enhance air quality during the incident and even after incident clearance relative to pre-incident conditions.

\subsubsection{Upstream Effects}

If the receptor is receiving wind upstream of the incident then emissions will likely increase at some point during the incident cycle compared to concentrations prior to the incident. How much they increase and when is dependant on several factors including the pollutant of interest. Carbon Monoxide emissions are speed sensitive as shown in figure 4.1 and therefore mass emission rates in queues with high densities will be greater than at any other operating conditions. According to Part5 Emissions of $\mathrm{PM}_{2.5}$ per mile are speed insensitive and therefore mass emission rates in queues will be less than pre-incident rates. After queue clearance the acceleration zone propagates upstream thus dramatically increasing emission rates of both $\mathrm{CO}$ and PM from vehicles. This would be perceived by a sharp rise in concentrations by the downwind receptor. Figures 4.8 and 4.9 illustrate these concepts in the form of "pollution profiles". These profiles were generated based on emission rates estimated in figure 4.3 and on the concepts of queue formation and clearance (Stephanedes, 1995). The profiles include two reference points "a" and "b" for use in later discussion. 


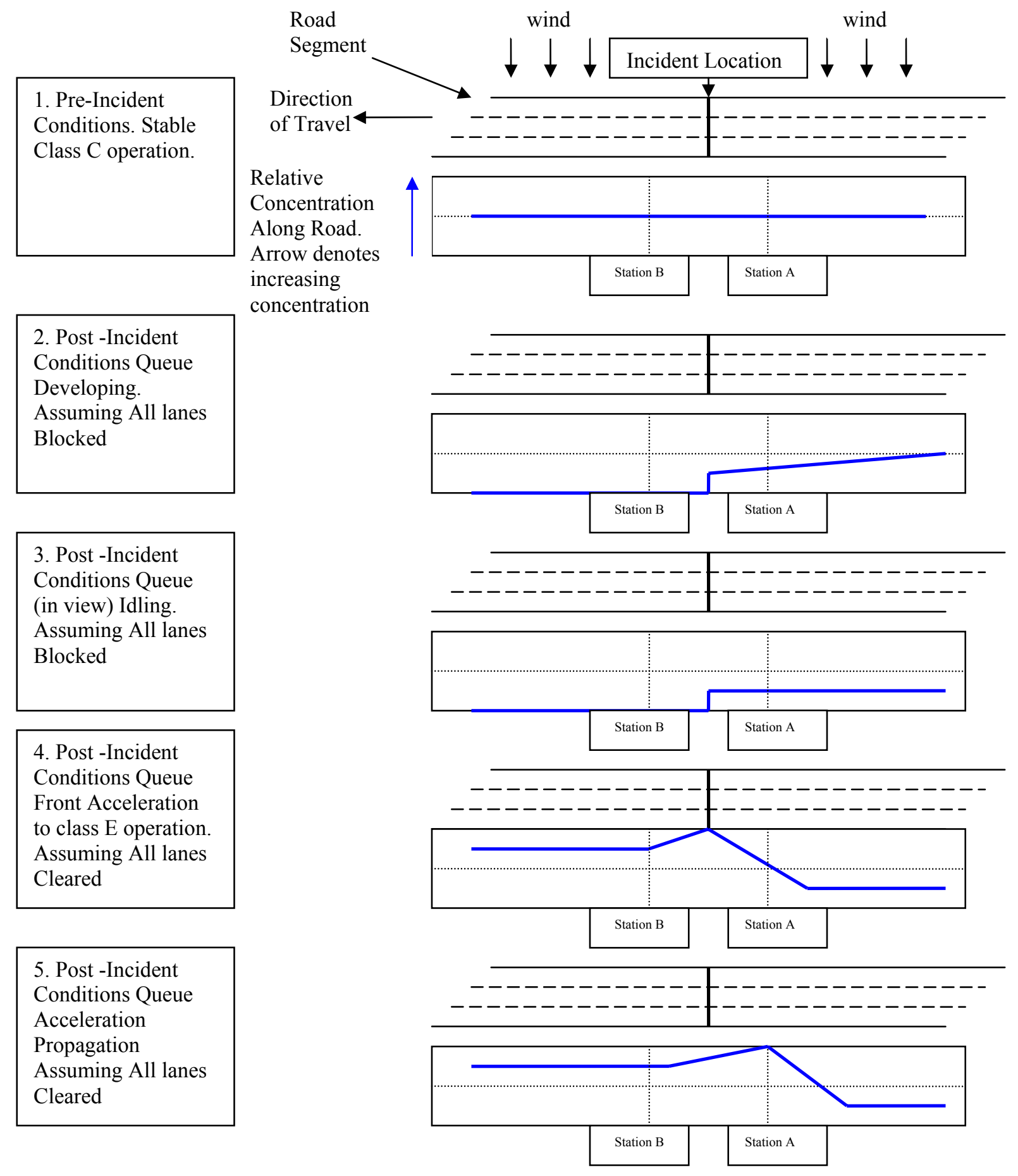

Figure 4.8: Theoretical PM2.5 Pollution Profile Along Roadway Segment 
1. Pre-Incident

Conditions. Stable

Class $\mathrm{C}$ operation.

2. Post -Incident

Conditions Queue

Developing.

Assuming All lanes

Blocked

3. Post-Incident

Conditions Idling

Queue propagating

upstream. Assuming

All lanes Blocked

4. Post-Incident Conditions Queue Front Acceleration to class E operation. Assuming All lanes

Cleared

5. Post -Incident Conditions Queue

Acceleration

Propagation

Assuming All lanes

Cleared

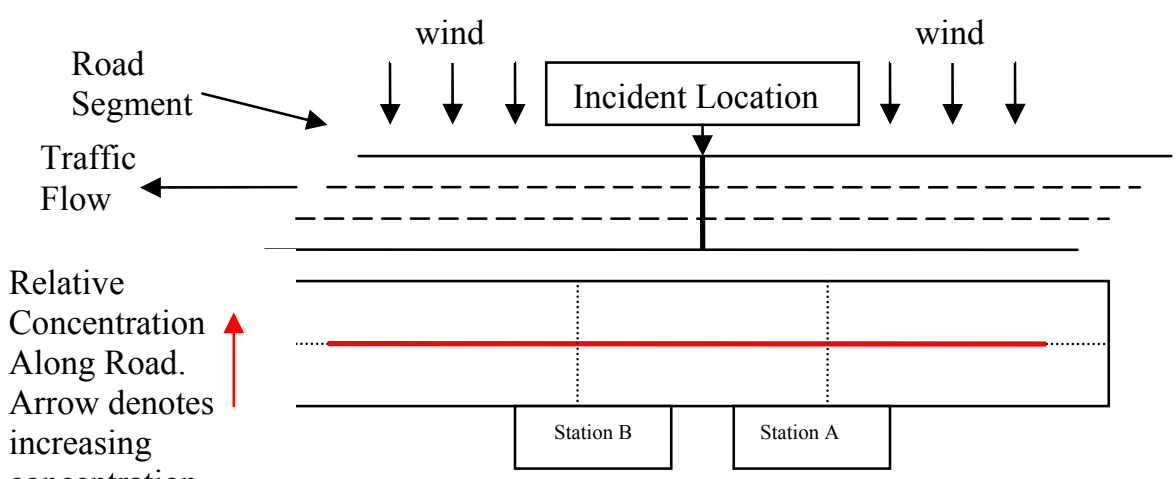

concentration
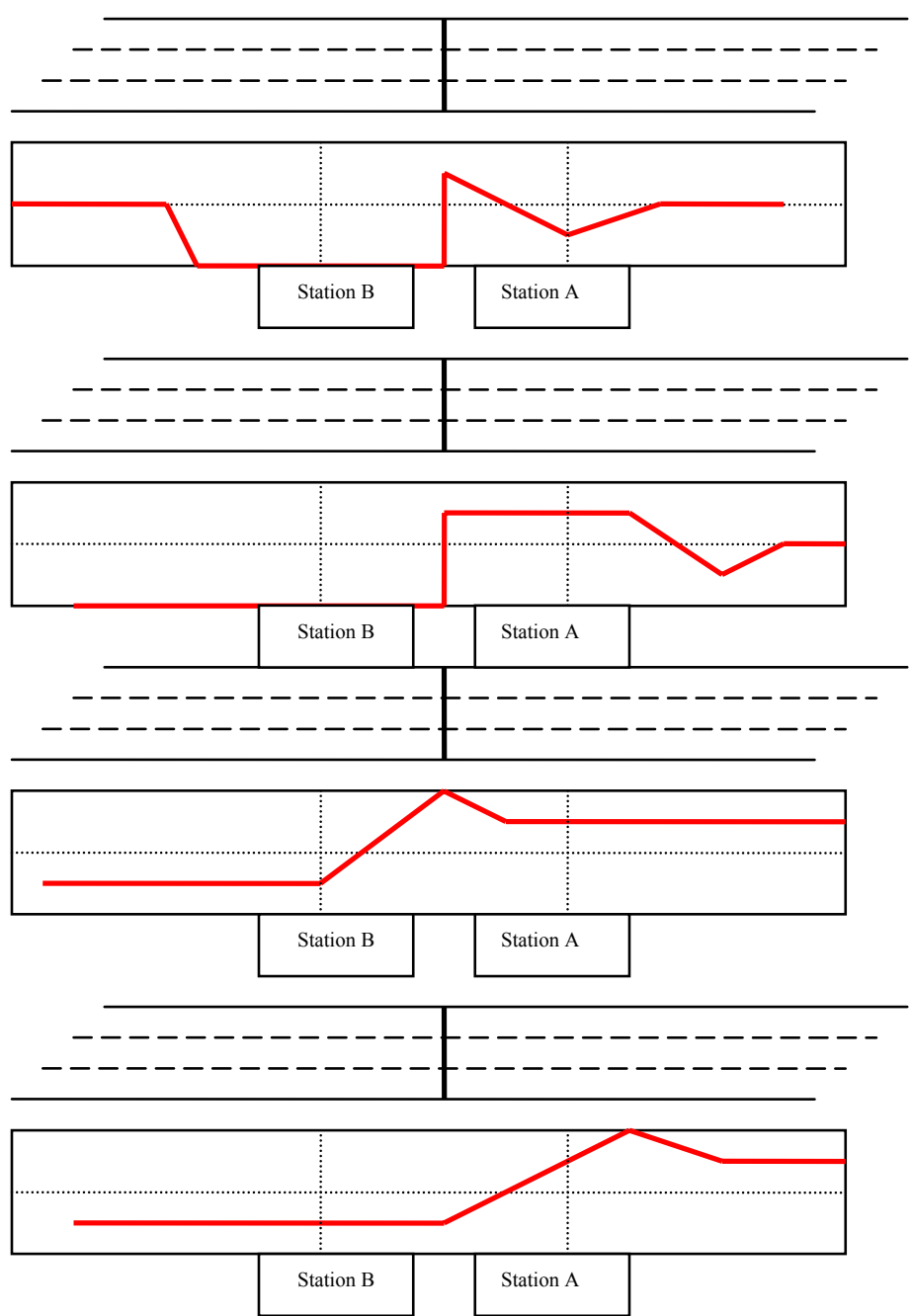

Figure 4.9: Theoretical CO Pollution Profile along roadway segment 
These profiles are theoretical and represent an idealized case where winds are perpendicular to the roadway. No chronological or geometric scale is implied. Obviously there are a multitude of profiles possible depending on conditions prior to an incident, number of lanes obstructed, number of lanes returned to service at a given time, and time required to clear the incident. Most of the time air will cross the roadway at an angle. The issue is further complicated by changing wind directions, wind speeds, and, if the incident is of very long duration, mixing heights. The profiles provide insight to what a receptor at various points along the roadway might measure.

Consider two monitoring stations, station "A" located adjacent to the road upstream of the incident shown in figures 4.8 and 4.9 and station "B" located adjacent to the road downstream of the incident. The upstream monitoring station (station "A") would record measurements similar to those shown in figures 4.10 and 4.11. The downstream monitoring station (station "B") would record measurements similar to those shown in figures 4.12 and 4.13.

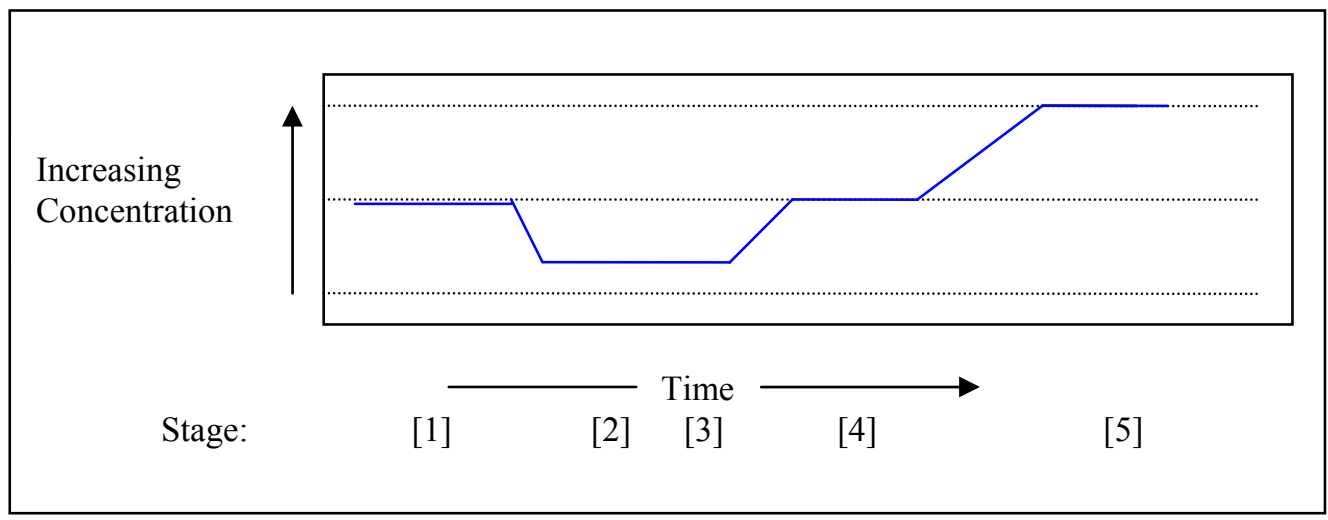

Figure 4.10: Theoretical PM2.5 Strip chart Record at Monitoring Station "A" (Upstream of Traffic Incident) 


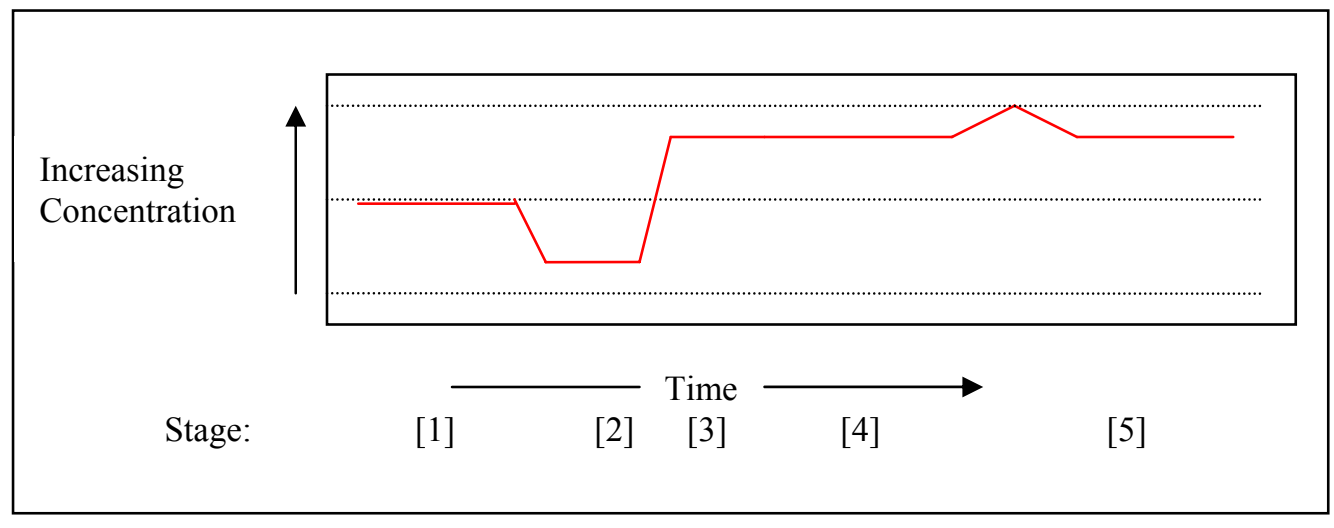

Figure 4.11: Theoretical CO Strip chart Record at Monitoring Station "A" (Upstream of Traffic Incident)

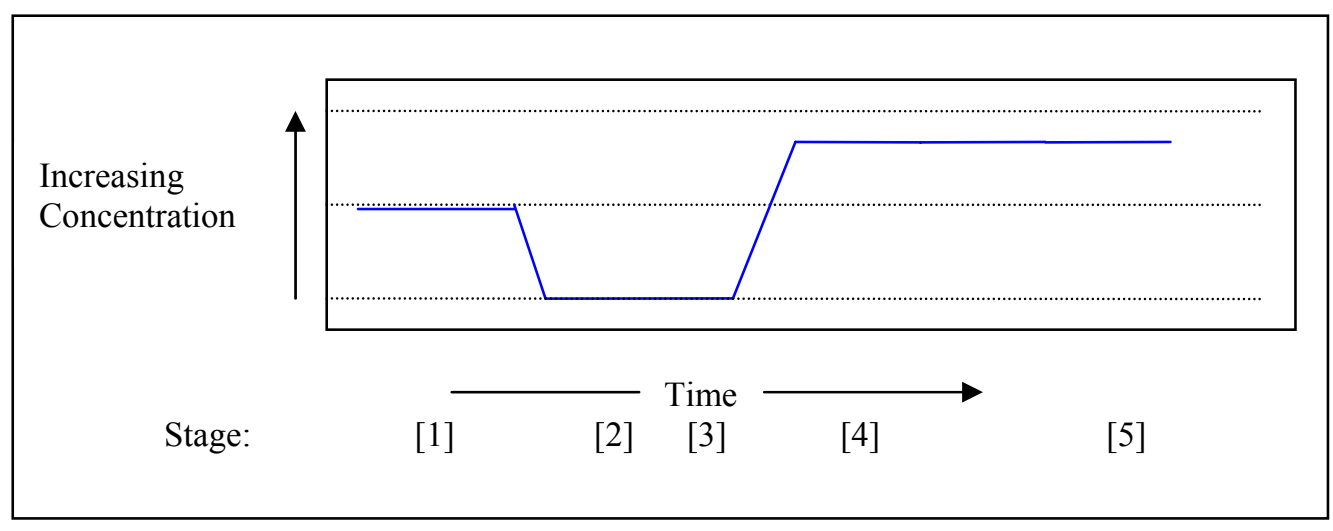

Figure 4.12: Theoretical $\mathrm{PM}_{2.5}$ Strip chart Record at Monitoring Station "B" (Downstream of Traffic Incident) 


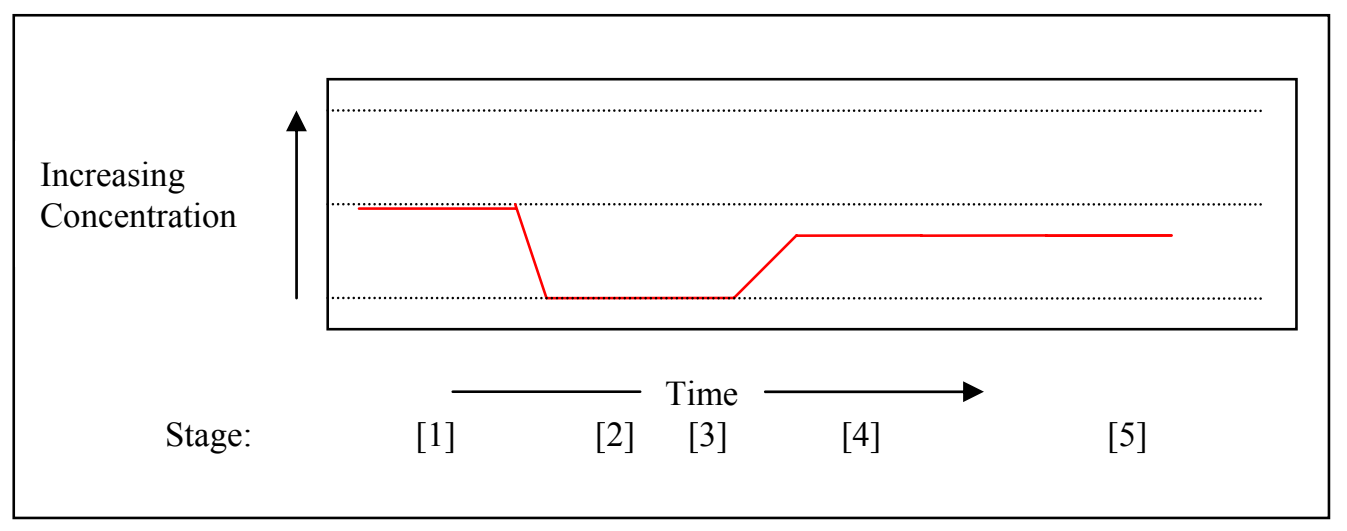

\section{Figure 4.13: Theoretical CO Strip chart Record at Monitoring Station "B" (Downstream of Traffic Incident)}

Careful inspection of the pollution profiles and the theoretical monitoring records shows that there are numerous pollution traces that could be recorded all depending on where a monitoring station is located. It should be clear from this discussion that there is no simple expected response from a traffic incident on the Borman Expressway. Determining the trace of an incident in the environmental record must be analyzed on a case-by-case basis.

However, this doesn't mean that the only method to analyze the data is to laboriously review every 10 -second data record of every day. Note that in each of the theoretical pollution profiles there are periods of significant change. Whether they be upward trends or downward trends a traffic incident can produce rapid change in local air quality that is not characteristic of background pollution signals. With change comes variability in data. The variability in the signal can also be used as an indicator of incident effects. Therefore periods of rapid change and increased variability in the data are very likely the product of change on the highway segment. 


\subsection{Observed Serial Results}

In addition to the environmental record, two other data resources were used to determine the effect of the Borman Expressway on local air quality. The Hoosier Helper logbook database provided a record of all assistance and activities of each Hoosier Helper employee. The type of obstacle encountered (abandoned automobiles, directions, accident and debris clearance etc.), location of service (lane of highway, direction, mile marker), and service rendered to remedy the situation are all recorded. This information combined with the time and duration of service can be joined with the environmental record to explain some environmental incidents.

This approach does have its limitations. It won't account for environmental effects brought on by construction lane restrictions and it won't account for environmental effects created by non-accident traffic congestion. However, if traffic congestion results in accidents, which it often does, the effect of accidents can be observed. For example, if congested conditions existed and three semi-tractor trailers collided, the logbook would tell us the state of the incident at response. If the logbook recorded a vehicle in the center and left lanes and a response duration of 2 hours, we would expect that traffic downstream of the incident would be significantly reduced and a sizable queue would form upstream. The exact traffic density and flow downstream or length of queue upstream would not be known but typically the loss of 2 out of 3 lanes of traffic reduces flow by about 75\% (HCP, 2000). If the wind intersects the Borman prior to reaching the monitoring station we may see the effects of these types of incidents. 
In figure 4.14 for example, a major incident occurred near mile marker 1 on the Westbound Borman Expressway. This is about 3.1 miles west of the monitoring station. The bearing from the site to this mile marker is 271.4 degrees or almost due west. The winds in the morning are opposite the incident location at 100 to 110 degrees therefore the monitoring station is measuring $\mathrm{PM}_{2.5}$ and $\mathrm{CO}$ from traffic downstream of the westbound MM 1 incident.

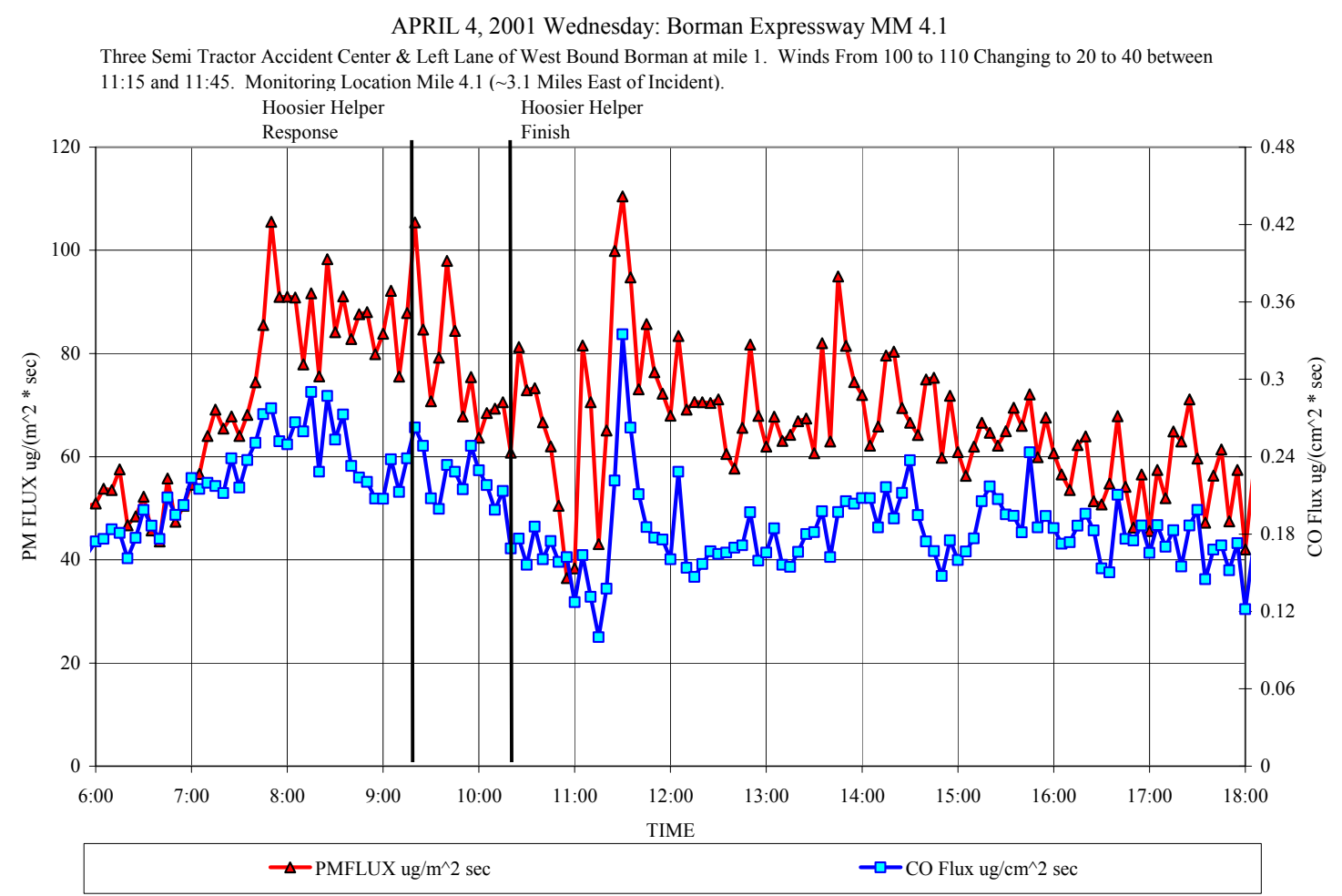

Figure 4.14: April 4, 2001 Accident Response Flux

The effect of the accident and subsequent westbound lane restriction is apparent.

First, consider the direction of the winds prior to 11:15. An average wind direction of 105 degrees means that the monitoring station is measuring the $\mathrm{PM}_{2.5}$ and $\mathrm{CO}$ resulting from traffic near mile marker 5, approximately 4 miles east of the accident. Therefore a 
lag due to the time for traffic queuing between the incident response and clearance and what is measured at the site was expected. A second component in response lag is the distance from the monitoring station to the source. With winds averaging 15 feet per second between 9:00 and 11:00, the time to travel the 4300 feet from the site to the center of the Borman at mile marker 5 is about 5 minutes. Figure 4.14 shows a precipitous drop in $\mathrm{PM}_{2.5}$ flux shortly after the Hoosier Helper Response was completed. The decline in $\mathrm{CO}$ flux is not so dramatic but it does decline. At 11:15 both CO flux and $\mathrm{PM}_{2.5}$ flux rise rapidly. This coincides with the beginning of a shift in wind direction from $\sim 105$ degrees to $\sim 30$ degrees. At first it might seem that the rise in flux was a result of change in angle of exposure and not due to traffic congestion. However, consider that as previously shown in figure 3.3 the monitoring station is in fact less sensitive to traffic emissions from the Borman when winds are between 20 and 40 as compared to winds between 100 and 110. Therefore if only the angle of exposure were changing and the traffic conditions remained constant we would expect flux to decrease not increase as in figure 4.14. The shift in wind direction occurs as the queue is clearing and accelerating and a rapid spike is observed followed by a return to less variable conditions as the road segment returns to normal conditions.

Figure 4.15 depicts the same incident with units of concentration for easier comprehension in lieu of flux. Note the difference factoring in wind makes in the morning hours. Concentrations are considerably higher in the morning and fall as wind speed increases. The effect of the incident is still plainly evident. 
APRIL 4, 2001 Wednesday: Borman Expressway MM 4.1

Three Semi Tractor Accident Center \& Left Lane of West Bound Borman at mile 1. Winds From 100 to 110 Changing to 20 to 40 between

11:15 and 11:45. Monitoring Location Mile 4.1 ( 3.1 Miles East of Incident).

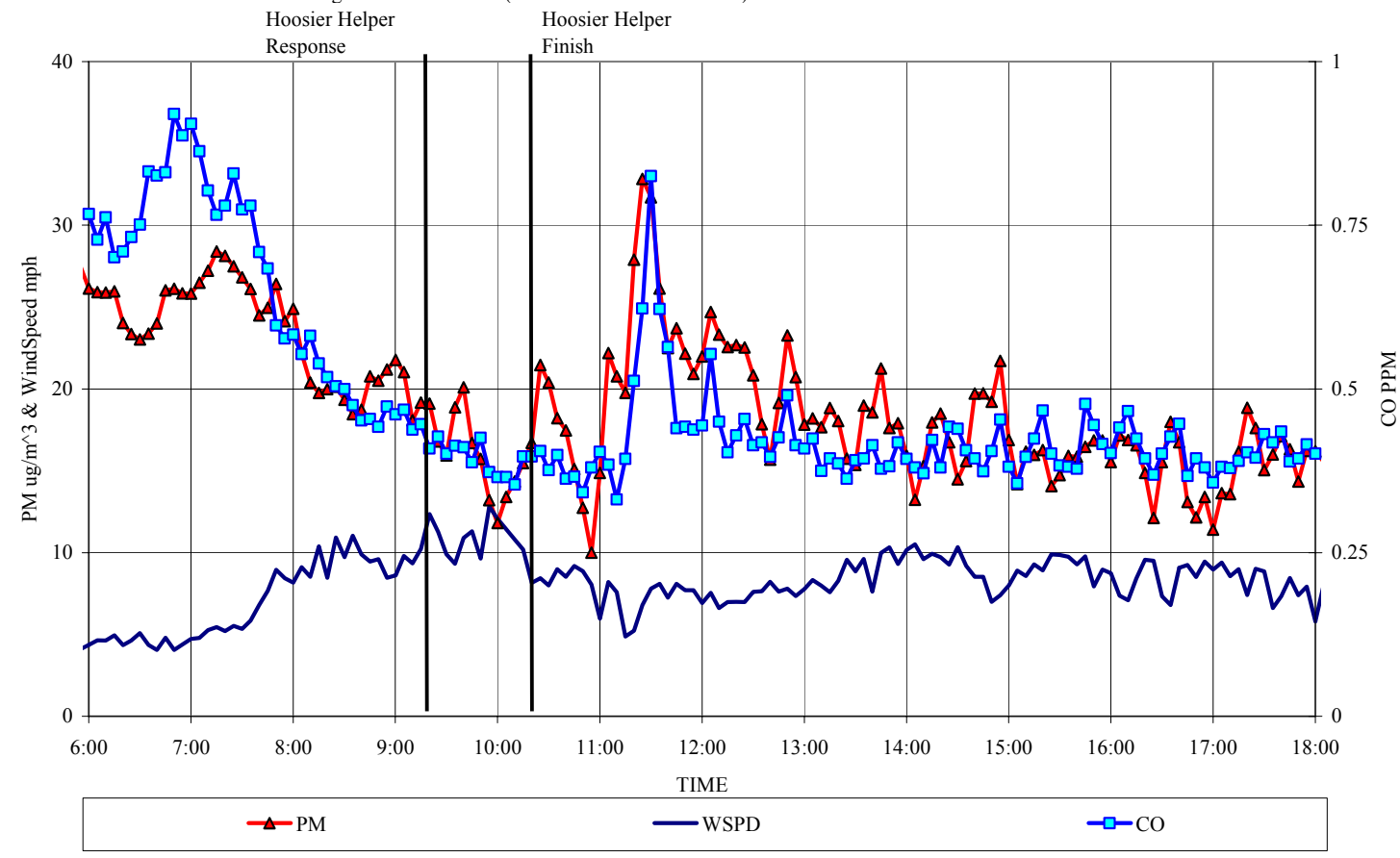

Figure 4.15: April 4, 2001 Accident Response: Concentration

On February 10, 2000 four vehicles, including two semi trailers, were involved in an accident in the westbound center lane at mile marker 8 . The response lasted from 10:40 to 14:45 Indiana time. The result of the long period of traffic restriction on local air quality is evident in figure 4.16. The concentration of both pollutants begins to drop prior to the Hoosier Helper response as would be expected. The initial response time is not the time of the accident but the time that the respondent logs in their arrival. Likewise the queue appears to be released sometime before the Hoosier Helper Finish time. Like the response time, the finish time is not when traffic was cleared but when the response was finished. The meandering northerly winds from 6 am to 14:30 provided varied exposure to the Borman Expressway and demonstrates that the restriction had a major effect on local air quality. The release of the queue is dramatically shown between 
13:00 and 13:45. $\mathrm{PM}_{2.5}$ concentrations increase from $16 \mu \mathrm{g} / \mathrm{m}^{3}$ to $57 \mu \mathrm{g} / \mathrm{m}^{3}$ and $\mathrm{CO}$ concentrations increase from 0.4 PPM to 1.3 PPM. Both pollutants increase in concentration by more than a factor of 3 . By 13:45 both pollutant concentrations had subsided to pre-incident conditions similar to those occurring around 9:00.

February 10, 2000 Thursday: Borman Expressway Air Quality Measurements at MM 4.1

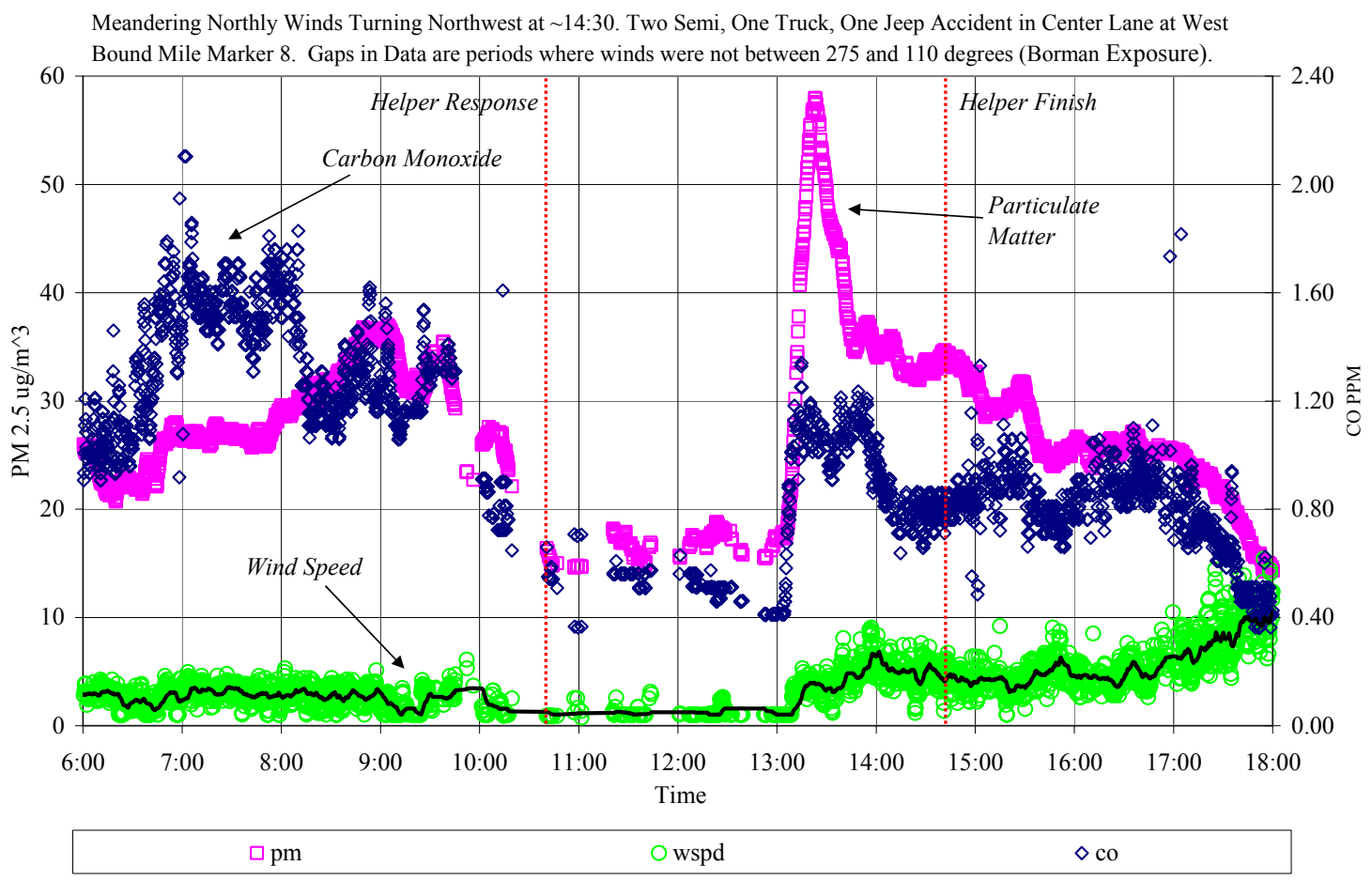

Figure 4.16: February 10, 2000 Accident Effect

While the Hoosier Helper logbook was helpful in identifying events that were likely to affect local air quality, what exactly was going on in traffic near the site remained unknown. Having traffic data permits a better understanding of what is occurring real time and requires less conjecture in incident analysis. Accidents aren't the only source of traffic congestion. Frequently, sheer vehicle volume and human factors 
will create traffic jams. Thus having detailed traffic data is an essential part of characterizing the relationship between the Borman Expressway and local air quality.

Figure 4.17 demonstrates a simple case of the relationship between traffic and environmental factors. Note that CO flux units have been changed to $\mu \mathrm{g} /\left(\mathrm{cm}^{3} * \mathrm{sec}\right)$ to facilitate scaling of the graph.

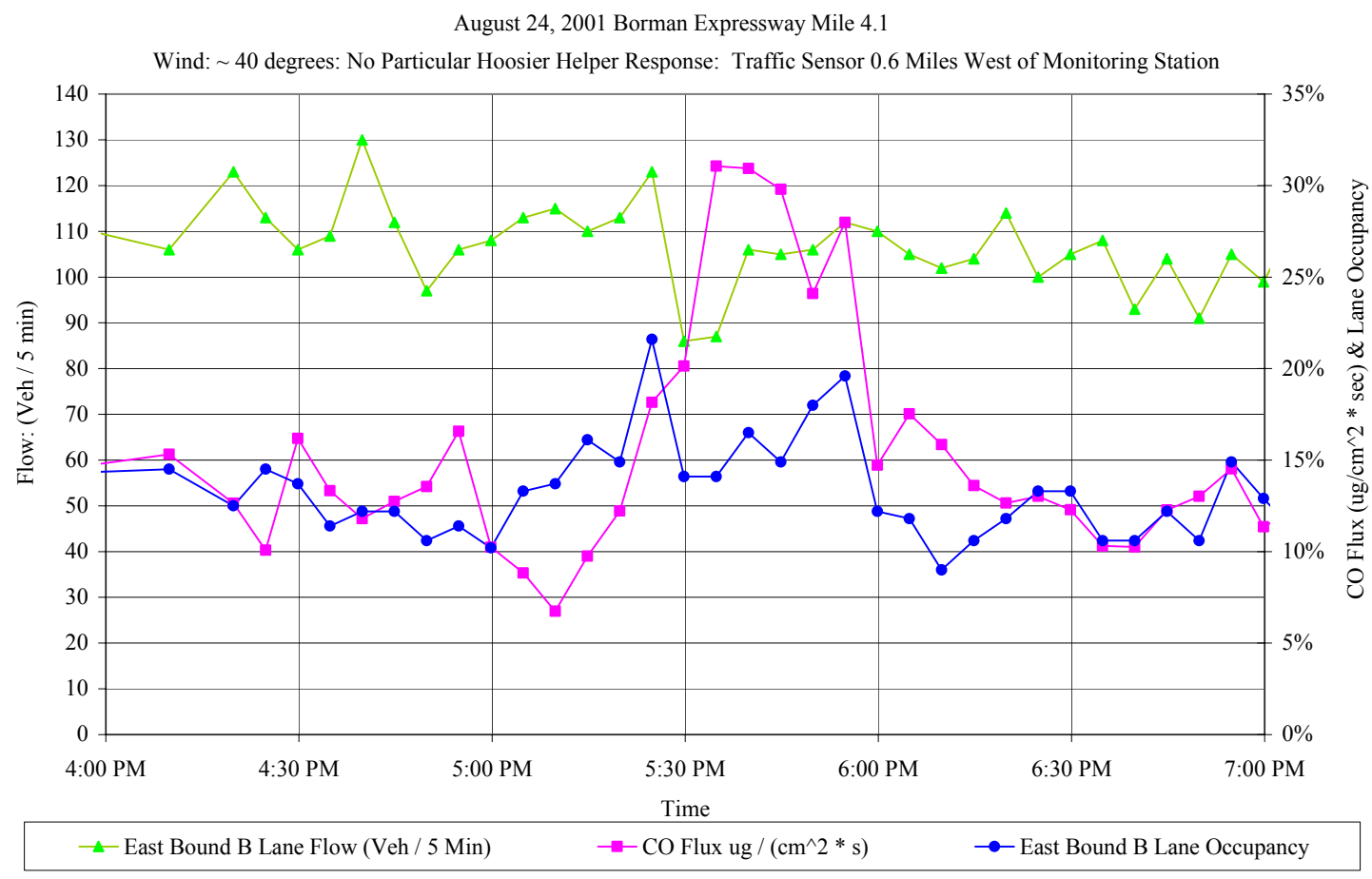

\section{Figure 4.17: August 24, 2001 Congestion Event: Flux}

Between 4:00 pm and 5:00 pm CO Flux and Lane Occupancy follow a fairly constant pattern varying between 0.1 and $0.17 \mu \mathrm{g} / \mathrm{cm}^{2} \mathrm{sec}$ and $10 \%$ and $15 \%$ respectively. At about 5:00 pm, occupancy begins to rise until something disrupts traffic around 5:20 pm. This disruption is verified by the sharp drop in flow from between 110 to 120 vehicles $/ 5$ min to below $90 \mathrm{veh} / 5 \mathrm{~min}$. At 6:00 pm lane occupancy has stabilized and CO flux returned to pre-incident conditions. 
As shown previously in aggregate pollutant effects, Figure 4.17 shows that there is a relationship between lane occupancy and pollutant flux. In this case, as lane occupancy increased, flux increased and when lane occupancy returned to pre-incident conditions, flux returned to pre-incident conditions.

Figure 4.18 illustrates the same period of time but showing the effect on concentration. CO Concentration rises from 0.60 PPM to 1.70 PPM, an increase of more than 150\% between 5:00 PM and 5:50 pm and then subsides when lane occupancy returns to earlier conditions.

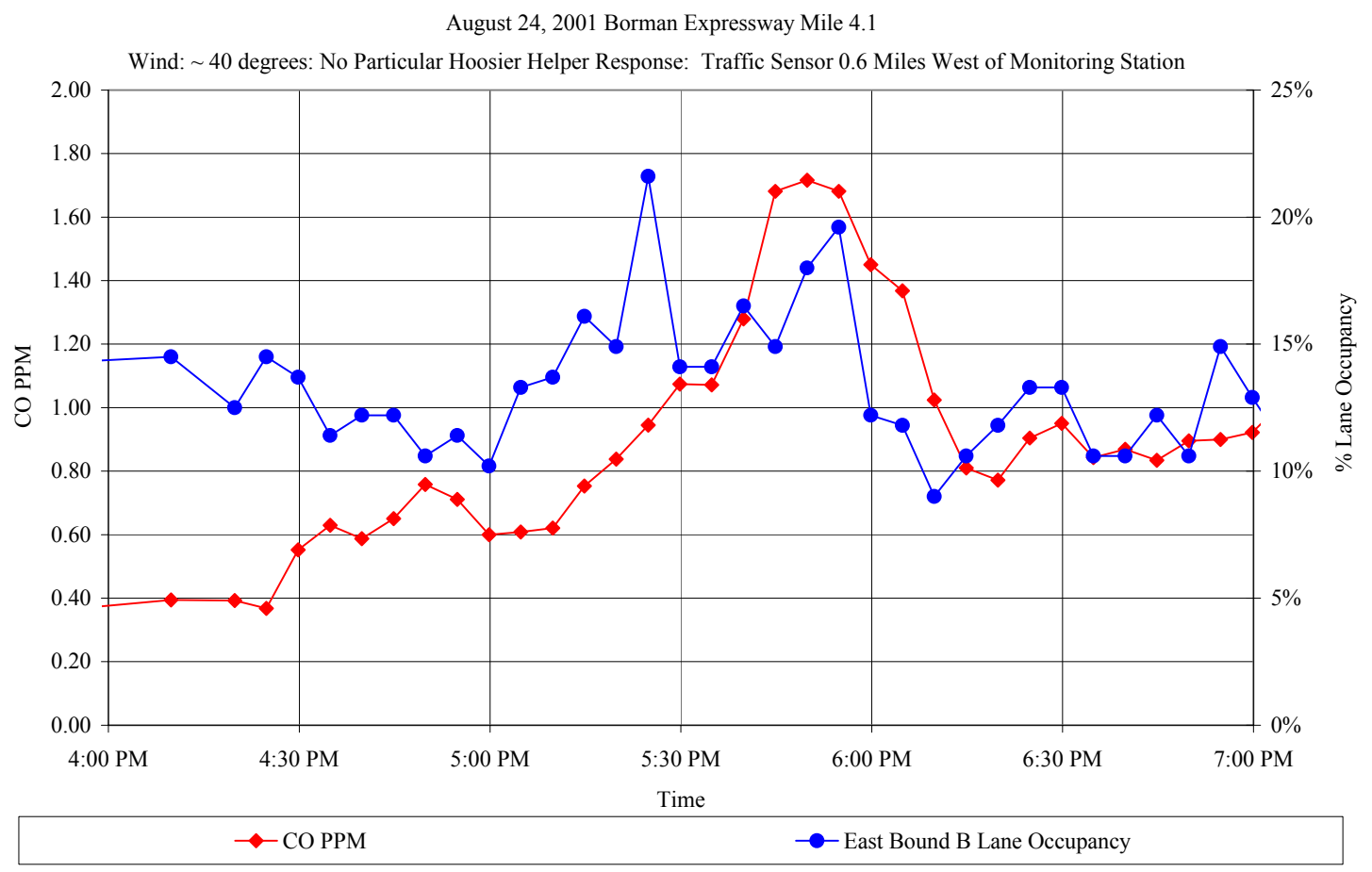

Figure 4.18: August 24, 2001 Congestion Event: Concentration 
A more complicated series of events is shown in figure 4.19. In this case an accident did occur in the period of interest but it doesn't immediately or directly affect the local air quality near the monitoring station, instead it creates a scenario for congestion that affects the air quality later in time.

Between 7:00 am and 7:45 lane occupancy and flow are high as measured at mile marker 3.5. The Hoosier Helper response indicates there was an accident sometime prior to the response start time of 8:20 am. The precipitous drop in flow and occupancy at the traffic monitoring station suggests that the accident occurred around 7:50 am. This accident restricted flow upstream of the traffic monitoring station and the air quality monitoring station. Traffic flow resumed quickly, around 8:10 am but not to pre incident rates. At 8:55 am $\mathrm{PM}_{2.5}$ and $\mathrm{CO}$ flux rose rapidly to a peak at 9:05 and then subsided by 9:25 am. Soon thereafter a Spike is observed in the occupancy and a sharp drop in flow was observed at the monitoring station to the west. Note that the winds were 20 degrees east of north during this period. This suggests that the queue released from the incident moved east until something triggered a brief jam that propagated back through traffic, first detected at our pollution monitoring station as indicated by the rise in pollution concentration and then soon after detected as a brief jam at the traffic monitoring station. 
July 11,2001: Monday: Borman Expressway Mile 4.1

Wind: 20 degrees: Traffic Sensor 0.6 Miles West of Monitoring Station Near MM 3.5. Accident Response At MM 2. 1.5 MM Upstream of Traffic Sensor

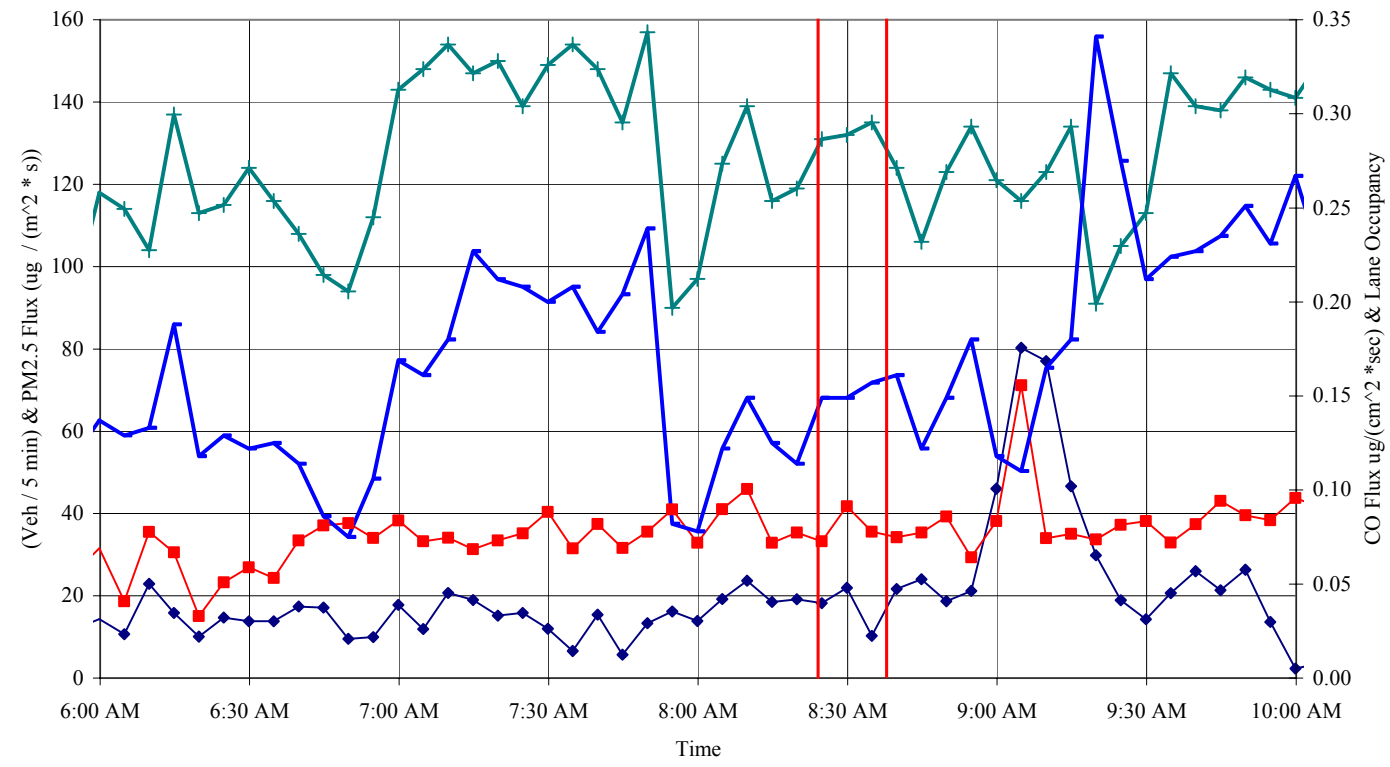

$\multimap-$ PM Flux ug / $\left(\mathrm{m}^{\wedge} 2 * \mathrm{~s}\right) \longrightarrow$ East Bound B Lane Flow (Veh / 5 Min)

$\rightarrow$ CO Flux ug / $\left(\mathrm{cm}^{\wedge} 2 * \mathrm{~s}\right) \quad$ East Bound B Lane Occupancy

Figure 4.19: July 11, 2001 Accident / Congestion Event 
Figure 4.20 is an example of a series of congested deceleration/acceleration incidents. As in the previous example the winds are slightly east of north and the incidents are first observed at the monitoring station then after a period of 20 to 25 minutes the traffic fluctuation is detected at the traffic monitoring site as the incidents propagate backward in the traffic flow.

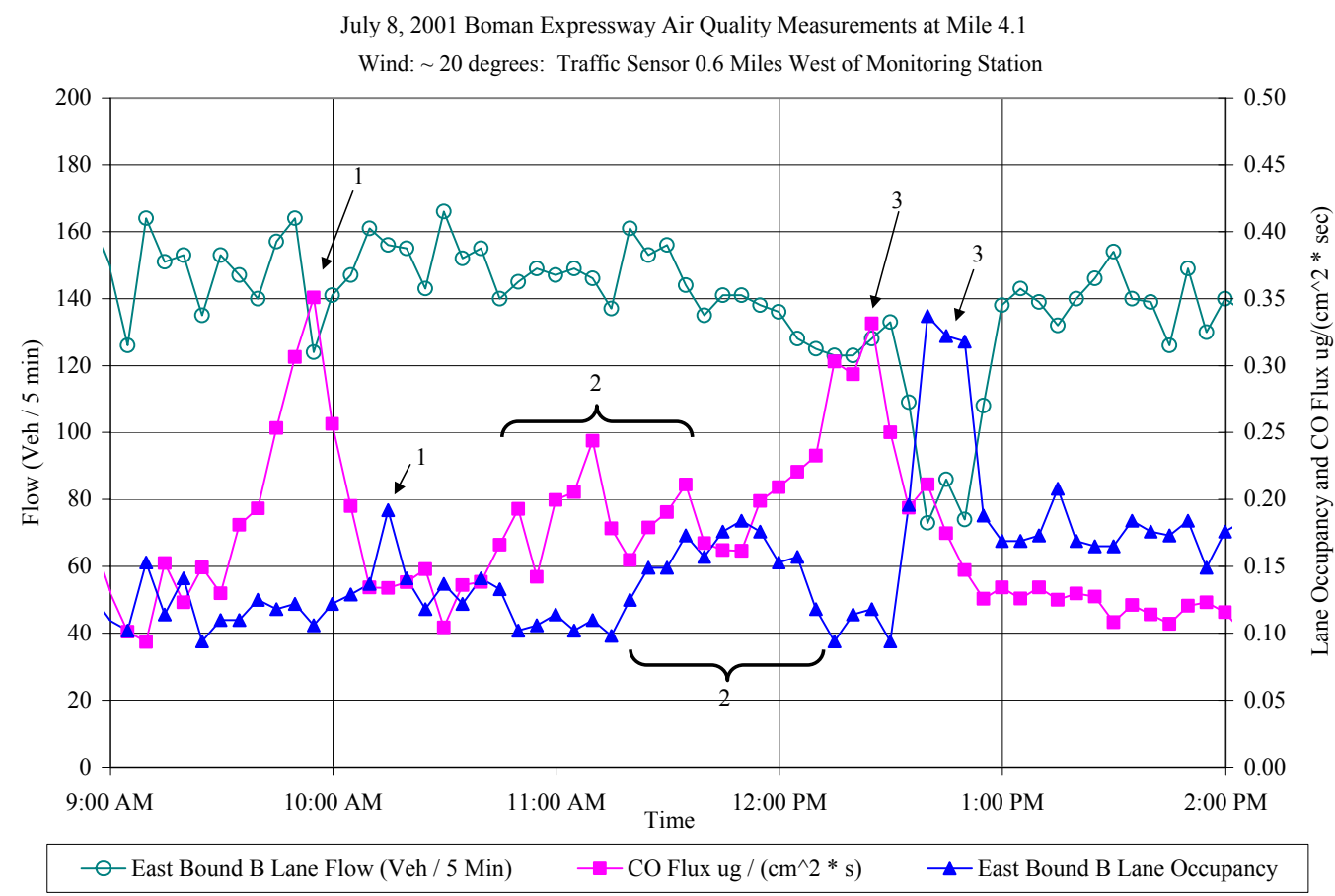

Figure 4.20: July 8, 2001 Acceleration / Deceleration Event

Note the similarity between the character of the occupancy disturbance and the character of the flux change. The change in occupancy designated by arrow "1" is sharp and brief. The correlating change in flux is likewise sharp but spans a broader period of 
time. Lane occupancy disturbance 2 is broad in time and had three small peaks. These peaks were amplified in the correlating flux disturbance. Disturbance 3 was the worst of the three in terms of traffic disruption. Flow was disrupted and decreased from $130 \mathrm{veh} / 5$ minutes to below $80 \mathrm{veh} / 5$ minutes. Again, note the similarity in the two parameters. The time near peak, 10 minutes, is the same for both Flux and Occupancy and as in disturbance one the flux response spans a broader period of time than did the measured traffic disturbance at the monitoring station.

Figure 4.21 illustrates several interesting effects of accidents and their effect on local air quality. These graphs illustrate a series of events and therefore separate graphs have been prepared for $\mathrm{CO}$ and PM measurements. 
August 23, 2001: Thursday: Borman Expressway MM 4.1

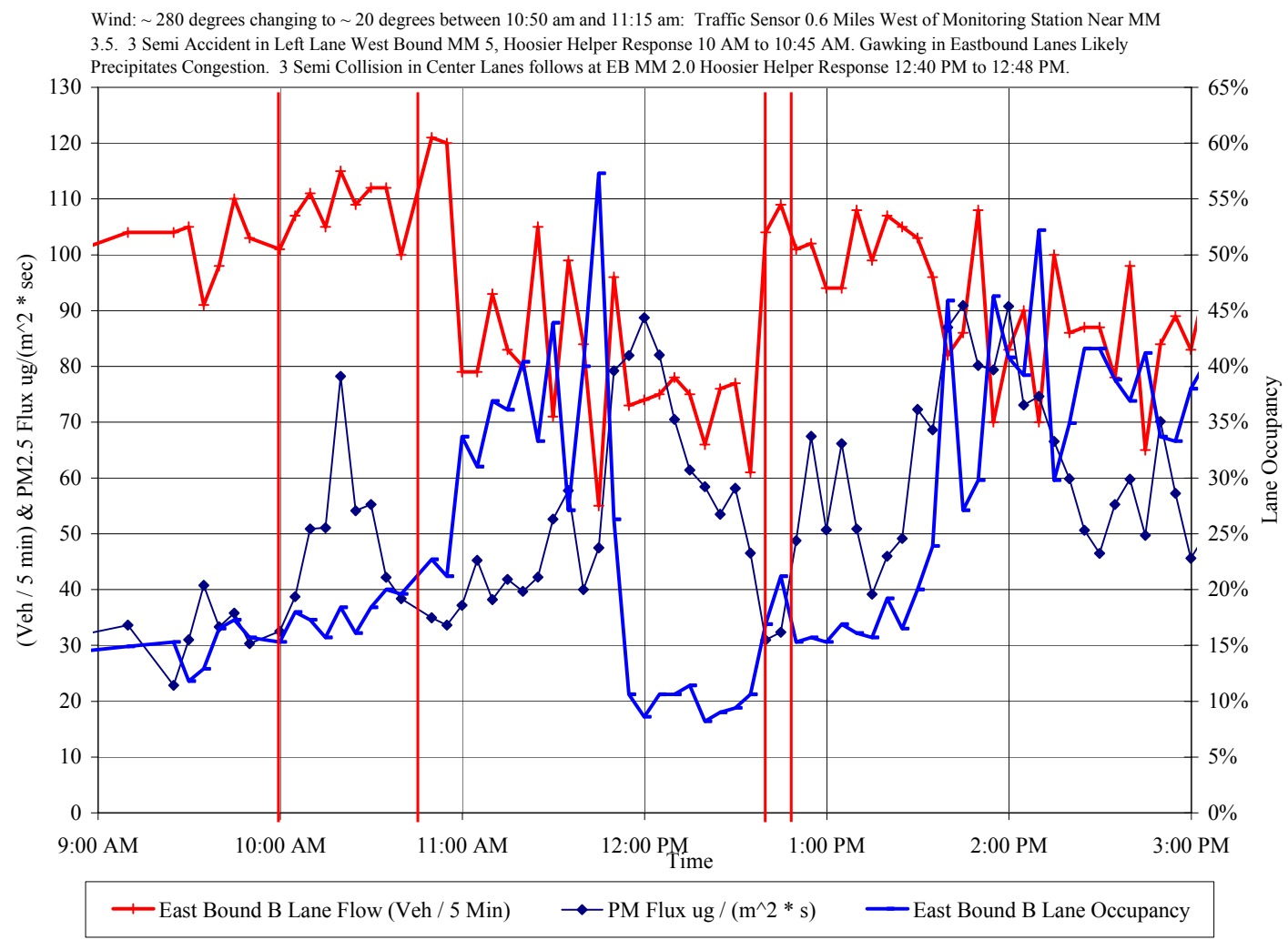

Figure 4.21: August 23, 2001 Accident and Recovery with Congestion Downstream: PM $_{2.5}$ Flux

The first Hoosier Helper Response at 10:00 am was in response to a 3 semi trailer accident in the west bound lanes at mile marker 5. This is less than a mile from the site and given the typical high flow and occupancy on the Borman any gawking by drivers passing by the accident scene would lead to congestion in the eastbound lanes. Between 11:00 am and 11:45 am eastbound traffic flow breaks down as occupancy rises sharply from $20 \%$ to over $50 \%$ and flow drops from $\sim 110$ vehicles / 5 minutes to $\sim 80$ vehicles / 5 minutes at mile marker 3.5. Both lane occupancy and flow are more variable than typical in this period implying stop and go driving conditions. Sometime prior to $12: 40 \mathrm{pm}$ a 3 
semi trailer accident occurred in the center lanes of east bound traffic at mile marker 2 . Mile marker two is upstream of the traffic monitoring station and the result was that traffic occupancy and flow dropped at the traffic monitoring site. Demand on the freeway segment between the incident and whatever restriction downstream in traffic that caused the congestion was reduced allowing the congestion to clear. In the ensuing acceleration of this clearance we see that PM flux rose and then subsided as both occupancy and flow dropped between 12:00 and 12:40 pm. After flow was restored from the accident at mile marker 2, occupancy and flow rise to a brief peak at 12:45 pm. This is later observed as this group of traffic passes the monitoring site in flux peaks saddling 1:00 pm. At 1:40 pm traffic occupancy has spiked again and with it PM flux. It is unlikely the initial spike in PM Flux in this period (between 10:00 am and 10:40 am) could be attributed to accident clearance and truck acceleration. Winds in this period were $\sim 280$ degrees, a bearing that intersects the Borman at mile 3.7 , or 1.3 miles downstream of the accident. At typical power to weight ratios most all of vehicles would have finished acceleration in the 1.3 miles between this location and the westbound accident at mile 5. It is unknown know what else was occurring on the westbound lanes in this period as west bound traffic data was not available until mid October 2001.

Carbon Monoxide flux, figure 4.22, was similar to PM flux with a few exceptions that may reflect the acceleration performance differences between light gasoline vehicles and heavy diesel trucks. 
August 23, 2001: Thursday: Borman Expressway MM 4.1

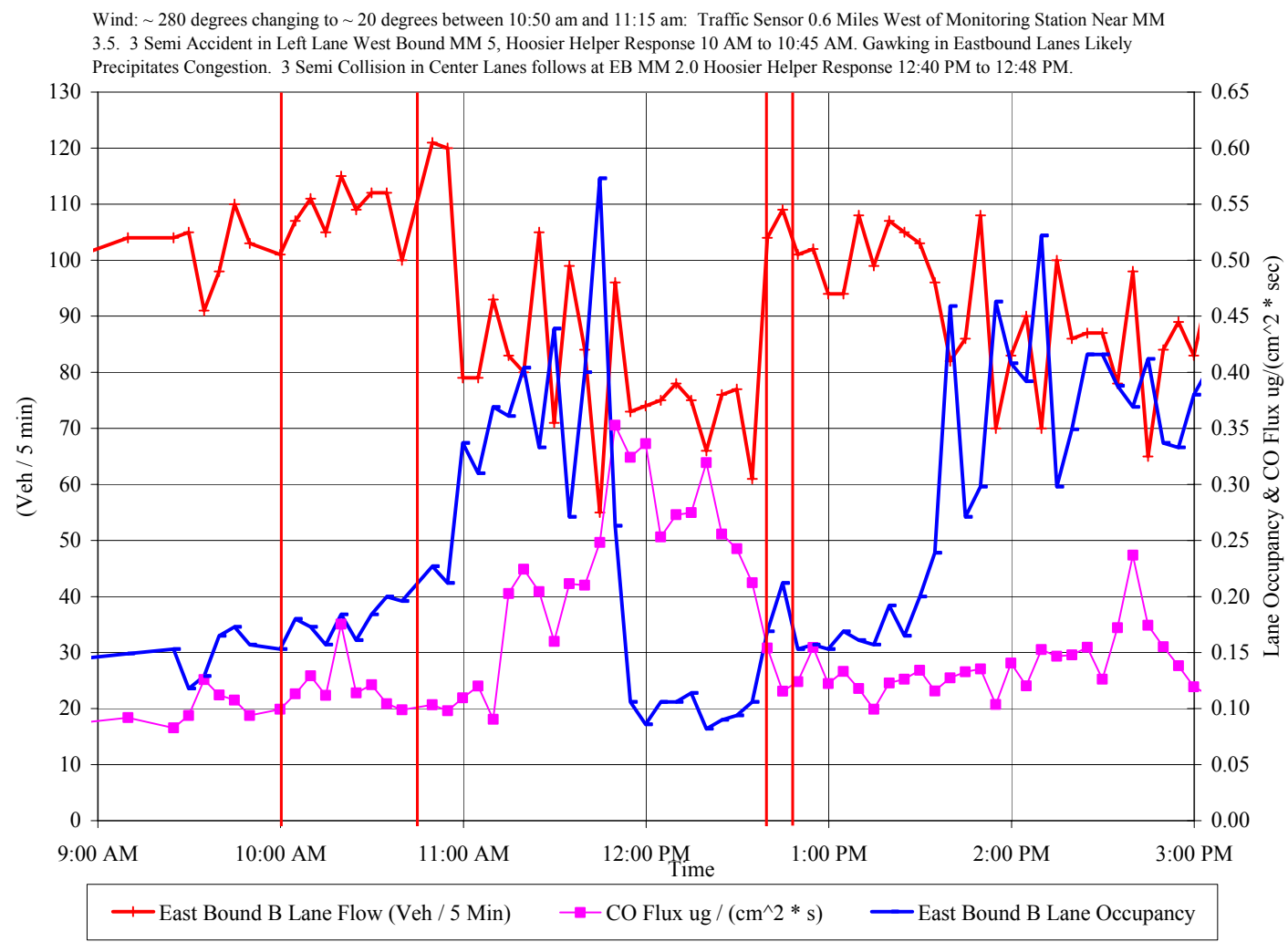

Figure 4.22: August 23, 2001 Accident and Recovery with Congestion Downstream: CO Flux

Unlike PM flux, CO flux began to rise noticeably in the high occupancy period between 11:10 am and 11:50 am. This may reflect the idling emissions from gasoline fueled vehicles. In figure 4.21 PM flux did not rise comparatively as much in this same time period. As shown previously in figure 4.3, $\mathrm{CO}$ emissions per mile are greatest at jam traffic density (represented by a surrogate of lane occupancy here). In contrast, PM emissions are near their lowest at jam densities where idling is common. For both $\mathrm{PM}_{2.5}$ and CO flux, as the queue cleared and accelerated the concentration of these pollutants rose. 
Figures 4.23 and 4.24 illustrate the same periods and incidents with units of concentration and figure 4.23 includes a plot of wind speed. Wind Speed is shown for reference.

August 23, 2001: Thursday: Borman Expressway MM 4.1

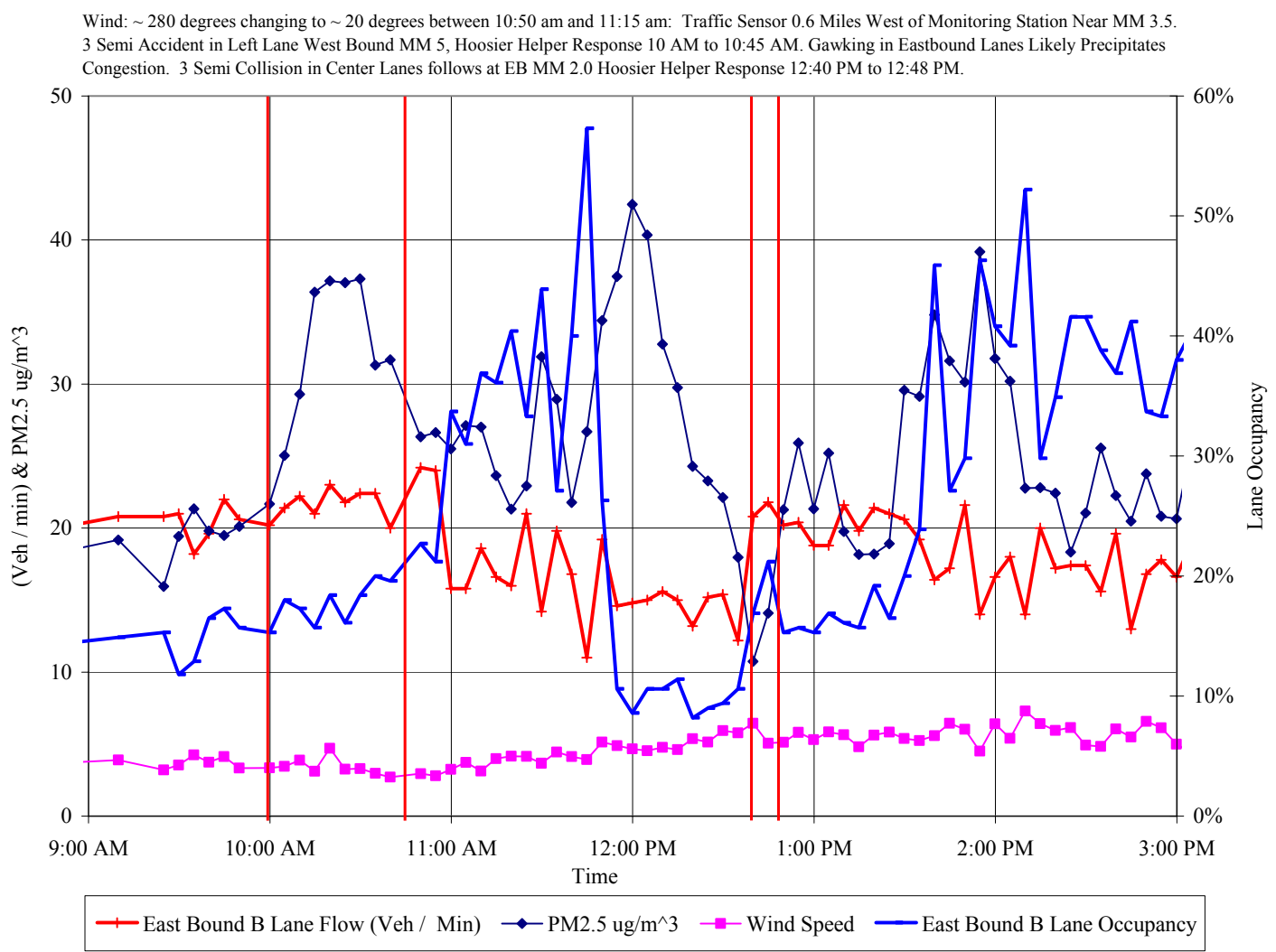

Figure 4.23: August 23, 2001 Accident and Recovery with Congestion Downstream:

$\mathbf{P M}_{2.5}$ Concentration 
August 23, 2001: Thursday: Borman Expressway MM 4.1

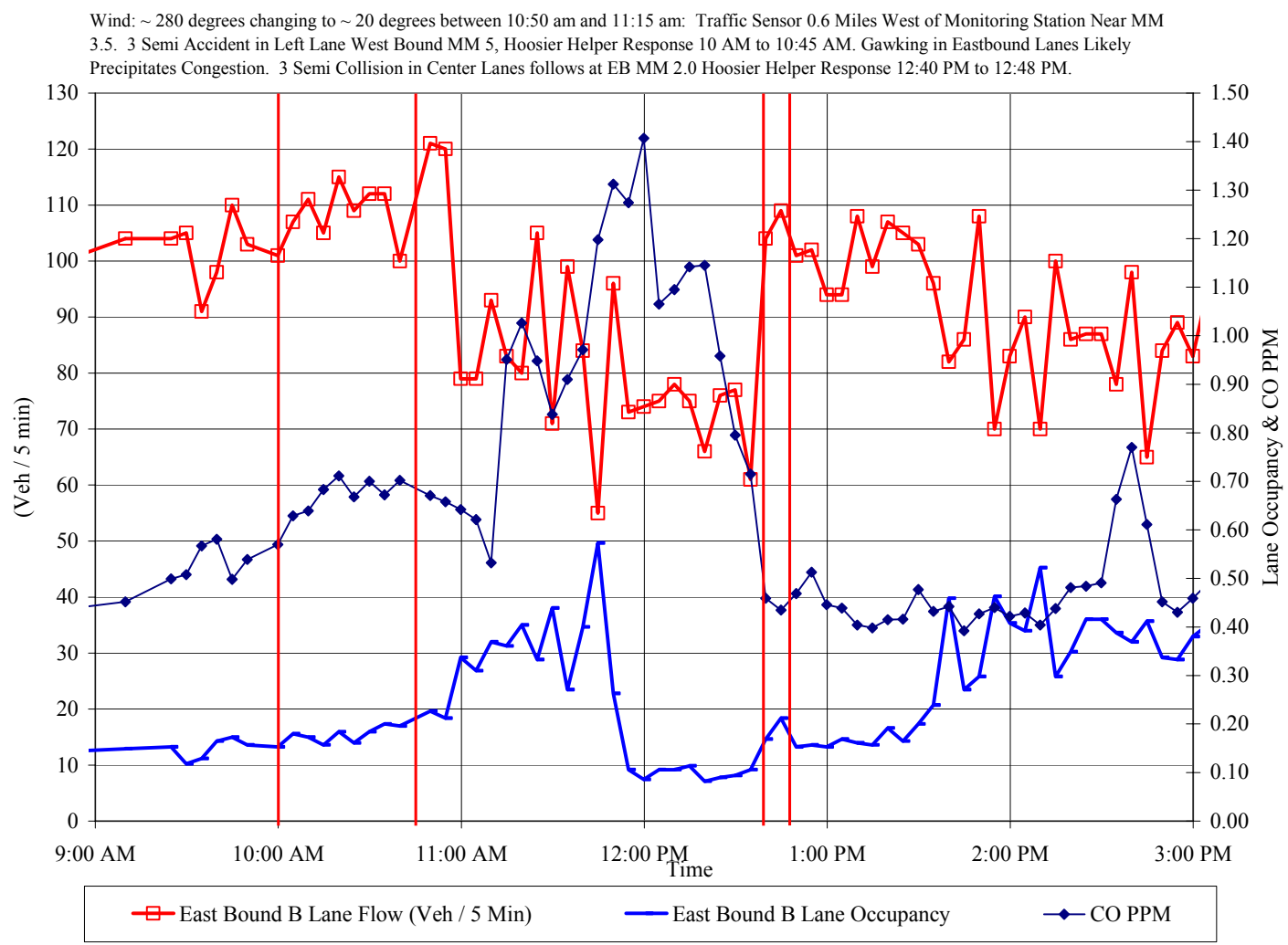

Figure 4.24: August 23, 2001 Accident and Recovery with Congestion

\section{Downstream: CO Concentration}

Figure 4.25 illustrates the effects of an extended period of congestion on $\mathrm{PM}_{2.5}$ flux. For purpose of scale units of vehicle flow in this graph are vehicles / minute not vehicles / 5 minutes as in previous figures. Note that between 1:10 am and 10:15 am the drop in $\mathrm{PM}_{2.5}$ flux that coincides with the high (80\%) occupancy and very low flow. This very high average occupancy is indicative of either a complete stop in traffic or extremely slow operation. As traffic continues halting operation from 10:30 am to 1:00 $\mathrm{pm}^{\mathrm{PM}_{2.5}}$ flux climbs steadily and remains high until $\sim 3: 30$. This is 2.5 hours after traffic at the monitoring station returned to normal. This at first might suggest that there was some 
kind of persistence of $\mathrm{PM}_{2.5}$ in the area. However, the winds in this period were not calm. Winds averaged a steady 6 miles per hour so any the lag time from vehicle emission to measured concentration would be about 40 seconds to the middle of the Borman.

June 8, 2001: Friday: Borman Expressway Mile 4.1

Wind: $\sim 15$ degrees: Traffic Sensor 0.6 Miles West of Monitoring Station Near MM 3.5. No Specific HoosierHelper Response. Construction Related Lane Restrictions Near Monitoring Station.

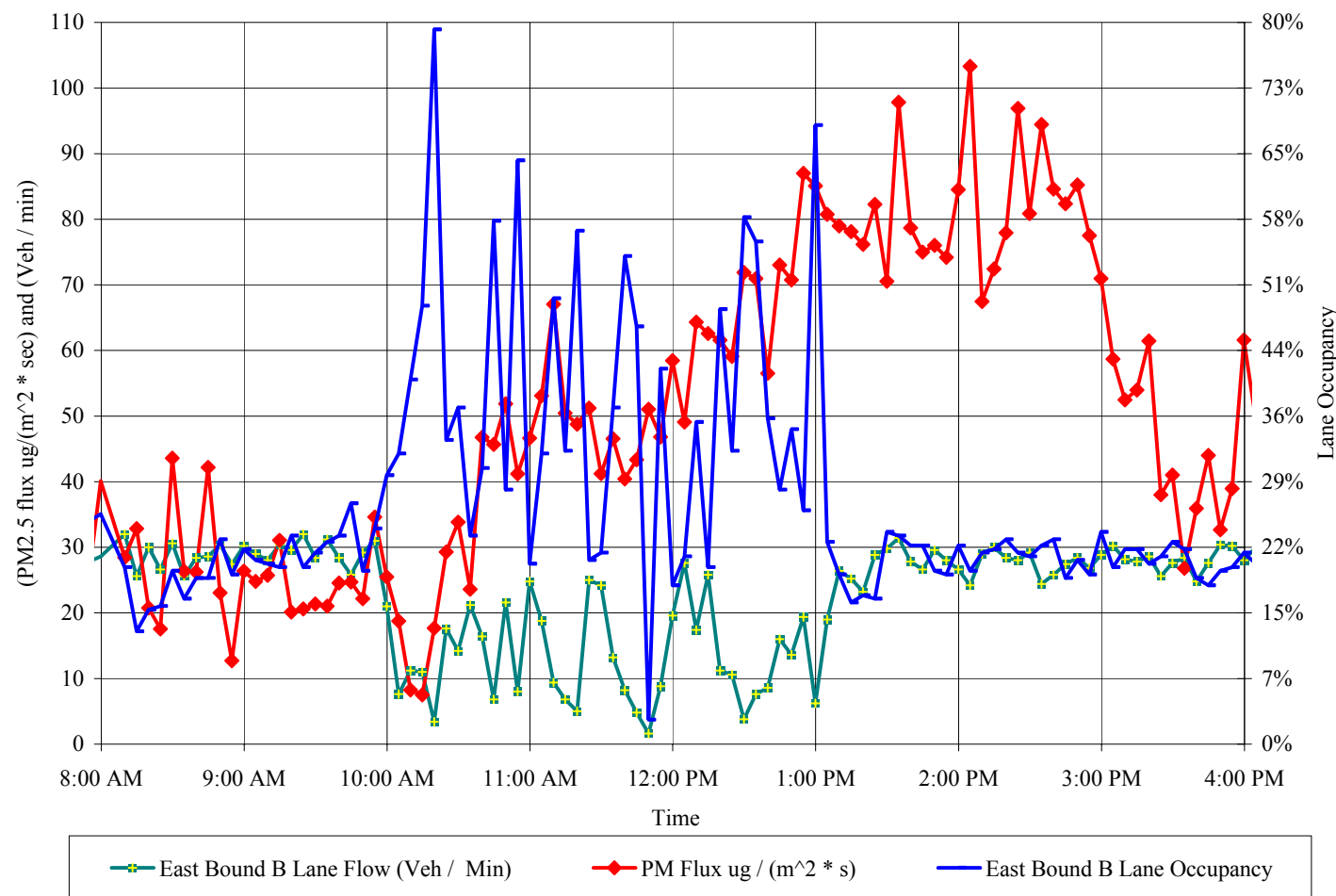

This means that the traffic flow disturbance persisted where the winds intersected the Borman enroute to the monitoring station for at least 2 hours after the conditions had cleared at the monitoring site. Had the traffic monitoring station sensors between Kennedy and Cline avenues not been damaged by road construction activities we could have confirmed this. 


\subsection{CONCLUSIONS}

The Borman Expressway supplies a substantial portion of the $\mathrm{CO}$ and $\mathrm{PM}_{2.5}$ in its local vicinity. The average concentration in winds intersecting the Borman expressway from January 1, 2000 to November 30, 2001 was $12.5 \mu \mathrm{g} / \mathrm{m}^{3} \mathrm{PM}_{2.5}$ and 0.56 PPM CO. The average Borman Expressway intersecting flux in this same period was $25.6 \mu \mathrm{g} /\left(\mathrm{m}^{2}\right.$ sec) $\mathrm{PM}_{2.5}$ and $1412 \mu \mathrm{g} /\left(\mathrm{m}^{2} \mathrm{sec}\right) \mathrm{CO}$. The Borman Expressway supplied on average $77 \%$ of the $\mathrm{CO}$ and $72 \%$ of the $\mathrm{PM}_{2.5}$ as determined by regression analysis of traffic and environment data. The Borman Expressway supplied on average $56 \%$ of the $\mathrm{CO}$ and $27 \%$ of the $\mathrm{PM}_{2.5}$ by comparison of similarly developed and populated northerly and southerly azimuth arcs. Additional regression analysis will be employed on both east and westbound traffic data to arrive at a final Borman component of local air quality.

Northwestern Indiana has many sources of $\mathrm{PM}_{2.5}$ and carbon monoxide. Several of the United State's largest sources of both pollutants are located in Lake County, Indiana. Analysis by ISCST3 showed that even with these sources in the azimuth of Borman exposure, less than $14 \%$ of the azimuth was potentially substantially affected by permitted industrial stationary point sources. Data from the Borman monitoring station suggested the effect on the site was even less than that suggest by the modeling work.

Carbon monoxide and $\mathrm{PM}_{2.5}$ concentrations and flux can increase by a factor of 2 to 3 over pre-incident / pre - congestion conditions during accident / congestion events. These air quality deviations have been correlated to both accident initiation and clearance as well as with non-accident related congestion and high traffic occupancy. Therefore the Borman expressway is the dominant component of local air quality during accident or congestion episodes. The duration of environmental impact is roughly equivalent to the 
duration of occupancy deviation, when traffic occupancy returns to pre-incident conditions $\mathrm{CO}$ and $\mathrm{PM}_{2.5}$ flux return to pre-incident conditions.

Elevated pollutant flux has been correlated with high (>22\%) traffic occupancy. Elevated flux is particularly associated with jam conditions, as indicated by high occupancy and reduced traffic flows. Traffic flow has also been associated with higher flux but with the caveat that occupancy must be considered. Pollutant flux increases with traffic flow during under-saturated traffic conditions (i.e. class a to e levels of service). The relationship between pollutant flux and vehicle flow in oversaturated traffic conditions is ambiguous. Analysis is ongoing in this area

Typically, greater than $22 \%$ occupancy is associated with surges in pollutant flux. The following table illustrates the significance of occupancy in pollutant flux. Data was summarized in two ranges. Data was selected and average from a sub $22 \%$ category of $18 \%$ to $20 \%$ traffic occupancy and a super $22 \%$ category of $24 \%$ to $26 \%$ occupancy. Note that the flow $\sim 1610 \mathrm{veh} / \mathrm{lane} /$ hour is nearly identical for both conditions; the only difference is in the level of service.

\section{Table 5.1 Level of Service Effect on Local Air Quality}

\begin{tabular}{|l|r|r|r|}
\hline Category & $\mathbf{1 8 \%}$ to 20\% Occupancy & $\mathbf{2 4 \%}$ to 26\% Occupancy & Difference \\
\hline Flow Rate veh/hour/lane & 1608 & 1612.8 & $0.3 \%$ \\
\hline Average Occupancy & $19 \%$ & $25 \%$ & $31.6 \%$ \\
\hline Average Density veh/mile/lane (calculated) & 42.3 & 55.8 & $31.9 \%$ \\
\hline Average PM2.5 Flux ug/(m^2 $* \mathrm{sec})$ & 31.78 & 42.65 & $34.2 \%$ \\
\hline Average PM2.5 Concentration ug $/ \mathrm{m}^{\wedge} 3$ & 15.23 & 19.40 & $27.4 \%$ \\
\hline Average CO Flux ug/ $\left(\mathrm{m}^{\wedge} 2 * \mathrm{sec}\right)$ & 1376 & 1601 & $16.4 \%$ \\
\hline Average CO Concentration PPM & 0.51 & 0.61 & $20.2 \%$ \\
\hline
\end{tabular}


Table 5.1 shows that any means that can prevent or reduce oversaturated traffic conditions should substantially reduce the presence of pollution in the local environment. The net flow of vehicles is the same in both cases, the only difference is in the operating condition of the highway.

At this time no specific cause and effect relationship can be demonstrated as to the final benefit of the Borman ITS program because the ITS system is not complete. The ITS system installation has been considerably delayed and is not yet fully operational at the time of this draft. While the variable message boards are now functioning as of the time of this draft, the full traffic data system is not online yet and so no specific relationships can be drawn. In general however, as table 5.1 showed, avoiding or minimizing oversaturated conditions by whatever means will make a substantial improvement in local air quality. 


\section{REFERENCES}

40 Code of Federal Regulations 58. United States Government Printing Office

Amdur, Mary O.; Doull, John; Klaassen, Curtis D.. 1991. Casarett and Doull's

Toxicology: the basic science of poisons. McGraw Hill.

Highway Capacity Manual 2000. The National Academy of Sciences. 2000.

Rupprecht \& Patashnick Co., Inc. Operating Manual, TEOM Series 1400a; Ambient

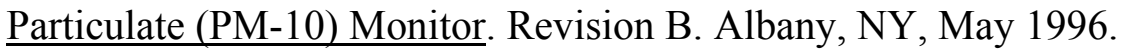

Stephanedes, Yorgos. 1995. in The Civil Engineering Handbook. Ed. W. F. Chen. CRC Press, Inc. Boca Raton, Florida 